\title{
Nickel Phosphide Electrocatalysts for Hydrogen Evolution Reaction
}

\author{
Cun Hu ${ }^{1}$, Chao Lv ${ }^{1}$, Shuai Liu ${ }^{2}$, Yan Shi ${ }^{1}$, Jiangfeng Song ${ }^{1}$, Zhi Zhang ${ }^{1}$, Jinguang Cai ${ }^{1, *(\mathbb{D}}$ \\ and Akira Watanabe 3 \\ 1 Institute of Materials, China Academy of Engineering Physics, Jiangyou 621908, China; \\ hucun402@163.com (C.H.); lvchao219@foxmail.com (C.L.); shiyan@caep.cn (Y.S.); \\ songjiangfeng@caep.cn (J.S.); zhangzhi@caep.cn (Z.Z.) \\ 2 School of Chemistry and Chemical Engineering, Southwest Petroleum University, Chengdu 610500, China; \\ shuailiu@swpu.edu.cn \\ 3 Institute of Multidisciplinary Research for Advanced Materials, Tohoku University, 2-1-1 Katahira, Aoba-ku, \\ Sendai 980-8577, Japan; watanabe@tagen.tohoku.ac.jp \\ * Correspondence: caijinguang@foxmail.com
}

Received: 31 December 2019; Accepted: 20 January 2020; Published: 5 February 2020

\begin{abstract}
The production of hydrogen through electrochemical water splitting driven by clean energy becomes a sustainable route for utilization of hydrogen energy, while an efficient hydrogen evolution reaction (HER) electrocatalyst is required to achieve a high energy conversion efficiency. Nickel phosphides have been widely explored for electrocatalytic HER due to their unique electronic properties, efficient electrocatalytic performance, and a superior anti-corrosion feature. However, the HER activities of nickel phosphide electrocatalysts are still low for practical applications in electrolyzers, and further studies are necessary. Therefore, at the current stage, a specific comprehensive review is necessary to focus on the progresses of the nickel phosphide electrocatalysts. This review focuses on the developments of preparation approaches of nickel phosphides for HER, including a mechanism of HER, properties of nickel phosphides, and preparation and electrocatalytic HER performances of nickel phosphides. The progresses of the preparation and HER activities of the nickel phosphide electrocatalysts are mainly discussed by classification of the preparation method. The comparative surveys of their HER activities are made in terms of experimental metrics of overpotential at a certain current density and Tafel slope together with the preparation method. The remaining challenges and perspectives of the future development of nickel phosphide electrocatalysts for HER are also proposed.
\end{abstract}

Keywords: nickel phosphide; hydrogen evolution reaction; electrocatalysts; phosphidation reaction; nanocatalysts; water splitting

\section{Introduction}

The rapid energy depletion and increasing environmental stress necessitate the exploration of sustainable clean energy to replace traditional fossil fuels. Hydrogen has been widely recognized as a promising and sustainable energy carrier to address the above two issues due to its high energy density and environmentally-friendly features [1,2]. An ideal sustainable approach for producing hydrogen is to utilize the electricity produced from clean energy, such as solar cells, to drive the water splitting reaction [3-5], while an efficient hydrogen evolution reaction (HER) electrocatalyst is necessary to reach a high-energy utilization efficiency. It is well-known that Pt-based materials are the most active electrocatalysts for HER, but the large-scale applications are considerably hindered by the high cost and scarcity.

In recent years, plenty of HER electrocatalysts based on earth-abundant transition metal compounds, such as sulphides, selenides, phosphides, nitrides, carbides, and borides, have been 
developed with remarkable activities [6-8]. In particular, nickel phosphides, which possess unique electronic properties, efficient electrocatalytic activities, and anti-corrosion features, have attracted significant research attention and are recognized as efficient and low-cost HER catalysts, especially in the acidic electrolyte $[9,10]$. However, the HER activities of nickel phosphide electrocatalysts are still low for practical applications in electrolyzers, and further studies are necessary. Therefore, at the current stage, a specific comprehensive review is necessary to focus on the progresses of the nickel phosphide electrocatalysts, even though some excellent reviews and perspectives on transition-metal based electrocatalysts for HER or oxygen evolution reaction (OER) have been published [6-8,10-21]. This review is focusing on the developments of preparation approaches of nickel phosphides for HER, which is divided into three main parts: mechanism of HER, properties of nickel phosphides, and preparation and electrocatalytic HER performances of nickel phosphides. The first part will briefly explain the mechanism of HER. The second part will introduce the properties of nickel phosphides. The third part mainly focuses on the progresses of the preparation and HER activities of the nickel phosphide electrocatalysts, which is classified by the preparation method. In this part, the comparative surveys of their activities are made in terms of experimental metrics of overpotential at a certain current density and Tafel slope together with the preparation method. Lastly, the remaining challenges and perspectives of the future development of nickel phosphide electrocatalysts for HER are proposed.

\section{Mechanism of HER}

Water molecules will be split into hydrogen and oxygen under an external electric field following the reaction equation [22]. $\mathrm{H}_{2} \mathrm{O}(\mathrm{L})+$ energy $\rightarrow \mathrm{H}_{2}(\mathrm{~g})+1 / 2 \mathrm{O}_{2}(\mathrm{~g})$. Under standard conditions $(298 \mathrm{~K}$, $1 \mathrm{~atm})$, the change of Gibbs free energy $\Delta \mathrm{G}^{\theta}$ for this reaction is $+237.1 \mathrm{~kJ} \mathrm{~mol}^{-1}$, and the corresponding thermodynamic potential of water electrolysis $\mathrm{E}$ is $1.23 \mathrm{~V}$ against the reversible hydrogen electrode (RHE) [7]. The reaction of water electrolysis can be divided into two half reactions including a hydrogen evolution reaction (HER) at the cathode and an oxygen evolution reaction (OER) at the anode [23-25]. The mechanism of HER is highly dependent on the $\mathrm{pH}$ of the electrolyte. In acidic solutions, the water electrolysis reactions at the cathode and anode take place as follows [15].

$$
\begin{gathered}
2 \mathrm{H}^{+}+2 \mathrm{e}^{-} \rightarrow \mathrm{H}_{2} \text { (Cathode) } \\
\mathrm{H}_{2} \mathrm{O} \rightarrow 1 / 2 \mathrm{O}_{2}+2 \mathrm{H}^{+}+2 \mathrm{e}^{-} \text {(Anode) }
\end{gathered}
$$

In alkaline solutions, the water electrolysis reactions at the cathode and anode take place as follows [26]

$$
\begin{aligned}
& 2 \mathrm{H}_{2} \mathrm{O}+2 \mathrm{e}^{-} \rightarrow \mathrm{H}_{2}+2 \mathrm{OH}^{-} \text {(Cathode) } \\
& 2 \mathrm{OH}^{-} \rightarrow 1 / 2 \mathrm{O}_{2}+\mathrm{H}_{2} \mathrm{O}+2 \mathrm{e}^{-} \text {(Anode) }
\end{aligned}
$$

In theory, water electrolysis can be achieved when the overall cell potential is $1.23 \mathrm{~V}$. In fact, the externally applied voltage required to drive water electrolysis is dependent on the thermodynamic potential of water electrolysis and the overpotentials with the reaction on the anode/cathode and ohmic drop of the cells. The externally applied voltage can be defined as follows [27].

$$
E_{\mathrm{op}}=E_{\mathrm{tp}}+\eta_{\mathrm{a}}+\eta_{\mathrm{c}}+i R
$$

where $E_{\mathrm{op}}$ is the externally applied voltage, $E_{\mathrm{tp}}$ is thermodynamic potential of water electrolysis, $\eta_{\mathrm{a}}$ and $\eta_{\mathrm{c}}$ are the overpotentials with the reactions on the anode and cathode, respectively, and $i R$ refers to ohmic drop of the cells $[28,29]$. Therefore, the externally applied voltage must be more than the theoretical voltage of water electrolysis for the reaction to proceed smoothly. High-efficiency catalysts of water electrolysis have high activation energy, which can accelerate the electron transfer and drive the rapid formation of intermediates on the electrode surface. Therefore, it can reduce the overpotentials for water electrolysis. 
HER usually occurs on the catalyst surface in one of two different steps and can follow the Volmer-Tafel mechanism or Volmer-Heyrovsky mechanism [11,30,31]. In acidic solutions, the two-electron transfer reaction that occurs on the catalyst surface by two steps is shown in Figure 1 [10]. The first step of HER is called Volmer or the discharge reaction, which discharges protons $\left(\mathrm{H}^{+}\right)$through coupling with an electron on the active surface of the catalyst to form adsorbed hydrogen intermediates $\left(\mathrm{H}_{\mathrm{ads}}\right)$ [32]. The source of protons depends on the $\mathrm{pH}$ of the electrolyte. In acidic solutions, it is the hydrogen cation in the electrolyte, while, in alkaline electrolyte, it is the water molecule. In the second step, the formation of the hydrogen molecule in both acidic and basic electrolytes may occur through two different reaction mechanisms, depending on the $\mathrm{H}_{\mathrm{ads}}$ coverage on the catalyst surface [33]. If the $\mathrm{H}_{\mathrm{ads}}$ coverage on the surface is large, two adjacent $\mathrm{H}_{\mathrm{ads}}$ on the electrode surface will recombine with each other to generate a hydrogen molecule, which is called a combination or Volmer-Tafel reaction [34]. If the $\mathrm{H}_{\mathrm{ads}}$ coverage on the surface is low, the single $\mathrm{H}_{\mathrm{ads}}$ would prefer to combine with $\mathrm{H}^{+}$from the solution and an electron simultaneously to form a hydrogen molecule, which is called the atom + ion or the Volmer-Heyrovsky reaction [35]. For the binding strength of the reaction intermediates, the inherent catalytic activity of the HER catalyst is closely related with the H-adsorption Gibbs free energy $\left(\Delta \mathrm{G}_{\mathrm{H}^{*}}\right)$ where ${ }^{*}$ represents the active site on the surface of the catalyst [32]. The $\Delta \mathrm{G}_{\mathrm{H}^{*}}$ can be a good descriptor for determining the HER rate. If the $\Delta \mathrm{G}_{\mathrm{H}^{*}}$ is negative for the catalyst, the $\mathrm{H}^{*}$ will bind better to the surface of the electrode and make the Volmer step (initial step) take place very easily. If a catalyst has a large $\left|\Delta G_{H^{*}}\right|$ value, the Heyrovsky or Tafel step will be difficult and eventually the entire reaction will become slow. Therefore, the active catalyst for HER needs to have a $\Delta \mathrm{G}_{\mathrm{H}^{*}}$ near zero. It is well-known that the mechanism is distinguished by the Tafel slopes measured during the HER process. If the Volmer reaction (discharge reaction) is fast and the hydrogen molecules are generated by the rate determining combination (Tafel) reaction, the corresponding Tafel slope is $29 \mathrm{mV} / \mathrm{dec}$. If the discharge reaction is fast and the hydrogen molecules are produced by a rate determining atom + ion (Heyrovsky) reaction, the corresponding Tafel slope is $38 \mathrm{mV} / \mathrm{dec}$. If the discharging of $\mathrm{H}^{+}$is slow, the hydrogen is evolved either by a rate determining atom + ion reaction or a combination reaction. The corresponding Tafel slope is $116 \mathrm{mV} / \mathrm{dec}$ [32].
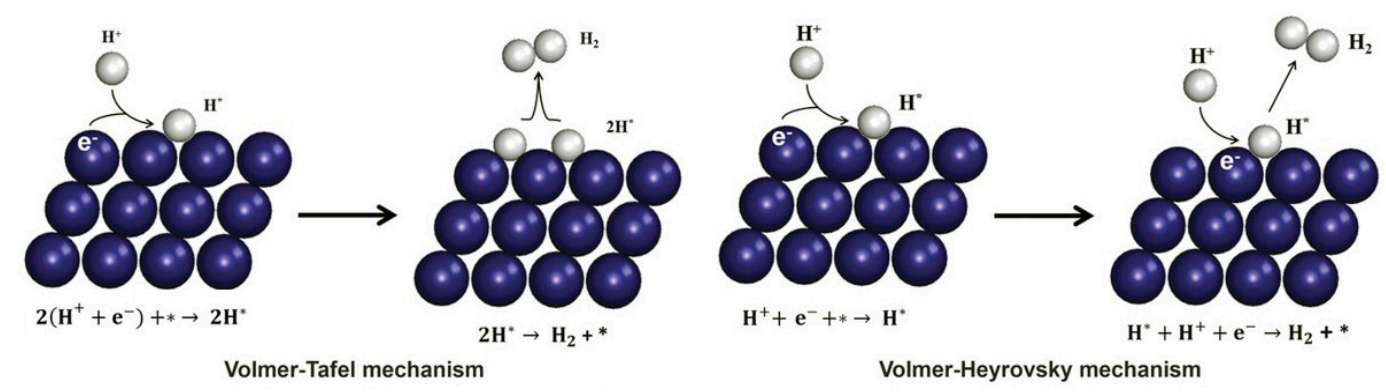

Figure 1. HER mechanisms on the catalyst surface in acidic solutions. Where the ${ }^{*}$ denotes the active sites of the catalyst, $\mathrm{H}^{*}$ denotes the adsorbed hydrogen atom at the active site of the catalyst. Reproduced with permission from Reference [33]. Copyright Wiley-VCH, 2019.

\section{Properties of Nickel Phosphides}

It is well-known that $\mathrm{MoS}_{2}$ shows high catalytic activities toward both HER and hydrodesulfurization (HDS) [36,37]. Both HDS and HER rely on the catalyst to reversibly combine hydrogen and hydrogen dissociates to produce $\mathrm{H}_{2} \mathrm{~S}$ in HDS with protons bound to the catalyst to promote the formation of hydrogen in HER $[38,39]$. These commonalities between the mechanisms and putative active sites of $\mathrm{MoS}_{2}$ for both HDS and HER catalysis suggest that other materials used for catalytic HDS may also be active electrocatalysts for HER. Typically, Figure 2a shows the crystal structure of the nickel phosphide $\left(\mathrm{Ni}_{2} \mathrm{P}\right)$, which possesses a hexagonal structure [40], and it has been demonstrated that nickel phosphide $\left(\mathrm{Ni}_{2} \mathrm{P}\right)$ shows excellent catalytic performance toward HDS [41] and water gas shift reactions for the production of hydrogen [42-44]. Therefore, it can be 
speculated that nickel phosphide has electrocatalytic activities toward HER. Nickel phosphides show high physicochemical stability and a superior anticorrosion feature, especially in the acidic electrolyte, which are very important for the applications in the electrolyzers.

As is well-known, in nature, hydrogenase enzymes are a kind of highly efficient biocatalysts to catalyze HER with rapid rates at room temperature. One kind of the hydrogenases has been distinguished as [NiFe] hydrogenases, according to the metal content. Liu et al. studied the behavior of a series of HER catalysts including $[\mathrm{NiFe}]$ hydrogenase and the analogues of the $\left[\mathrm{Ni}\left(\mathrm{PS}^{*}\right)(\mathrm{CO})\right]^{1-}$ and $\left[\mathrm{Ni}(\mathrm{PNP})_{2}\right]^{2+}$ complexes as well as surfaces of $\mathrm{Ni}(111), \mathrm{Pt}(111)$, and $\mathrm{Ni}_{2} \mathrm{P}(001)$ through density functional theory (DFT) calculations [39]. They concluded that the catalytic activity of $\mathrm{Ni}_{2} \mathrm{P}(001)$ toward HER is associated with an ensemble effect and the presence of $\mathrm{P}$ will decrease the number of active Ni sites (Figure $2 b, c$ ), which leads to moderate bonding of the intermediates and products with the surface. The $\mathrm{P}$ sites also directly participate in the HER. The results suggested $\mathrm{Ni}_{2} \mathrm{P}$ as a potential excellent catalyst for HER.

Notably, nickel phosphides have eight mono-phosphides and poly-phosphides with different Ni/P ratios, i.e., $\mathrm{Ni}_{3} \mathrm{P}, \mathrm{Ni}_{5} \mathrm{P}_{2}, \mathrm{Ni}_{12} \mathrm{P}_{5}, \mathrm{Ni}_{2} \mathrm{P}, \mathrm{Ni}_{5} \mathrm{P}_{4}, \mathrm{NiP}, \mathrm{NiP}_{2}$, and $\mathrm{NiP}_{3}$, and the stoichiometric compositions, crystal phases, and crystal facets show influences on the electrocatalytic HER activity. The nickel phosphides of $\mathrm{Ni}_{2} \mathrm{P}$ [45], $\mathrm{Ni}_{5} \mathrm{P}_{4}$ [46], $\mathrm{Ni}_{12} \mathrm{P}_{5}$ [47], $\mathrm{Ni}_{3} \mathrm{P}$ [48], and $\mathrm{NiP}_{2}$ [49] phases are generally obtained according to the reported results. Pan et al. investigated the HER performance of different types of nickel phosphides $\left(\mathrm{Ni}_{12} \mathrm{P}_{5}, \mathrm{Ni}_{2} \mathrm{P}\right.$, and $\left.\mathrm{Ni}_{5} \mathrm{P}_{4}\right)$ and found that their catalytic performance followed the order of $\mathrm{Ni}_{5} \mathrm{P}_{4}>\mathrm{Ni}_{2} \mathrm{P}>\mathrm{Ni}_{12} \mathrm{P}_{5}$ [50]. It was suggested that the Ni-poor phosphides show a relatively high HER activity. First principle calculations were used to determine the optimal stoichiometry as an HER electrocatalyst among various phases of nickel phosphides. Normally, the hydrogen adsorption free energy $\left(\Delta \mathrm{G}_{\mathrm{H}}\right)$ has been used as a description to correlate the theoretical predictions with the experimental results of the HER activity for various systems. The calculation models for hydrogen adsorbed on the (001) faceted surface of the $\mathrm{Ni}_{4} \mathrm{P}_{5}$-terminated $\mathrm{Ni}_{12} \mathrm{P}_{5}, \mathrm{Ni}_{3} \mathrm{P}_{2}$-terminated $\mathrm{Ni}_{2} \mathrm{P}, \mathrm{Ni}_{4} \mathrm{P}_{3}$-terminated $\mathrm{Ni}_{5} \mathrm{P}_{4}$, and P-terminated $\mathrm{NiP}_{2}$ are shown in Figure $2 \mathrm{~d}$. It can be seen from the calculation results in Figure 2e that $\mathrm{NiP}_{2}$ shows the lowest $\Delta \mathrm{G}_{\mathrm{H}}$ of only $-0.16 \mathrm{eV}$, which suggests the highest HER activity among the four phases. This is consistent with the experimental results [51]. Moreover, some studies have reported the influences of the crystal phase and morphology of nickel phosphides on the catalytic HER performances, which will be discussed in Part 4.1 because the studies are based on the nickel phosphide nanocrystals prepared through the solution phase method. Unfortunately, so far, the dependence of the HER activity on the stoichiometric compositions, crystal phases, and crystal facets for nickel phosphide electrocatalysts has not been fully elucidated yet, which requires further studies.
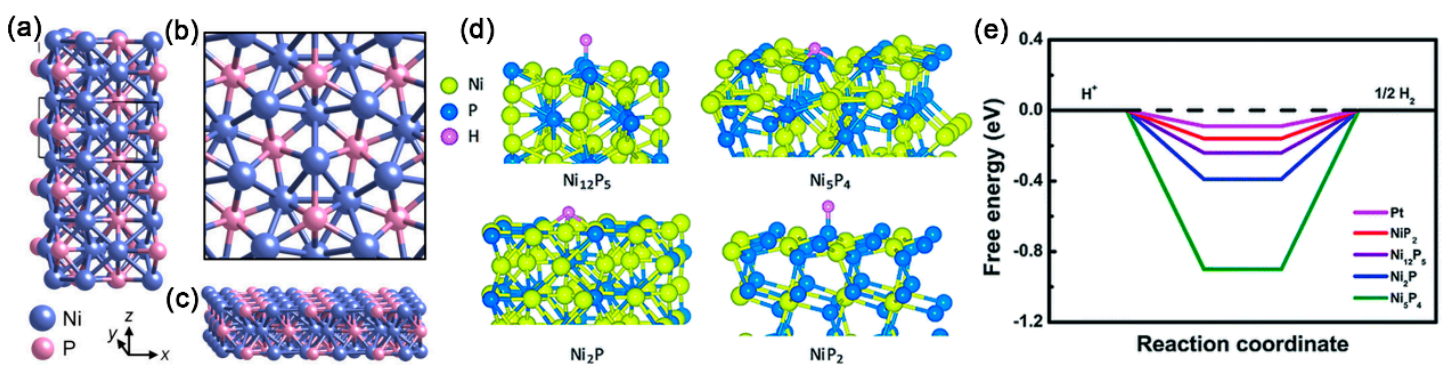

Figure 2. Crystal structure of $\mathrm{Ni}_{2} \mathrm{P}$ : four-unit cells stacked on top of one another, with a single unit cell outlined (a), top view of the $\mathrm{Ni}_{2} \mathrm{P}(001)$ surface $(\mathbf{b})$, and a two-dimensional slice of $\mathrm{Ni}_{2} \mathrm{P}$, showing the (001) surface on top (c). Reproduced with permission from Reference [45] the American Chemical Society, 2015. Optimized surface structures for the (001) faceted $\mathrm{Ni}_{4} \mathrm{P}_{5}$-terminated $\mathrm{Ni}_{12} \mathrm{P}_{5}, \mathrm{Ni}_{3} \mathrm{P}_{2}$-terminated $\mathrm{Ni}_{2} \mathrm{P}, \mathrm{Ni}_{4} \mathrm{P}_{3}$-terminated $\mathrm{Ni}_{5} \mathrm{P}_{4}$, and $\mathrm{P}$-terminated $\mathrm{NiP}_{2}(\mathbf{d})$ and corresponding free energy profiles for $\mathrm{Pt}, \mathrm{Ni}_{12} \mathrm{P} 5, \mathrm{Ni}_{2} \mathrm{P}, \mathrm{Ni}_{5} \mathrm{P}_{4}$, and $\mathrm{NiP}_{2}$ (e). Reproduced with permission from Reference [51]. The Royal Society of Chemistry, 2019. 


\section{Preparation of Nickel Phosphides and their Electrocatalytic HER Performances}

To date, various approaches have been developed to prepare nickel phosphide electrocatalysts, which can be mainly classified into five routes according to the different generation routes of phosphine in nickel phosphides, i.e., solution-phase method, thermal phosphidation with hypophosphite, thermal phosphidation with red phosphorus, hydrogen reduction of phosphates, and electrochemical deposition. In this part, progress on the synthesis of nickel phosphide electrocatalysts and corresponding HER performances are comprehensively reviewed and summarized for a comparison of the preparation approaches.

\subsection{Solution-Phase Method}

Solution-phase methods, such as the oil-phase reaction, the hydrothermal reaction, and the solvothermal reaction, are generally employed to prepare highly dispersed nanoparticles or nanocrystals. Because of the difficulties in the generation of phosphine species in the environment with oxygen and water, the preparation of nickel phosphide nanostructures is generally carried out in an oil phase solution, which can provide a reduction environment and protect the reaction against oxygen and water. For example, Popczun et al. first proposed a simple solvothermal method to synthesize $\mathrm{Ni}_{2} \mathrm{P}$ nanoparticles, which were fulfilled by heating nickel acetylacetonate in 1-octadecene, oleylamine, and trioctylphosphine (TOP) at $320{ }^{\circ} \mathrm{C}$ for $2 \mathrm{~h}$ [45]. The $\mathrm{Ni}_{2} \mathrm{P}$ nanoparticles were obtained through phosphidation of the in-situ formed Ni nanoparticles with TOP. The transmission electron microscope (TEM) image in Figure 3a revealed quasi-spherical nanoparticles with an average diameter of $21 \pm 2 \mathrm{~nm}$. The high-resolution TEM (HRTEM) image in Figure $3 \mathrm{~b}$ clearly showed that the $\mathrm{Ni}_{2} \mathrm{P}$ nanoparticles are single crystal and faceted, and the lattice fringes of $5.2 \AA$ correspond to the (100) and (010) planes of $\mathrm{Ni}_{2} \mathrm{P}$. The (001) crystal planes of $\mathrm{Ni}_{2} \mathrm{P}$ have been predicted to show higher HER activity. The $\mathrm{Ni}_{2} \mathrm{P}$ nanoparticles loaded on a Ti foil electrode exhibit excellent HER performance in $0.5 \mathrm{M} \mathrm{H}_{2} \mathrm{SO}_{4}$ solution with a low overpotential of $130 \mathrm{mV}$ to achieve a current density of $20 \mathrm{~mA} / \mathrm{cm}^{2}$ (Figure 3c) and a Tafel slope as low as $46 \mathrm{mV} / \mathrm{dec}$ (Figure $3 \mathrm{~d}$ ). Moon et al. synthesized $\mathrm{Ni}_{2} \mathrm{P}$ nanoparticles through a ligand stabilization method [52], which involves the first preparation of Ni-TOP solution by mixing nickel acetylacetonate and TOP and introducing into the trioctylphosphine oxide (TOPO) under vigorous stirring at $310{ }^{\circ} \mathrm{C}$. The as-prepared $\mathrm{Ni}_{2} \mathrm{P}$ electrocatalyst exhibited a high HER activity with a low onset potential for the HER at around $-0.02 \mathrm{~V}$ vs. RHE and a Tafel slope of $75 \mathrm{mV} / \mathrm{dec}$. Wang et al. reported the preparation of a nanohybrid of carbon nanotubes decorated with $\mathrm{Ni}_{12} \mathrm{P}_{5}$ nanocrystals $\left(\mathrm{Ni}_{12} \mathrm{P}_{5} / \mathrm{CNT}\right)$ by in situ one-pot hot-solution methods at a relatively mild temperature [47]. The $\mathrm{Ni}_{12} \mathrm{P}_{5} / \mathrm{CNT}$ nanohybrids showed excellent HER performance with a low overpotential of $129 \mathrm{mV}$ for HER at a current density $10 \mathrm{~mA} / \mathrm{cm}^{2}$ and a small Tafel slope of $56 \mathrm{mV} / \mathrm{dec}$. Similarly, Li et al. reported a simple and straight-forward hydrothermal route to grow $\mathrm{Ni}_{2} \mathrm{P}$ nanofilms in situ on the surfaces of carbon nanosheets (CNS), which results in strongly coupled 3D structured nanohybrids $\left(\mathrm{Ni}_{2} \mathrm{P} / \mathrm{CNS}\right)$ [53]. The as-prepared $\mathrm{Ni}_{2} \mathrm{P} / \mathrm{CNS}$ exhibits excellent HER performance in acidic solution and alkaline solution.

Besides nanoparticles and nanocrystals, some other nickel phosphide nanostructures have also been successfully fabricated through the solution phase method for electrocatalytic HER, and the structure-dependent catalytic performance was also studied. For example, Li et al. synthesized nanostructured $\mathrm{Ni}_{2} \mathrm{P}$ with different morphologies (nanorods and nanoparticles) by a one-step solution phase route in which the mixture of TOPO and TOP was used as solvent, but their electrocatalytic HER performances were not fully compared [54]. Pan et al. synthesized nickel phosphide $\left(\mathrm{Ni}_{2} \mathrm{P}\right)$ nanoparticles (NPs) with different sizes through thermal decomposition of bis(triphenylphosphine) nickel dichloride (BTND) single source precursor in the presence of oleylamine by controlling the reaction temperature, and the $\mathrm{Ni}_{2} \mathrm{P}$ NPs with a small size exhibit higher electrocatalytic activity due to the larger electrochemical active surface area and higher conductivity [55]. They also reported the synthesis of monodispersed nickel phosphide nanocrystals (NCs) with different phases $\left(\mathrm{Ni}_{12} \mathrm{P}_{5}\right.$, $\mathrm{Ni}_{2} \mathrm{P}$, and $\left.\mathrm{Ni}_{5} \mathrm{P}_{4}\right)$ via the thermal decomposition approach using nickel acetylacetonate as the nickel 
source, TOP as the phosphorus source, and oleylamine in 1-octadecene as the reductant. As shown in Figure $4 \mathrm{a}$, the phases of the nickel phosphide NCs could be easily controlled by changing the P/Ni precursor ratio. The as-synthesized nickel phosphide NCs exhibited good catalytic HER performance, and the HER activity showed a tendency of $\mathrm{Ni}_{12} \mathrm{P}_{5}<\mathrm{Ni}_{2} \mathrm{P}<\mathrm{Ni}_{5} \mathrm{P}_{4}$. The superior catalytic activity is attributed to the higher positive charge of $\mathrm{Ni}$ and a stronger ensemble effect of $\mathrm{P}$ in $\mathrm{Ni}_{5} \mathrm{P}_{4} \mathrm{NCs}$. Zhang et al. proposed a facile approach for fabricating nanostructured $\mathrm{Ni}_{2} \mathrm{P}$ and $\mathrm{Ni}_{12} \mathrm{P}_{5}$ by employing phosphonium-based ionic liquid, tetrabutylphosphonium chloride as a novel phosphorus source and reaction medium, upon microwave heating in 1-2 min or conventional heating at $350^{\circ} \mathrm{C}$ for $3 \mathrm{~h}$. As shown in Figure $4 b$, controlling counter anions of various nickel salts could conveniently tune the phase of as-synthesized nickel phosphides. When the $\mathrm{Ni}(\mathrm{acac})_{2}$ and $\mathrm{Ni}(\mathrm{OAc})_{2} \cdot 4 \mathrm{H}_{2} \mathrm{O}$ are used as $\mathrm{Ni}$ sources, the products are $\mathrm{Ni}_{2} \mathrm{P}$ nanoparticles, while the sources of $\mathrm{NiCl}_{2} \cdot 6 \mathrm{H}_{2} \mathrm{O}$ and $\mathrm{NiSO}_{4} \cdot 7 \mathrm{H}_{2} \mathrm{O}$ produce $\mathrm{Ni}_{12} \mathrm{P}_{5}$ nanocrystals. The as-synthesized $\mathrm{Ni}_{2} \mathrm{P}$ nanoparticles presented higher catalytic efficiency than $\mathrm{Ni}_{12} \mathrm{P}_{5} . \mathrm{Ni}_{2} \mathrm{P}$ nanoparticles prepared from $\mathrm{Ni}(\mathrm{acac})_{2}$ require an overpotential of only $102 \mathrm{mV}$ to reach $10 \mathrm{~mA} / \mathrm{cm}^{2}$ with a small Tafel slope of $46 \mathrm{mV} / \mathrm{dec}$. This novel ionic liquid-mediated method for the preparation of nickel phosphides shows advantages, that is, it can be operated by microwave heating in a short period of time, which is of particular interest from the viewpoint of energy saving, fast synthesis, and easy operation.
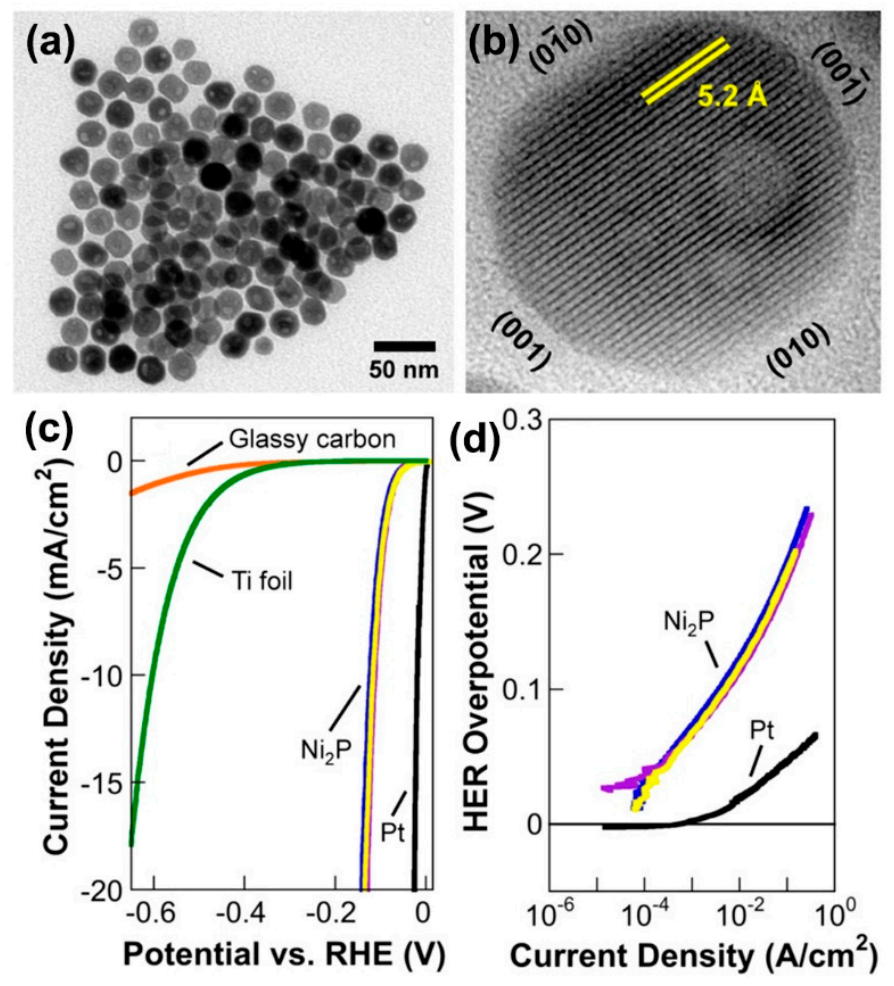

Figure 3. TEM image (a) and HRTEM image $(\mathbf{b})$ of a representative $\mathrm{Ni}_{2} \mathrm{P}$ nanoparticle, highlighting the exposed $\mathrm{Ni}_{2} \mathrm{P}(001)$ facet and the $5.2 \AA$ lattice fringes that correspond to the (010) planes. Polarization curves for $\mathrm{Ni}_{2} \mathrm{P}$ electrodes, glassy carbon, $\mathrm{Ti}$ foil, and $\mathrm{Pt}$ in $0.5 \mathrm{M} \mathrm{H}_{2} \mathrm{SO}_{4}$ for comparison (c) and corresponding Tafel plots (d). Reproduced with permission from Reference [45], the American Chemical Society, 2015. 
(a)

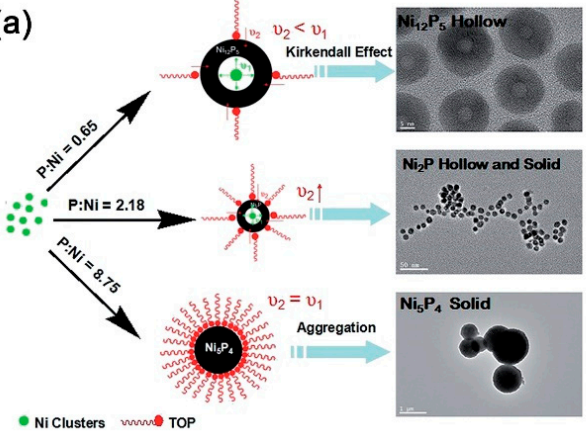

(b)

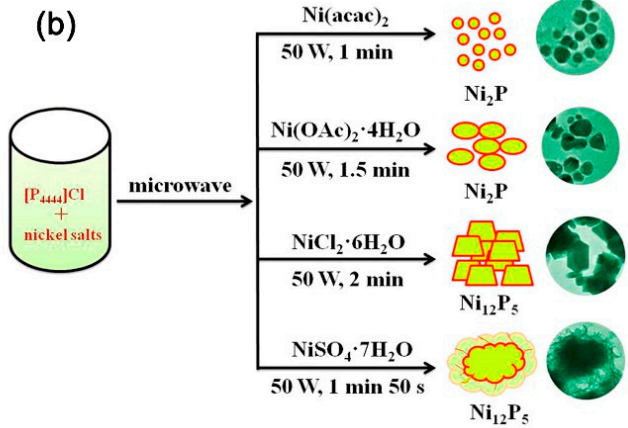

Figure 4. Possible formation mechanism of the as-synthesized nickel phosphide NCs with different phases and morphologies (a). Reproduced with permission from Reference [50], Copyright, The Royal Society of Chemistry, 2015. Typical schematic illustration for synthesizing various nickel phosphides controlled by the counter anions of nickel salts (b). Reproduced with permission from Reference [56], Copyright, the American Chemical Society, 2018.

Nickel phosphide nanoparticles with different Ni/P ratios can be synthesized by solution-phase reactions, which usually need polymer binders like Nafion to adhere catalysts to the electrodes for HER. Polymer binders generally increase electrical resistance and may reduce active sites, which results in reduced effective catalytic activity and affects long-term stability. Therefore, efforts are devoted to developing approaches for directly growing nickel phosphides on conductive substrates through solution-phase reactions. Wang et al. reported an easy one-step route for the fabrication of an integrated nickel phosphide nanorods/nickel $\left(\mathrm{Ni}_{2} \mathrm{P}-\mathrm{NRs} / \mathrm{Ni}\right)$ electrode by direct phosphidation of a commercially available $\mathrm{Ni}$ foam current collector under solvothermal conditions using red phosphorus (P) as the precursor [57]. The XRD pattern of the solvothermally-derived product in Figure 5a can be indexed as a hexagonal $\mathrm{Ni}_{2} \mathrm{P}$ phase with little admixture of a tetragonal $\mathrm{Ni}$-rich $\mathrm{Ni}_{12} \mathrm{P}_{5}$ phase and un-reacted Ni foam underneath. The SEM image in Figure 5b clearly shows the morphology of the nickel phosphides on Ni foam. Densely and vertically arranged NR arrays have formed on the entire surface of the nickel foam ligament. Figure 5c,d are typical dark- and bright-field TEM micrographs, which unambiguously confirm the rod-like shape of the grown $\mathrm{Ni}_{2} \mathrm{P}$. The HRTEM image in Figure 5e shows that the measured inter-planar spacings of 0.28 and $0.25 \mathrm{~nm}$ correspond to the distance of (101) and (200) crystal planes of hexagonal $\mathrm{Ni}_{2} \mathrm{P}$, respectively. Corresponding EDX elemental mapping images in Figure $5 \mathrm{f}$ further indicate that both $\mathrm{Ni}$ and $\mathrm{P}$ elements are uniformly distributed on the as-prepared electrode. According to the data in polarization curves (Figure 5g) and Tafel plots (Figure 5h), when used as an integrated cathode in acidic medium, the as-fabricated $\mathrm{Ni}_{2} \mathrm{P}-\mathrm{NRs} / \mathrm{Ni}$ electrode exhibits remarkable electrocatalytic activity toward HER with a small overpotential of $131 \mathrm{mV}$ to attain the current density of $10 \mathrm{~mA} / \mathrm{cm}^{2}$ and a Tafel slope of $106.1 \mathrm{mV} / \mathrm{dec}$. Furthermore, the electrode also shows reasonably good long-term stability. The novel fabrication method reported is scalable and can be extended to obtain other integrated transition metal phosphide/transition metal electrodes, and, therefore, represents an important development toward water electrolyzer cathode materials. Yu et al. fabricated a 3D carbon-coated nickel phosphide nanosheets array on the surface of Ni foam via a simple one-step solvothermal procedure with red phosphorus as the P source [58]. The as-prepared $\mathrm{C@Ni}_{8} \mathrm{P}_{3}$ exhibits excellent HER activity and extraordinary duration in both acidic and basic media. Shi et al. demonstrated the growth of $\mathrm{Ni}_{2} \mathrm{P}$ nanosheets on $\mathrm{Ni}$ foam by using a low concentration of TOP as a $\mathrm{P}$ source [59]. The $\mathrm{Ni}_{2} \mathrm{P} / \mathrm{Ni}$, acting as a robust 3D self-supported super-aerophobic hydrogen-evolving cathode, shows superior catalytic performance, stability, and durability in aqueous media over a wide $\mathrm{pH}$ value of $0-14$. Lai et al. successfully synthesized a rice-shape nanocrystalline $\mathrm{Ni}_{5} \mathrm{P}_{4}$ on $\mathrm{Ni}$ foam by a simple one-step hydrothermal process with sodium hypophosphite as the P source [46]. The $\mathrm{Ni}_{5} \mathrm{P}_{4} / \mathrm{NF}$ showed excellent HER performance with a low overpotential of $64 \mathrm{mV}$ at a current density of $10 \mathrm{~mA} / \mathrm{cm}^{2}$ and a small Tafel slope of $64 \mathrm{mV} / \mathrm{dec}$. Some other studies on the preparation of nickel phosphide nanostructures with various morphologies have also been reported through a 
one-step hydrothermal method with different phosphorus compounds as the P source (e.g., TOP, sodium hypophosphite, and red phosphorus). All the morphologies, precursors, and corresponding HER performance in acidic or alkaline electrolyte are summarized in Table 1 (acidic) and Table 2 (alkaline) for comparison. Based on the above results, it can be easily found that the solution-phase method generally produces nickel phosphide nanoparticles with different compositions or crystal phases, which can act as model catalysts to study and compare the HER performance between different compositions, crystal phases, or facets and are useful to make catalyst inks for practical applications in membrane electrodes. However, it is difficult to control the morphologies of the nickel phosphides and some of the precursors are high cost for practical use.
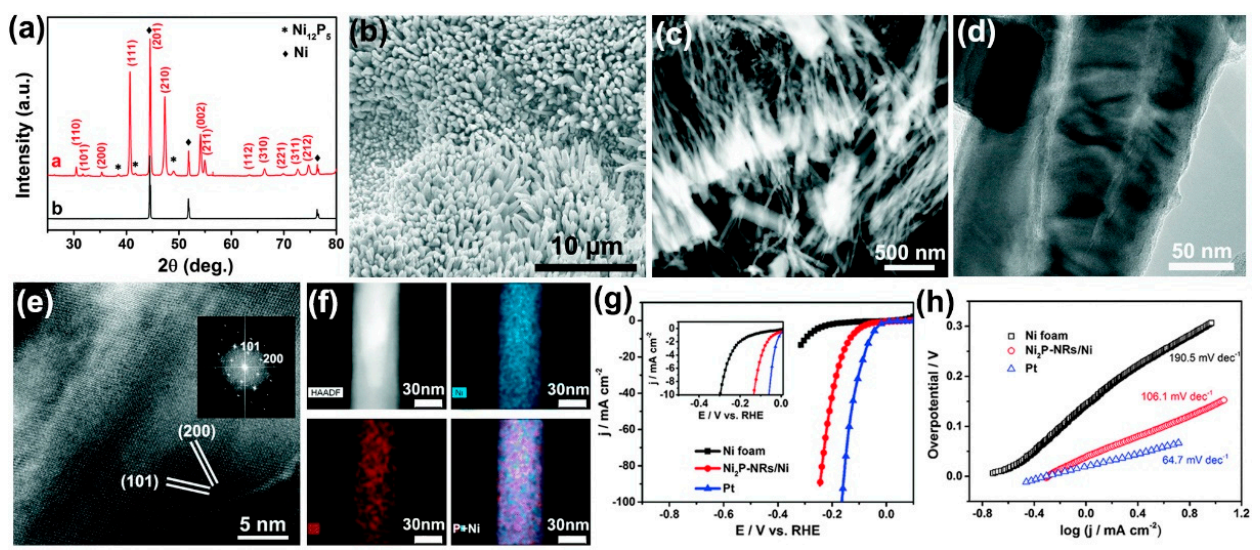

Figure 5. XRD patterns of (a) the as-fabricated $\mathrm{Ni}_{2} \mathrm{P}-\mathrm{NRs} / \mathrm{Ni}$ composite electrode, (b) SEM image, (c) Dark-field, and (d) bright-field TEM micrographs of $\mathrm{Ni}_{2} \mathrm{P}-\mathrm{NRs}$. (e) HRTEM image of a single $\mathrm{Ni}_{2} \mathrm{P}-\mathrm{NR}$. Inset: FFT-ED pattern. (f) HAADF STEM image of a single NR and the corresponding EDX elemental maps of Ni, $\mathrm{P}$, and $\mathrm{Ni}+\mathrm{P}$. (g) Polarization curves for $\mathrm{Ni}_{2} \mathrm{P}-\mathrm{NRs} / \mathrm{Ni}$ composite electrode in $0.5 \mathrm{M} \mathrm{H}_{2} \mathrm{SO}_{4}$. (h) The Corresponding Tafel plots. Reproduced with permission from Reference [57]. Copyright the Royal Society of Chemistry, 2015.

Table 1. Summary of the nickel phosphide electrocatalysts prepared through a solution-phase method for HER in an acidic electrolyte.

\begin{tabular}{|c|c|c|c|c|c|c|c|c|}
\hline $\begin{array}{l}\text { Material and } \\
\text { Morphology }\end{array}$ & Precursors $^{1}$ & $\begin{array}{l}\text { Phosphorus } \\
\text { Sources }^{2}\end{array}$ & Supports ${ }^{3}$ & $\begin{array}{c}\text { Loadingmg/ } \\
\mathrm{cm}^{2}\end{array}$ & $\begin{array}{c}\text { Tafel Slope } \\
\text { mV/dec }\end{array}$ & $\underset{\mathrm{mA} / \mathrm{cm}^{2}}{\mathrm{~J}}$ & $\eta \mathbf{m V}$ & Reference \\
\hline $\mathrm{Ni}_{2} \mathrm{P}$ nanocrystals & $\mathrm{Ni}(\mathrm{acac})_{2}$ & ТPP & Ti foil & $\sim 1$ & 70 & 10 & 107 & [60] \\
\hline $\mathrm{Ni}_{2} \mathrm{P}$ nanosheets & Ni foam & TOP & Ni foam & - & 68 & 1 & 80 & [59] \\
\hline $\mathrm{Ni}_{12} \mathrm{P}_{5}$ nanoparticle & $\mathrm{Ni}(\mathrm{ac})_{2}$ & TPP & Ti foil & 3 & 63 & 10 & 107 & [61] \\
\hline $\mathrm{Ni}_{2} \mathrm{P}$ nanoparticles & $\mathrm{Ni}(\text { acac })_{2}$ & TOP & GC & 0.2 & 74 & 10 & 159 & [62] \\
\hline $\mathrm{Ni}_{2} \mathrm{P}$ nanoparticles & $\mathrm{NiCl}_{2}\left(\mathrm{Ph}_{3} \mathrm{P}\right)_{2}$ & $\mathrm{NiCl}_{2}\left(\mathrm{Ph}_{3} \mathrm{P}\right)_{2}$ & GC & 0.199 & 83.3 & 20 & 228 & [55] \\
\hline $\mathrm{Ni}_{5} \mathrm{P}_{4}$ Nanocrystals & $\mathrm{Ni}(\text { acac })_{2}$ & TOP & GC & 0.12 & 51 & 10 & 103 & [63] \\
\hline $\mathrm{Ni}_{12} \mathrm{P}_{5}$ nanoplates & $\mathrm{Ni}(\text { acac })_{2}$ & TOP & Ti foil & 1 & 60.6 & 10 & 128 & [12] \\
\hline $\mathrm{Ni}_{2} \mathrm{P}$ nanoparticles & $\mathrm{Ni}(\mathrm{acac})_{2}$ & TOP & carbon paper & 3 & 55 & 10 & 120 & [64] \\
\hline $\mathrm{Ni}_{5} \mathrm{P}_{4}$ nanoparticles & $\mathrm{Ni}(\text { acac })_{2}$ & TOPO & Ti foil & - & 33 & 10 & 23 & [65] \\
\hline $\mathrm{Ni}_{2} \mathrm{P}$ nanoparticles & $\mathrm{Ni}(\mathrm{acac})_{2}$ & TOP & GC & 0.195 & 81 & 10 & 185 & [66] \\
\hline $\mathrm{Ni}_{2} \mathrm{P}$ nanoparticles & $\mathrm{Ni}(\text { acac })_{2}$ & TOP & GC & - & 74 & 1 & 20 & [52] \\
\hline $\mathrm{Ni}_{2} \mathrm{P}$ nanoparticles & $\mathrm{Ni}(\text { acac })_{2}$ & TOP & GC & 0.1843 & 59 & 10 & 102 & [70] \\
\hline $\mathrm{Ni}_{2} \mathrm{P}$ nanoparticles & $\mathrm{Ni}(\mathrm{acac})_{2}$ & TOP & Ti foil & 1 & 46 & 20 & 130 & [45] \\
\hline $\mathrm{Ni}_{2} \mathrm{P}$ nanowires & $\mathrm{Ni}(\mathrm{acac})_{2}$ & TOP & GC & 0.3 & 70 & 20 & 120 & [71] \\
\hline $\mathrm{Ni}_{12} \mathrm{P}_{5}$ nanoparticles & $\mathrm{Ni}(\text { acac })_{2}$ & TOP & Ti foils & 1.0 & 56 & 10 & 129 & [47] \\
\hline $\mathrm{Ni}_{2} \mathrm{P}$ nanowires & $\mathrm{Ni}(\text { acac })_{2}$ & TOP & GC & 1.42 & 60 & 10 & 133 & [72] \\
\hline
\end{tabular}

${ }^{1} \mathrm{Ni}(\text { acac })_{2}$ : nickel acetylacetonate. $\mathrm{Ni}(\mathrm{ac})_{2}$ : nickel acetate. $\mathrm{NiCl}_{2}\left(\mathrm{Ph}_{3} \mathrm{P}\right)_{2}$ : bis(triphenylphosphine)nickel dichloride. ${ }^{2}$ TPP: triphenylphosphine. TOP: trioctylphosphine. RP: red phosphorous. TOPO: trioctylphosphine oxide. ${ }^{3}$ GC: glassy carbon. 
Table 2. Summary of the nickel phosphide electrocatalysts prepared through a solution-phase method for HER in alkaline electrolyte.

\begin{tabular}{|c|c|c|c|c|c|c|c|c|}
\hline $\begin{array}{l}\text { Material and } \\
\text { Morphology }\end{array}$ & Precursors ${ }^{1}$ & $\begin{array}{l}\text { Phosphorus } \\
\text { Sources }^{2}\end{array}$ & Supports ${ }^{3}$ & $\begin{array}{l}\text { Loading } \\
\mathrm{mg} / \mathrm{cm}^{2}\end{array}$ & $\begin{array}{c}\text { Tafel Slope } \\
\text { mV/dec }\end{array}$ & $\underset{\mathrm{mA} / \mathrm{cm}^{2}}{\mathrm{~J}}$ & $\eta \mathrm{mV}$ & Reference \\
\hline $\mathrm{Ni}_{2} \mathrm{P}$ Nanosheets & Ni foam & TOP & Ti foil & - & 50 & 1 & 41 & [59] \\
\hline $\mathrm{C} @ \mathrm{Ni}_{8} \mathrm{P}_{3}$ nanosheet & Ni foam & $\mathrm{RP}$ & Ni foam & 1.9 & 59 & 10 & 144 & [58] \\
\hline $\mathrm{Ni}_{2} \mathrm{P}$ nanofilms & $\mathrm{NiCl}_{2}$ & $\mathrm{RP}$ & Ni foam & 0.429 & 120 & 10 & 315 & [53] \\
\hline $\mathrm{Ni}_{5} \mathrm{P}_{4}$ nanoparticles & $\mathrm{Ni}(\text { acac })_{2}$ & TOPO & Ti foil & - & 98 & 10 & 49 & [65] \\
\hline $\begin{array}{c}\mathrm{Ni}_{2} \mathrm{P} / \mathrm{Ni}_{12} \mathrm{P}_{5} \\
\text { nanoparticles }\end{array}$ & $\mathrm{Ni}\left(\mathrm{NO}_{3}\right)_{2}$ & $\mathrm{RP}$ & GC & - & 98 & 10 & 234 & [73] \\
\hline Flakelike $\mathrm{Ni}_{12} \mathrm{P}_{5}$ & $\mathrm{Ni}(\mathrm{ac})_{2}$ & $\mathrm{RP}$ & GC & $\sim 3$ & $\sim 106$ & 10 & 240 & [74] \\
\hline $\mathrm{Ni}_{2} \mathrm{P}$ nanocrystals & $\mathrm{Ni}(\text { acac })_{2}$ & $\mathrm{P}(\mathrm{Bu})_{4} \mathrm{Cl}$ & GC & 0.35 & 46 & 10 & 102 & [56] \\
\hline Multi-shelled $\mathrm{Ni}_{2} \mathrm{P}$ & $\mathrm{NiCl}_{2}$ & $\mathrm{NaH}_{2} \mathrm{PO}_{2}$ & Ni foam & 2 & 86.4 & 10 & 98 & [75] \\
\hline $\mathrm{Ni}_{5} \mathrm{P}_{4}$ nanoparticles & $\mathrm{NiCl}_{2}$ & $\mathrm{NaH}_{2} \mathrm{PO}_{2}$ & GC & - & 64 & 10 & 64 & [46] \\
\hline
\end{tabular}

${ }^{1} \mathrm{Ni}(\text { acac })_{2}$ : nickel acetylacetonate. $\mathrm{Ni}(\text { ac })_{2}$ : nickel acetate. ${ }^{2}$ TOP: trioctylphosphine. RP: red phosphorous. TOPO: trioctylphosphine oxide. $\mathrm{P}(\mathrm{Bu})_{4} \mathrm{Cl}$ : tetrabutylphosphonium chloride. ${ }^{3} \mathrm{GC}$ : glassy carbon.

\subsection{Thermal Phosphidation with Hypophosphite}

Although the solution-phase methods could produce nickel phosphide nanoparticles or nanocrystals with efficient HER activities, it requires effective immobilization of these catalysts on conductive support electrodes using a polymer binder such as Nafion or polytetrafluoroethylene (PTFE) for practical use. These polymer binders generally increase series resistance and may block active sites and inhibit diffusion, which leads to reduced catalytic HER activity. As a result, it is of significant importance to develop a binder-free HER cathode by directly growing the active nickel phosphide catalysts on current collectors. Jiang et al. reported a two-step strategy toward this direction to construct P-rich $\mathrm{NiP}_{2}$ nanosheet arrays supported on carbon cloth $\left(\mathrm{NiP}_{2} \mathrm{NS} / \mathrm{CC}\right)$, which involved the first step to grow $\mathrm{Ni}(\mathrm{OH})_{2}$ nanosheet arrays on $\mathrm{CC}\left(\mathrm{Ni}(\mathrm{OH})_{2} \mathrm{NS} / \mathrm{CC}\right)$ hydrothermally followed by converting into $\mathrm{NiP}_{2} \mathrm{NS} / \mathrm{CC}$ by a low-temperature phosphidation reaction with hypophosphite [76]. The X-ray diffraction (XRD) pattern in Figure 6a clearly indicates the crystal phase of $\mathrm{Ni}_{2} \mathrm{P}$. The SEM images of $\mathrm{Ni}(\mathrm{OH})_{2} \mathrm{NS} / \mathrm{CC}$ in Figure $6 \mathrm{~b}, \mathrm{c}$ and $\mathrm{NiP}_{2} \mathrm{NS} / \mathrm{CC}$ in Figure $6 \mathrm{~d}$,e indicate that the $\mathrm{Ni}(\mathrm{OH})_{2}$ nanosheet precursor on carbon cloth can be converted into $\mathrm{NiP}_{2} \mathrm{NS} / \mathrm{CC}$ while the structures and morphologies remain unchanged. The corresponding energy dispersive $X$-ray (EDX) spectrum in Figure $6 \mathrm{f}$ shows the atomic ratio between $\mathrm{Ni}$ and $\mathrm{P}$ to be close to 1:2. The TEM (Figure 6g), HRTEM (Figure 6h), and selected-area electron diffraction (SAED) (Figure 6i) images further confirmed the morphology and crystal phase of the $\mathrm{NiP}_{2}$ nanosheet. The corresponding EDX elemental mapping images in Figure 6j further indicate that both $\mathrm{Ni}$ and $\mathrm{P}$ elements are uniformly distributed in the whole $\mathrm{NiP}_{2}$ nanosheet arrays. The $\mathrm{NiP}_{2} \mathrm{NS} / \mathrm{CC}$ electrode exhibits high catalytic performance in acidic solutions with overpotentials of 75 and $204 \mathrm{mV}$ to afford current densities of 10 and $100 \mathrm{~mA} / \mathrm{cm}^{2}$, respectively, a Tafel slope of $51 \mathrm{mV} / \mathrm{dec}$, an exchange current density of $0.26 \mathrm{~mA} / \mathrm{cm}^{2}$, and nearly $100 \%$ Faradaic efficiency. Similarly, Cao et al. reported the synthesis of a hollow $\mathrm{Ni}_{2} \mathrm{P}$ microsphere structure via a facile two-step process, including hydrothermal synthesis of $\mathrm{Ni}(\mathrm{OH})_{2}$ followed by phosphidation with $\mathrm{NaH}_{2} \mathrm{PO}_{2}$ under argon [77]. Wang et al. successfully synthesized flower-like nickel phosphide microballs ( $\mathrm{Ni}_{5} \mathrm{P}_{4}-\mathrm{MBs}$ ) on the surface of a Ti foil substrate by a facile hydrothermal preparation of precursors followed by a post-phosphidation process with hypophosphite (Figure 6k). All possible Ni and $\mathrm{P}$ active sites of nickel phosphide were investigated by DFT simulation at a different hydrogen coverage (Figure 61,m,n). According to the DFT calculation results, the $\mathrm{P}$ site of $\mathrm{Ni}_{5} \mathrm{P}_{4}$ and $\mathrm{NiP}_{2}$ had an endothermic $\Delta \mathrm{G}_{\mathrm{H}^{*}}$ of 0.196 and $0.219 \mathrm{eV}$, respectively, which implies an energetically unfavorable interaction with hydrogen. Therefore, the $\mathrm{Ni}$ site of $\mathrm{Ni}_{5} \mathrm{P}_{4}$ is the main catalytically active site for the HER. The flower-like $\mathrm{Ni}_{5} \mathrm{P}_{4}$ microballs electrocatalyst exhibits excellent activity for the HER with a low overpotential of $35.4 \mathrm{mV}$ to reach a current density of $10 \mathrm{~mA} / \mathrm{cm}^{2}$ and a small Tafel slope of $48 \mathrm{mV} / \mathrm{dec}$ in acidic solution. By employing a similar strategy, various structures and morphologies of nickel-containing precursors have been prepared through hydrothermal methods, and then are chemically converted into nickel phosphide electrocatalysts by a low-temperature 
phosphidation reaction using hypophosphite as a P source. The structures and morphologies and corresponding electrocatalytic HER performances in acidic or alkaline electrolyte are summarized in Tables 3 and 4 , respectively.
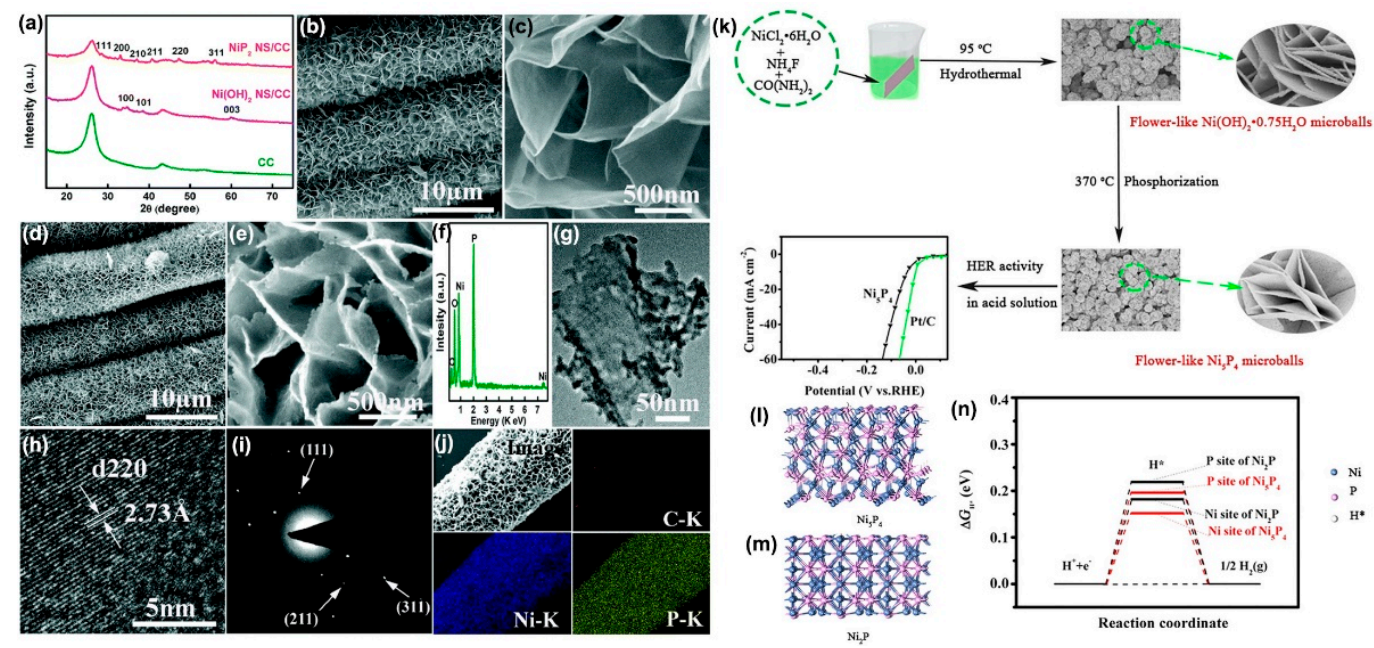

Figure 6. $\mathrm{XRD}$ patterns for $\mathrm{CC}, \mathrm{Ni}(\mathrm{OH})_{2} \mathrm{NS} / \mathrm{CC}$, and $\mathrm{NiP}_{2} \mathrm{NS} / \mathrm{CC}(\mathbf{a})$, low (b) and high (c) magnification SEM images of $\mathrm{Ni}(\mathrm{OH})_{2} \mathrm{NS} / \mathrm{CC}$, low (d) and high (e) magnification SEM images and the EDX spectrum (f) of $\mathrm{NiP}_{2} \mathrm{NS} / \mathrm{CC}$. TEM (g) and HRTEM (h) images and SAED pattern (i) of $\mathrm{NiP}_{2} \mathrm{NS}$. STEM image and corresponding EDX elemental mapping images of $\mathrm{C}, \mathrm{Ni}$, and $\mathrm{P}$ for $\mathrm{NiP}_{2} \mathrm{NS} / \mathrm{CC}(\mathbf{j})$. Reproduced with permission from Reference [75], Copyright the Royal Society of Chemistry, 2014. Schematic diagram of the growth of $\mathrm{Ni}_{5} \mathrm{P}_{4}$ and $\mathrm{Ni}_{2} \mathrm{P}$ on Ti foil with different morphologies (k), DFT-calculated HER activities, top view of the theoretical model of an $\mathrm{H}$ atom adsorbed on the $\mathrm{Ni}$ sites of a $\mathrm{Ni}_{5} \mathrm{P}_{4}$ and $\mathrm{Ni}_{2} \mathrm{P}_{\text {surface }}$ $(\mathbf{l}, \mathbf{m})$ and Gibbs Free energy diagrams for the HER on $\mathrm{Ni}$ and $\mathrm{P}$ of $\mathrm{Ni}_{5} \mathrm{P}_{4}$ and $\mathrm{Ni}_{2} \mathrm{P}$, respectively (n). Reproduced with permission from Reference [78], Copyright Wiley-VCH, 2018.

Table 3. Summary of the nickel phosphide electrocatalysts prepared through thermal phosphidation with hypophosphite for HER in an acidic electrolyte.

\begin{tabular}{|c|c|c|c|c|c|c|c|}
\hline Material and Morphology & Precursors ${ }^{1}$ & Supports ${ }^{2}$ & $\begin{array}{l}\text { Loading } \\
\mathrm{mg} / \mathrm{cm}^{2}\end{array}$ & $\begin{array}{c}\text { Tafel Slope } \\
\text { mV/dec }\end{array}$ & $\underset{\mathrm{mA} / \mathrm{cm}^{2}}{\mathrm{~J}}$ & $\eta \mathrm{mV}$ & Reference \\
\hline $\mathrm{Ni}_{5} \mathrm{P}_{4} / \mathrm{Ni}_{2} \mathrm{P} / \mathrm{NiP}_{2}$ Nanocatalysts & $\mathrm{Ni}\left(\mathrm{NO}_{3}\right)_{2}$ & carbon paper & 0.15 & 46.1 & 10 & 62 & [79] \\
\hline Macroporous $\mathrm{Ni}_{2} \mathrm{P}$ & $\mathrm{NiCl}_{2}$ & Ni foam & 2 & 68.9 & 20 & 140 & [80] \\
\hline $\mathrm{Ni}_{2} \mathrm{P}$ nanorod & $\mathrm{NiCl}_{2}$ & GC & 5.34 & 64 & 10 & 186 & [82] \\
\hline $\mathrm{Ni}_{2} \mathrm{P}$ Nanosheets & $\mathrm{Ni}\left(\mathrm{NO}_{3}\right)_{2}$ & Ni foam & - & 51 & 10 & 75 & [83] \\
\hline Flower-like $\mathrm{Ni}_{5} \mathrm{P}_{4}$ & $\mathrm{NiCl}_{2}$ & Ti foil & 4.2 & 48 & 10 & 35.4 & [78] \\
\hline $\mathrm{Ni}_{5} \mathrm{P}_{4}$ nanosheet & Ni foam & Ni foam & 45 & 34 & 10 & 114 & [85] \\
\hline $\mathrm{Ni}_{5} \mathrm{P}_{4}$ and $\mathrm{Ni}_{2} \mathrm{P}$ nanoparticles & $\mathrm{Ni}\left(\mathrm{NO}_{3}\right)_{2}$ & GC & 0.5 & 54.5 & 10 & 111 & [86] \\
\hline $\mathrm{Ni}_{12} \mathrm{P}_{5} / \mathrm{Ni}_{2} \mathrm{P} / \mathrm{Ni}$ nanowire & Ni foam & Ni foam & 31.5 & 70.8 & 10 & 73 & {$[87]$} \\
\hline $\mathrm{Ni}_{2} \mathrm{P}$ nanoparticles & $\mathrm{Ni}\left(\mathrm{NO}_{3}\right)_{2}$ & GC & 0.35 & 62 & 10 & 172 & [88] \\
\hline $\mathrm{Ni}_{2} \mathrm{P}$ nanoparticles & $\mathrm{Ni}\left(\mathrm{NO}_{3}\right)_{2}$ & GC & 0.38 & 87 & 20 & 140 & [89] \\
\hline $\mathrm{Ni}_{2} \mathrm{P}$ nanoparticle & $\mathrm{Ni}\left(\mathrm{NO}_{3}\right)_{2}$ & Ti plate & 2 & 60 & 10 & 120 & [90] \\
\hline $\mathrm{Ni}_{2} \mathrm{P}$ nanoarray & $\mathrm{Ni}\left(\mathrm{NO}_{3}\right)_{2}$ & carbon foil & 0.367 & 67 & 10 & 63 & [94] \\
\hline $\mathrm{Ni}_{3} \mathrm{P}$ and $\mathrm{Ni}_{12} \mathrm{P}_{5}$ nanoparticles & $\mathrm{NiSO}_{4}$ & GC & 0.6 & 105 & 100 & 333 & [95] \\
\hline $\mathrm{Ni}_{2} \mathrm{P}$ nanoparticle & $\mathrm{NiSO}_{4}$ & Ti foils & - & 84 & 2 & 174 & [96] \\
\hline $\mathrm{Ni}_{2} \mathrm{P}$ nanoparticle & $\mathrm{Ni}\left(\mathrm{NO}_{3}\right)_{2}$ & carbon cloth & 10.8 & 55 & 10 & 69 & [97] \\
\hline $\mathrm{NiP}_{2}$ nanosheets & $\mathrm{Ni}\left(\mathrm{NO}_{3}\right)_{2}$ & carbon cloth & 2.8 & 33.2 & 10 & 44 & [97] \\
\hline $\mathrm{Ni}_{2} \mathrm{P}$ nanobelts & $\mathrm{NiSO}_{4}$ & GC & 0.255 & 62 & 16 & 187 & [98] \\
\hline
\end{tabular}

${ }^{1} \mathrm{Ni}(\mathrm{ac})_{2}$ : nickel acetate. ${ }^{2} \mathrm{GC}$ : glassy carbon. 
Table 4. Summary of the nickel phosphide electrocatalysts prepared through thermal phosphidation with hypophosphite for HER in an alkaline electrolyte.

\begin{tabular}{|c|c|c|c|c|c|c|c|}
\hline Material and Morphology & Precursors 1 & Supports ${ }^{2}$ & $\begin{array}{l}\text { Loading } \\
\mathrm{mg} / \mathrm{cm}^{2}\end{array}$ & $\begin{array}{c}\text { Tafel Slope } \\
\text { mV/dec }\end{array}$ & $\underset{\mathrm{mA} / \mathrm{cm}^{2}}{\mathrm{~J}}$ & $\eta \mathbf{m V}$ & Reference \\
\hline $\mathrm{NiP}_{2}$ Nanorod & $\mathrm{NiCl}_{2}$ & carbon paper & 0.24 & 93 & 10 & 131 & [99] \\
\hline $\mathrm{Ni}_{2} \mathrm{P}$ polyhedrons & $\mathrm{Ni}\left(\mathrm{NO}_{3}\right)_{2}$ & GC & 0.124 & 65 & 10 & 146 & [81] \\
\hline $\begin{array}{l}\text { Urchin-Like } \mathrm{Ni}_{2} \mathrm{P} \\
\text { Superstructures }\end{array}$ & $\mathrm{NiCl}_{2}$ & Ni foam & - & 72 & 10 & 98 & [100] \\
\hline Nanometric $\mathrm{Ni}_{5} \mathrm{P}_{4}$ Clusters & $\mathrm{Ni}\left(\mathrm{NO}_{3}\right)_{2}$ & Ni foam & - & 27 & 10 & 27 & [101] \\
\hline $\mathrm{Ni}_{2} \mathrm{P}-\mathrm{NiP}_{2}$ Polymorphs & $\mathrm{NiS}_{2}$ & Ni foam & - & 58.8 & 10 & 59.7 & [102] \\
\hline Flower-like $\mathrm{Ni}_{5} \mathrm{P}_{4}$ microballs & $\mathrm{NiCl}_{2}$ & Ti foil & 4.2 & 56 & 10 & 47.1 & [78] \\
\hline $\mathrm{Ni}_{5} \mathrm{P}_{4}$ nanosheet & $\mathrm{Ni}$ foam & $\mathrm{Ni}$ foam & 45 & 70 & 10 & 190 & [85] \\
\hline $\mathrm{Ni}_{12} \mathrm{P}_{5} / \mathrm{Ni}_{2} \mathrm{P} / \mathrm{Ni}$ nanowire & $\mathrm{Ni}$ foam & $\mathrm{Ni}$ foam & 31.5 & 115.2 & 10 & 148 & [87] \\
\hline Ni2P nanoparticles & $\mathrm{NiCl}_{2}$ & GC & 0.38 & 100 & 20 & 250 & [89] \\
\hline $\mathrm{Ni}_{2} \mathrm{P}$ nanosheets & $\mathrm{NiCl}_{2}$ & GC & 1.63 & 72.3 & 10 & 108 & [104] \\
\hline $\mathrm{Ni}_{2} \mathrm{P}$ nanoparticles & $\mathrm{Ni}\left(\mathrm{NO}_{3}\right)_{2}$ & GC & 1 & 99 & 10 & 188 & [92] \\
\hline $\mathrm{Ni}_{2} \mathrm{P}$ nanosheet & $\mathrm{Ni}$ foam & Ni foam & 2.7 & 90 & 10 & 102 & [107] \\
\hline $\mathrm{Ni}_{2} \mathrm{P}-\mathrm{Ni}_{5} \mathrm{P}_{4}$ nanosheet & $\mathrm{Ni}\left(\mathrm{NO}_{3}\right)_{2}$ & carbon cloth & - & 83 & 10 & 102 & [108] \\
\hline $\mathrm{Ni}_{2} \mathrm{P}$ nanosheets & Ni foam & Ni foam & 3 & 92 & 10 & 134 & [109] \\
\hline
\end{tabular}

${ }^{1} \mathrm{Ni}(\mathrm{ac})_{2}$ : nickel acetate. ${ }^{2} \mathrm{GC}$ : glassy carbon.

Recently, metal-organic frameworks (MOFs) have been proven to be ideal precursors for preparation of a variety of porous nanostructured carbon/metal composites with perfect dispersity of active sites, which can be employed to fabricate nickel phosphide electrocatalysts for the HER. For example, Yan et al. demonstrated the formation of ultrasmall nickel phosphide nanocrystals anchored on reduced graphene oxide $\left(\mathrm{Ni}_{2} \mathrm{P} / \mathrm{rGO}\right)$ by implanting Ni-containing MOFs (MOF-74-Ni) on graphene oxide followed by phosphidation with hypophosphite (Figure 7a) [108]. The $\mathrm{Ni}_{2} \mathrm{P} / \mathrm{rGO}$ can be used as highly efficient bifunctional electrocatalysts for overall water splitting. The high magnification SEM image (Figure 7d) and TEM image (Figure $7 \mathrm{e}$ ) of $\mathrm{Ni}_{2} \mathrm{P} / \mathrm{rGO}$ show that the $\mathrm{Ni}_{2} \mathrm{P}$ nanocrystals are uniformly anchored on $\mathrm{rGO}$ surfaces. The $\mathrm{Ni}_{2} \mathrm{P} / \mathrm{rGO}$ exhibited excellent catalytic performance for both HER and OER in $1.0 \mathrm{M} \mathrm{KOH}$. Furthermore, an electrolyzer employing $\mathrm{Ni}_{2} \mathrm{P} / \mathrm{rGO}$ as a bifunctional catalyst in both the cathode and anode generated $10 \mathrm{~mA} / \mathrm{cm}^{2}$ at a voltage of $1.61 \mathrm{~V}$ with excellent stability. Veeramani et al. reported the preparation of a new class of nickel phosphide/graphitic carbon ( $\mathrm{Ni}_{2} \mathrm{P} @ \mathrm{GC}$ ) hybrid through a two-step strategy [93]. They first synthesized Ni-based MOFs (Ni-BTC MOFs) as precursors, and the phosphidation was conducted with sodium hypophosphite to convert Ni-BTC MOFs to $\mathrm{Ni}_{2} \mathrm{P} @ G C$, which is schematically illustrated in Figure 7b. The SEM image in Figure $6 \mathrm{~h}$ indicates a stacked layer-like morphology of the precursor Ni-BTC MOF, which was changed to $\mathrm{Ni}_{2} \mathrm{P}$ nanoparticles on GC after the phosphidation reaction but maintained the overall morphologies (Figure 7i). Similarly, He et al. synthesized nickel phosphide@carbon ( $\left.\mathrm{Ni}_{2} \mathrm{P} @ \mathrm{C}\right)$ composites with unique nanorod array morphology via a facile phosphidation process using $\mathrm{Ni}(\mathrm{II})$-zeolitic imidazolate framework-67 (ZIF-67-Ni) as the precursor (Figure 7c) [82]. The $\mathrm{Ni}_{2} \mathrm{P} @ \mathrm{C}$ nanorod array exhibited the highest electrocatalytic activity toward HER in $0.5 \mathrm{M} \mathrm{H}_{2} \mathrm{SO}_{4}$ solution with a low overpotential of 186 $\mathrm{mV}$ at the current density of $10 \mathrm{~mA} / \mathrm{cm}^{2}$ and high durability. By using the same strategy, they also synthesized a hexagonal micro-rod of MOF-74-Ni first via a facile and ultrafast microwave-assisted approach, which was then utilized as a precursor for preparation of a porous $\mathrm{Ni}_{2} \mathrm{P} / \mathrm{C}$ composite. The precursor of the MOF-74-Ni structure (Figure 7f) possesses a hexagonal rod structure with smooth facets and uniform size distribution. Interestingly, the surface of the rod became very rough and numerous pores appeared after the phosphidation reaction with hypophosphite (Figure 7g). The as-prepared $\mathrm{Ni}_{2} \mathrm{P} / \mathrm{C}$ exhibited excellent electrocatalytic activity toward HER with a low onset potential of $94 \mathrm{mV}$, long-term stability, and a Tafel slope of $113.2 \mathrm{mV} / \mathrm{dec}$. Some other works have also demonstrated the preparation of nickel phosphide electrocatalysts for HER by phosphidation of MOF precursors with 
hypophosphite at a relatively low temperature, which are summarized in Tables 3 and 4 based on the acidic or alkaline electrolyte.

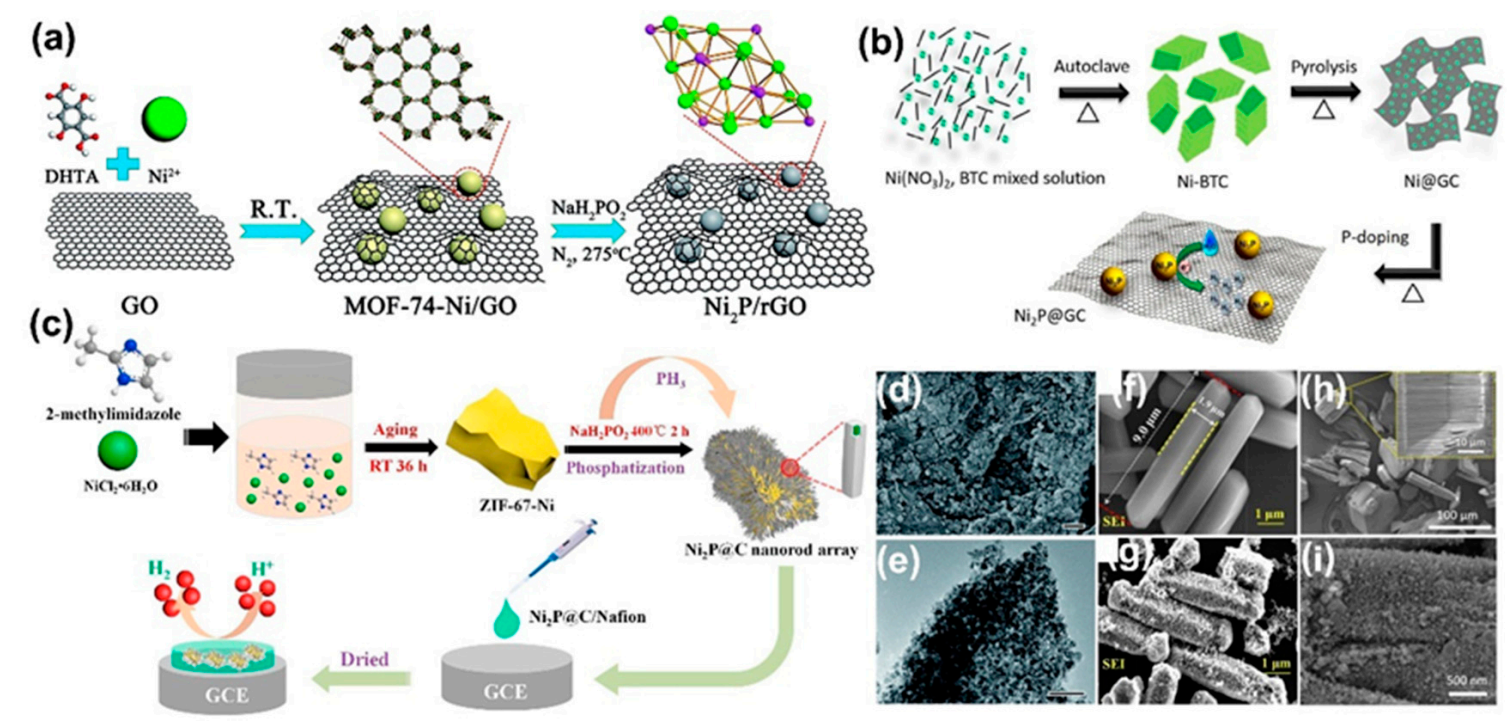

Figure 7. Schematic illustration of the synthesis procedure for the $\mathrm{Ni}_{2} \mathrm{P} / \mathrm{rGO}(\mathbf{a})$, high magnification SEM (d), and TEM (e) images of the $\mathrm{Ni}_{2} \mathrm{P} / \mathrm{rGO}$. Reproduced with permission from Reference [106], Copyright the Royal Society of Chemistry, 2018. Schematic representation for the simple synthesis of Ni@GC and $\mathrm{Ni}_{2}$ P@GC materials (b), SEM image of the Ni-BTC precursors (h), and SEM image of the Ni@GC samples (i). Reproduced with permission from Reference [93], Copyright Elsevier B.V., 2019. Schematic illustration of the preparation process of the $\mathrm{Ni}_{2} \mathrm{P} @ \mathrm{C}$ catalyst and its application as an electrocatalyst for HER (c). Reproduced with permission from Reference [82], Copyright Elsevier B.V., 2018. SEM images of MOF-74-Ni (f) and $\mathrm{Ni}_{2} \mathrm{P} / \mathrm{C}(\mathbf{g})$. Reproduced with permission from Reference [91], Copyright Elsevier B.V., 2018.

In addition, in spite of that transition, metal nickel has a high abundance and much lower cost as a source for preparation of nickel phosphide electrocatalysts for large-scale hydrogen production through electrochemical water splitting. It may be a more environmentally-friendly and cost-effective way if $\mathrm{Ni}$ waste and scrap can be recovered for preparing nickel phosphide electrocatalysts. However, it remains a challenge because of their large amounts of impurities. Recently, Zheng et al. proposed a simple method to synthesize $3 \mathrm{D} \mathrm{Ni} 2$ P nanoparticles from scrap nickel on carbon cloth $\left(\mathrm{Ni}_{2} \mathrm{P} \mathrm{NPs} / \mathrm{CC}\right)$ [110]. As shown in Figure $8 \mathrm{a}, \mathrm{b}$, they first dissolved nickel waste in formic acid solution by a simple ultrasonic method. Then $\mathrm{NiO}$ nanoparticles were fabricated by photochemical vapor generation and CVD. Lastly, the target product of $\mathrm{Ni}_{2} \mathrm{P}$ nanoparticles (NPs) was obtained by phosphidation at a low temperature with hypophosphite. The XRD patterns of NiO NPs (Figure 8c) and $\mathrm{Ni}_{2} \mathrm{P} \mathrm{NPs} / \mathrm{CC}$ (Figure $8 \mathrm{~d}$ ) at different temperatures demonstrated the formation of each crystal phase. It is intriguing that the $\mathrm{NiO}$ NPs consist of relatively regular nanoparticles that are 200-300 nm in size (Figure 8e,f). After phosphidation, the surface is composed of relatively loose nanoparticles with a coral-like morphology, as shown in Figure 8g,h. The polarization curves in Figure 8i,k and Tafel plots in Figure 8j,l, respectively, suggested as-prepared $\mathrm{Ni}_{2} \mathrm{P}$ NPs possessed significant electrocatalytic performance and excellent stability in both acidic and alkaline media toward the HER with low overpotentials of 69 and 73 $\mathrm{mV}$ at $10 \mathrm{~mA} / \mathrm{cm}^{2}$ and small Tafel slopes of 55 and $73 \mathrm{mV} / \mathrm{dec}$, respectively. This strategy is simpler, more cost-effective, and more environmentally-friendly when compared to conventional fabrication methods, which shows potentials in the preparation of multi-functional HER electrocatalysts from more abundant elements for efficient utilization of scrap transition metals. 

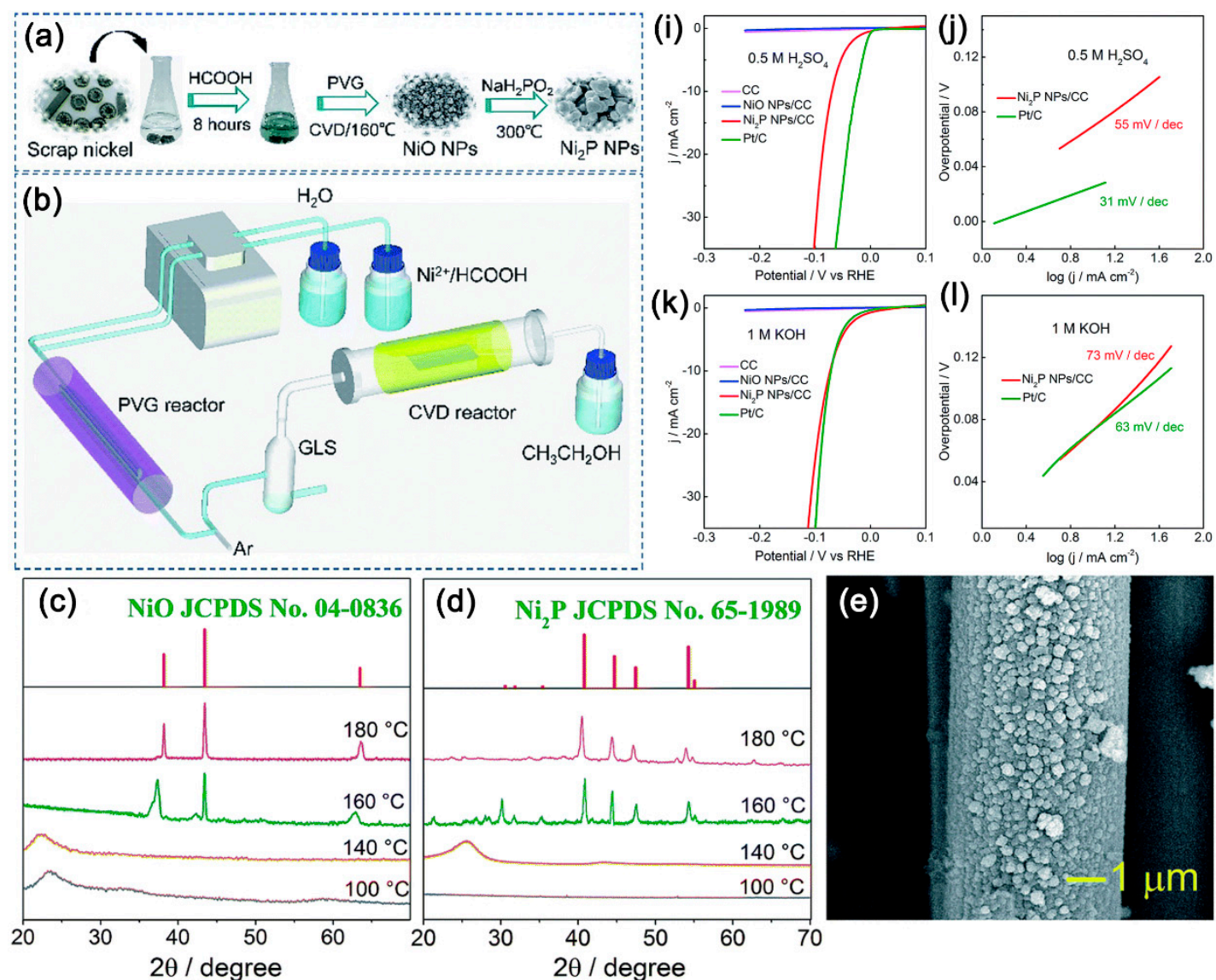

(d) $\quad \mathrm{Ni}_{2} \mathrm{P}$ JCPDS No. 65-1989
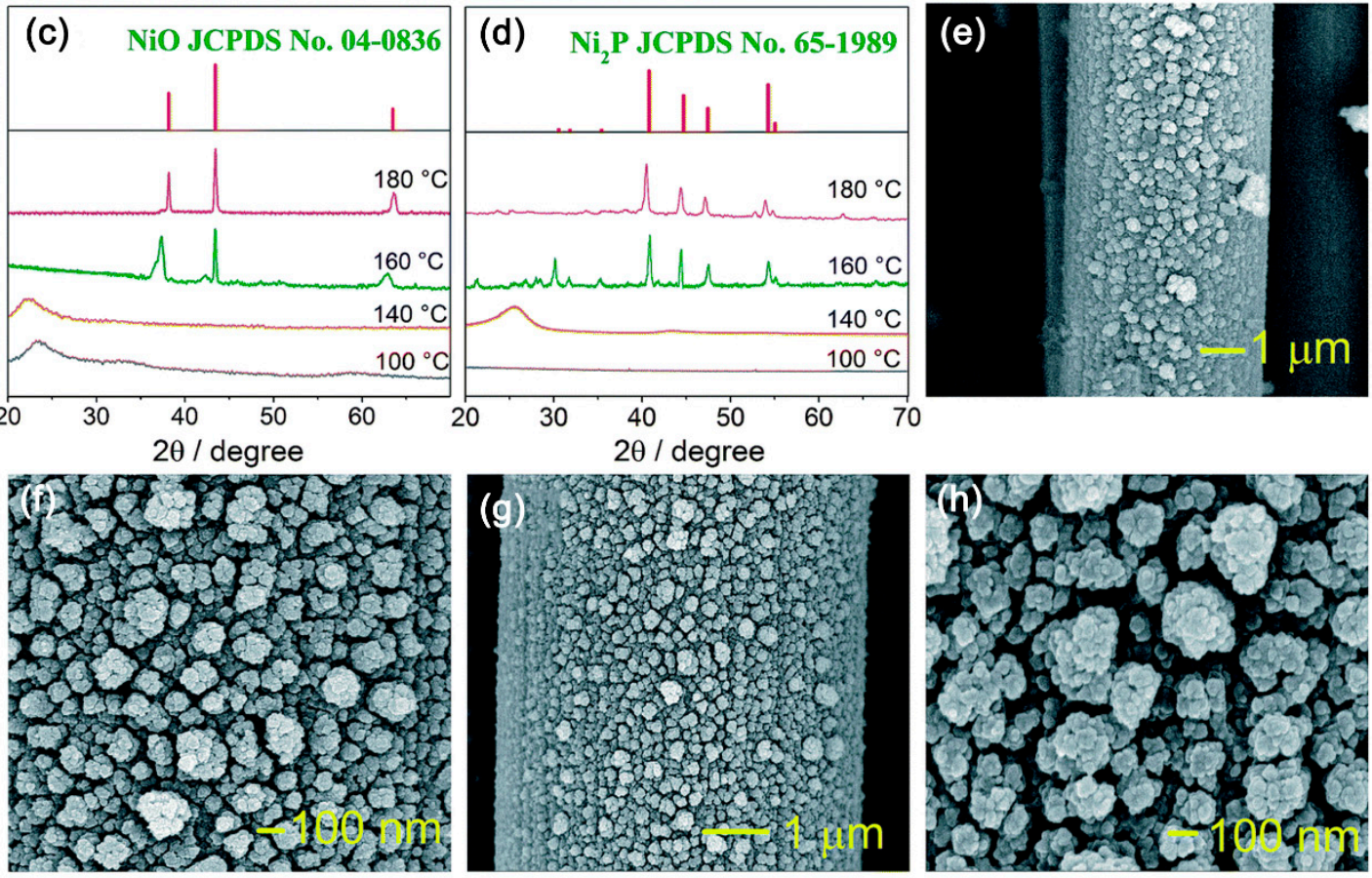

Figure 8. Schematic diagram of $\mathrm{Ni}_{2} \mathrm{P}$ NPs/CC preparation via acidic extraction, $\mathrm{PVG}$, low-temperature CVD, and phosphidation (a) and a detailed diagram of PVG (b), XRD patterns of NiO NPs (c), and $\mathrm{Ni}_{2} \mathrm{P}$ NPs/CC (d) prepared at 100, 140, 160, and $180^{\circ} \mathrm{C}$, low- (e) and high- (f) magnification SEM images of NiO NPs/CC prepared at $160^{\circ} \mathrm{C}$. Low- (g) and high- (h) magnification SEM images of $\mathrm{Ni}_{2} \mathrm{P} \mathrm{NPs} / \mathrm{CC}$. Polarization curves for $\mathrm{CC}, \mathrm{NiO}$, and $\mathrm{Ni}_{2} \mathrm{P} \mathrm{NPs} / \mathrm{CC}$ obtained at $160{ }^{\circ} \mathrm{C}$ in $0.5 \mathrm{M} \mathrm{H}_{2} \mathrm{SO}_{4}$ (i) and $1 \mathrm{M} \mathrm{KOH}$ $(\mathbf{k})$, and corresponding Tafel slopes $(\mathbf{j}, \mathbf{1})$. Reproduced with permission from Reference [110], Copyright the Royal Society of Chemistry, 2018.

\subsection{Thermal Phosphidation with Red Phosphorus}

Although the rational design and growth of nickel compound precursors followed by thermal phosphidation with hypophosphite show potentials to prepare nickel phosphides electrocatalysts with controllable morphologies for efficient HER. The $\mathrm{PH}_{3}$ gases generated during the process (Note: $\mathrm{PH}_{3}$ gases will be released from sodium hypophosphite at $\sim 300{ }^{\circ} \mathrm{C}[111,112]$ ) are toxic and dangerous to staff. Therefore, gentler phosphidation methods are necessary to lower the risk. A relatively low-toxic red phosphorus powder instead of hypophosphite was employed as a P source in the phosphidation reaction. Ledendecker et al. first demonstrated the simple preparation of highly ordered $\mathrm{Ni}_{5} \mathrm{P}_{4}$ nanoarchitectures directly on $\mathrm{Ni}$ foil through thermal phosphidation with red phosphorus powder at 
$550{ }^{\circ} \mathrm{C}$ for $1 \mathrm{~h}$ under an inert atmosphere [113]. The synthesized $\mathrm{Ni}_{5} \mathrm{P}_{4}$ nano-architecture electrode exhibits outstanding HER performance in a strong acidic electrolyte. Many interesting morphologies of nickel phosphides prepared by a direct phosphidation reaction method between $\mathrm{Ni}$ foam and red phosphorus have been reported because commercial nickel foam holds great promise as a starting material for preparing efficient catalysts due to its unique 3D structure, abundance of macropores, high conductivity, and low price. For example, Wang et al. [114], Mishra et al. [115], and Cai et al. [116] reported the very simple and straight-forward method to fabricate self-supported multi-phase nickel phosphide (e.g., $\mathrm{Ni}_{5} \mathrm{P}_{4}-\mathrm{NiP}_{2}$ or $\mathrm{Ni}_{5} \mathrm{P}_{4}-\mathrm{Ni}_{2} \mathrm{P}$ ) nanosheet array cathodes for electrocatalytic HER by placing red phosphorus and commercial nickel foams upstream and downstream of a ceramic crucible, respectively, in the argon atmosphere. In acidic medium, these nickel phosphide nanosheet arrays exhibit very stable and excellent HER performance. Notably, the placement of red phosphorus powder and Ni foam upstream and downstream separately (denoted as F-B method) makes the phosphidation reaction relatively insufficient and low reproducible because the concentration of the $P$ vapor in the reaction tube is significantly influenced by many factors, such as the carry-gas flow rate, the diameter of the tube, and the temperature control. In order to address such issues, we developed a facile, effective, and reproducible phosphidation method by placing a $\mathrm{Ni}$ foam above the red phosphorus powder at a distance of $1 \mathrm{~cm}$ inside a covered ceramic crucible (denoted as B-U method), which sufficiently allowed the phosphidation reaction [117]. As-prepared self-supported hierarchical porous nickel phosphide $\left(\mathrm{Ni}_{5} \mathrm{P}_{4} / \mathrm{NiP}_{2}\right)$ nanosheets exhibited significantly improved HER performance compared to the structures prepared by the general F-B method. Figure $9 \mathrm{a}, \mathrm{b}$ clearly show the schematic illustration of the B-U method and F-B method, respectively. The SEM images in Figure 9c,d suggest the nickel phosphide (B-U method) nanosheets are uniformly covered on the surface and have relatively small areas with sharp edges and nanopores. XRD patterns of the pristine $\mathrm{Ni}$ foam, $\mathrm{S}_{\mathrm{B}-\mathrm{U}}$, and $\mathrm{S}_{\mathrm{F}-\mathrm{B}}$ are shown in Figure 9e, which indicates that the $\mathrm{S}_{\mathrm{F}-\mathrm{B}}$ shows the $\mathrm{Ni}_{5} \mathrm{P}_{4}$ phase and unreacted Ni phase, while the $\mathrm{S}_{\mathrm{B}-\mathrm{U}}$ have two nickel phosphide phases, $\mathrm{Ni}_{5} \mathrm{P}_{4}$ and $\mathrm{NiP}_{2}$, which suggests the reliability of the B-U method. The polarization curves in Figure $9 \mathrm{f}$ and Tafel plots in Figure 9g clearly show that the HER performance of nickel phosphide nanosheets prepared by $\mathrm{S}_{\mathrm{B}-\mathrm{U}}$ method is better than the one prepared by the $\mathrm{S}_{\mathrm{F}-\mathrm{B}}$ method. Alternatively, Laursen et al. prepared $\mathrm{Ni}_{3} \mathrm{P}$ microparticles by a conventional solid-state reaction, which allowed $\mathrm{Ni}(\mathrm{s})$ and $\mathrm{P}(\mathrm{s})$ to react in an evacuated quartz tube at $700{ }^{\circ} \mathrm{C}$ for $24 \mathrm{~h}$ [48]. The microcrystalline $\mathrm{Ni}_{3} \mathrm{P}$ as a noble-metal-free electrocatalyst for HER shows high activity lower than those of $\mathrm{Ni}_{5} \mathrm{P}_{4}$ and $\mathrm{Pt}$, which are the two most efficient HER catalysts known. Mishra et al. demonstrated the preparation of hierarchical $\mathrm{CoP} / \mathrm{Ni}_{5} \mathrm{P}_{4} / \mathrm{CoP}$ microsheet arrays via a three-step process [115], i.e., $\mathrm{Ni}$ foam was first directly phosphidated at $500{ }^{\circ} \mathrm{C}$ in a tube furnace using red phosphorous to form nickel phosphide nanosheet arrays, which was then soaked in Co-ink $\left(\mathrm{Co}\left(\mathrm{NO}_{3}\right)_{2}\right.$ and a DMF mixture solution) followed by a second phosphidation at $500^{\circ} \mathrm{C}$. The as-prepared $\mathrm{CoP} / \mathrm{Ni}_{5} \mathrm{P}_{4} / \mathrm{CoP}$ microsheet arrays require an ultralow overpotential of only $33 \mathrm{mV}$ at a current density of $10 \mathrm{~mA} / \mathrm{cm}^{2}$. Similarly, Chen et al. prepared $\mathrm{Ni}_{5} \mathrm{P}_{4} / \mathrm{NiP}_{2}$ nanoparticles on $\mathrm{Ni}_{5} \mathrm{P}_{4} / \mathrm{NiP}_{2}$ nanosheets by first phosphidation of $\mathrm{Ni}$ foam with red phosphorus and dipping in a Ni precursor ink followed by the second phosphidation [118]. As-prepared hierarchical nickel phosphide structures exhibit an overpotential of only $35 \mathrm{mV}$ at a current density of $10 \mathrm{~mA} / \mathrm{cm}^{2}$ in an acidic solution and great stability at a high current density of $1200 \mathrm{~mA} / \mathrm{cm}^{2}$. 

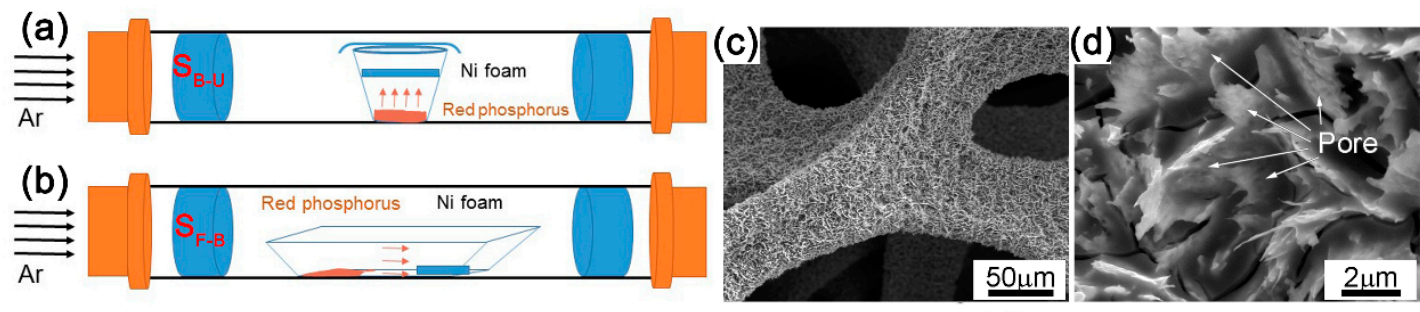

(e)

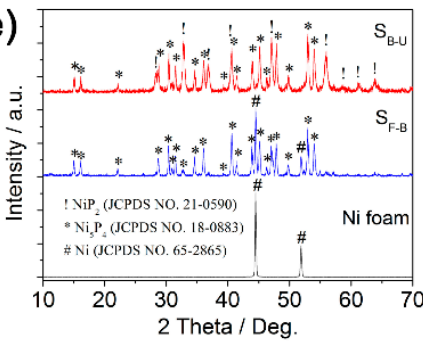

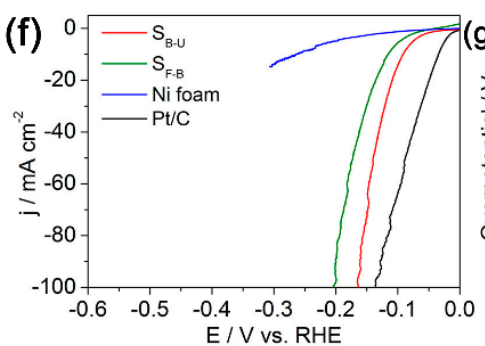

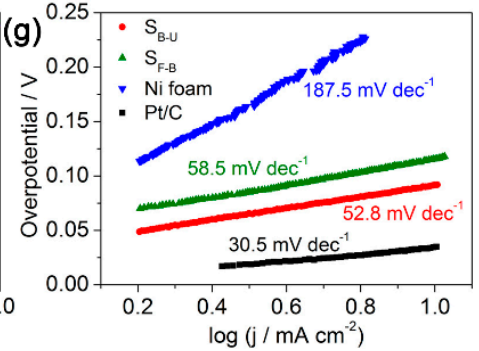

Figure 9. Schematic illustration for preparation of nickel phosphide by the method with bottom-up placement $\mathrm{S}_{\mathrm{B}-\mathrm{U}}$ (a) and an upstream-downstream placement $\mathrm{S}_{\mathrm{F}-\mathrm{U}}$ (b). Low- (c) and high- (d) magnification SEM images of $\mathrm{S}_{\mathrm{B}-\mathrm{U}}$. XRD patterns of the $\mathrm{S}_{\mathrm{B}-\mathrm{U}}\left(500^{\circ} \mathrm{C}\right), \mathrm{S}_{\mathrm{F}-\mathrm{B}}\left(500{ }^{\circ} \mathrm{C}\right)$, and the pristine $\mathrm{Ni}$ foam (e). Polarization curves (f) and Tafel plots $(\mathrm{g})$ of the $\mathrm{S}_{\mathrm{B}-\mathrm{U}}\left(500^{\circ} \mathrm{C}\right), \mathrm{S}_{\mathrm{F}-\mathrm{B}}\left(500{ }^{\circ} \mathrm{C}\right)$, pristine Ni foam, and Pt/C catalyst. Reproduced with permission from Reference [117], Copyright Elsevier B.V., 2019.

Nickel phosphides discussed above were synthesized by direct phosphidation of $\mathrm{Ni}$ foam or $\mathrm{Ni}$ foil with red phosphorous. Two issues should be considered in practical use when using metal Ni as precursors, i.e., the dissolution behavior of the unphosphidated Ni during electrocatalytic water splitting and the fragility of the nickel phosphide structures. Therefore, an alternative process should be developed to address such issues. Wang et al. reported a convenient and scalable approach for fabricating a self-supported 3D carbon fiber paper electrode deposited with vertically aligned Ni-P nanosheets (NSs) as bifunctional catalysts for HER and OER through electrodeposition of the Ni layer on the surface of carbon microfibers followed by a simple direct phosphidation process [119]. The self-supported 3D electrode can be directly used as either a cathode to drive HER or an anode to expedite OER, which exhibits excellent electrocatalytic activity and outstanding long-term durability. Recently, our group developed a general, facile, and scalable method to prepare nickel phosphide $\left(\mathrm{Ni}_{5} \mathrm{P}_{4} / \mathrm{NiP}_{2} / \mathrm{Ni}_{2} \mathrm{P}\right)$ porous nanosheets with high electrocatalytic HER activities through electroless $\mathrm{Ni}$ plating on arbitrary substrates, which is followed by a simple direct phosphidation reaction [120]. The preparation of the porous nickel phosphide nanosheets on carbon cloth is schematically shown in Figure 10a. The polarization curves in Figure 10b clearly show that the nickel phosphide electrode exhibits excellent HER performance in $0.5 \mathrm{M} \mathrm{H}_{2} \mathrm{SO}_{4}$ solution with very low overpotentials of $63 \mathrm{mV}$ and $120 \mathrm{mV}$ to achieve current densities of $10 \mathrm{~mA} / \mathrm{cm}^{2}$ and $100 \mathrm{~mA} / \mathrm{cm}^{2}$, respectively. Furthermore, a time-dependent potential curve in Figure 10c indicates that the electrode exhibits outstanding durability for $168 \mathrm{~h}$ under a constant current density of $10 \mathrm{~mA} / \mathrm{cm}^{2}$. The SEM images of Ni/CC-60 and Ni-P/CC-60-450 shown in Figure 10d,e,f,g, respectively, indicate that the carbon fibers are uniformly covered by high-density novel porous nickel phosphide nanosheets. This strategy was demonstrated in the preparation of porous nickel phosphide nanostructures on leaf vein (LV) and silkworm cocoon (SC), which are both highly active electrocatalysts for HER. The SEM images of Ni-P/LV in Figure 10h,i show that the nickel phosphide nanosheets are very thin and have many inner pores. The SEM images of Ni-P/SC in Figure 10j,k indicate that the nickel phosphide nanowires have relatively sharp tips and some pores inside. Therefore, this strategy is a general method to prepare transition-metal compound nanostructures in a facile, stable, and scalable way for various practical applications. 


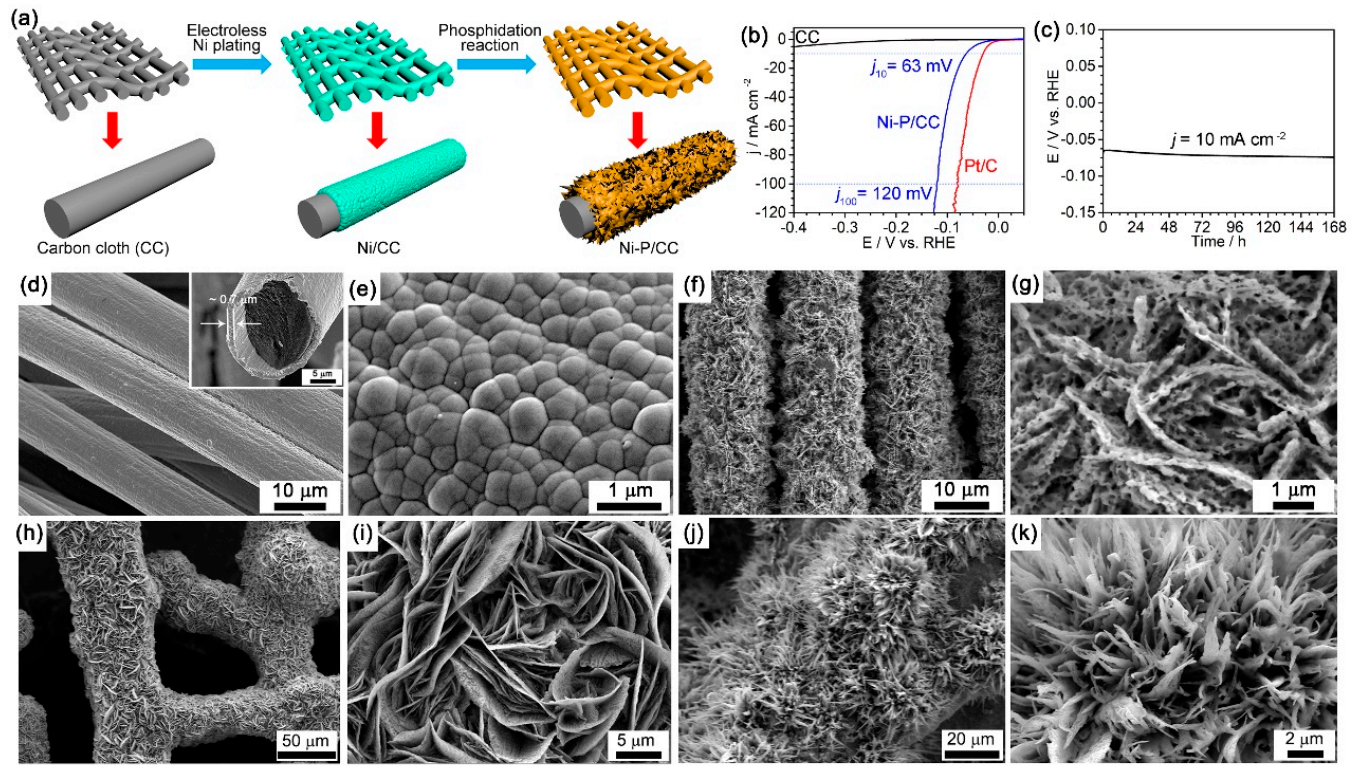

Figure 10. Schematic illustration for preparation of porous nickel phosphide nanosheets on carbon cloth (a), polarization curves for the carbon cloth (CC), $\mathrm{Pt} / \mathrm{CC}$, and $\mathrm{Ni}-\mathrm{P} / \mathrm{CC}$ electrode in $0.5 \mathrm{M} \mathrm{H}_{2} \mathrm{SO}_{4}$ (b), time-dependent potential curve of the Ni-P/CC-60-450 in $0.5 \mathrm{M} \mathrm{H}_{2} \mathrm{SO}_{4}$ electrolyte under a constant current density of $10 \mathrm{~mA} \mathrm{~cm}^{-2}$ for $168 \mathrm{~h}$ (c). Low-(d) and high- (e) magnification SEM images of the $\mathrm{Ni} / \mathrm{CC}-60$. Inset in (d) is a typical cross-sectional SEM image of one fiber in the Ni/CC-60. Low- (f) and high- (g) magnification SEM images of the Ni-P/CC-60-450. SEM images of the Ni-P/LV (h,i) and $\mathrm{Ni}-\mathrm{P} / \mathrm{SC}(\mathbf{j}, \mathbf{k})$. Reproduced with permission from Reference [120], Copyright The American Chemical Society, 2019.

In addition, $\mathrm{Ni}$-containing precursors instead of $\mathrm{Ni}$ forms or $\mathrm{Ni}$ layer plating can be synthesized by the electrospinning process, the hydrothermal method, or a direct annealing growth method. For instance, Kim et al. successfully prepared nickel phosphide embedded in carbon nanofibers (Ni-P/CNFs) through an electrospinning process followed by a simple direct phosphidation method [51]. Figure 11a shows the schematic illustration for the synthesis of the Ni-P/CNFs. The TEM images of the Ni/CNFs in Figure 11b and Ni-P/CNFs in Figure 11c indicate that the nickel nanoparticles and nickel phosphide nanoparticles are embedded in carbon nanofibers, respectively. The Ni-P/CNFs electrode exhibits excellent HER performance in $0.5 \mathrm{M} \mathrm{H}_{2} \mathrm{SO}_{4}$ solution with a low overpotential of $71 \mathrm{mV}$ to achieve a current density of $10 \mathrm{~mA} \mathrm{~cm}^{-2}$ with a small Tafel slope of $74 \mathrm{mV} / \mathrm{dec}$ and excellent catalytic stability over $100 \mathrm{~h}$ (Figure $11 \mathrm{~d}, \mathrm{e})$. Cao et al. successfully synthesized vertically aligned $\mathrm{NiP}_{2}$ nanosheets on $\mathrm{Ti}$ foil via a facile two-step process [49]. As shown in Figure 11f, the precursor of $\mathrm{Ni}(\mathrm{OH})_{2}$ nanosheets was first prepared on Ti foil through a facile hydrothermal method, and then was transformed into $\mathrm{NiP}_{2}$ nanosheets by thermal phosphidation with red phosphorus. The SEM images of $\mathrm{Ni}(\mathrm{OH})_{2}$ nanosheets in Figure $11 \mathrm{~g}$ and $\mathrm{NiP}_{2}$ nanosheets in Figure $11 \mathrm{~h}$ indicate that $\mathrm{Ni}(\mathrm{OH})_{2}$ nanosheets were successfully converted into $\mathrm{NiP}_{2}$ nanosheets with the structures and morphologies maintaining. Yan et al. proposed an effective synthetic method to obtain self-supported, hierarchical, and edge-rich nickel phosphide nanosheet arrays on nickel foam ( $\mathrm{Ni}_{2} \mathrm{P}$ NSs-NF), which were successfully employed as a high-efficiency, 3D binder-free electrode for HER. The Ni-precursor on Ni foam was prepared via a facile direct annealing growth method, and then the Ni-precursor was converted into hierarchical edge-rich $\mathrm{Ni}_{2} \mathrm{P}$ nanosheet arrays via a direct phosphidation reaction at $500^{\circ} \mathrm{C}$ with red phosphorus. The $\mathrm{Ni}_{2} \mathrm{P}$ NSs-NF electrode exhibits superior activity for the HER both in alkaline and acidic conditions. Generally, the direct phosphidation reaction with red phosphorus is carried out at a relatively high temperature of $\sim 500^{\circ} \mathrm{C}$. In order to solve this issue, Wu et al. successfully realized the temperature lowering down to $250{ }^{\circ} \mathrm{C}$ by using $\mathrm{H}_{2}$ plasma-activated red phosphorus, which enables the synthesis of self-supported $\mathrm{Ni}_{2} \mathrm{P}$ nanosheet $\left(\mathrm{Ni}_{2} \mathrm{P} / \mathrm{NF}\right)$ arrays on commercial nickel foam from a $\mathrm{NiO} / \mathrm{NF}$ precursor [121]. The 
obtained electrode exhibits an excellent hydrogen evolution activity in an acidic electrolyte and also good mechanical strength. The morphologies and HER performance in acidic and alkaline electrolytes of the nickel phosphide electrocatalysts prepared by thermal phosphidation with red phosphorus are summarized in Tables 5 and 6, respectively, for comparison. Although the approach of thermal phosphidation with red phosphorus shows relatively high safety compared to that with hypophosphite and potentials in the preparation of nickel phosphide electrocatalysts with high HER performance, the studies using this method are relatively fewer and mainly focus on the Ni metal precursors. Rare works have involved the control on the structures and morphologies. Therefore, studies are still required to exert the full potentials of this method on the production of nickel phosphide electrocatalysts with controllable structures, morphologies, components, crystal phases, and high HER activities.

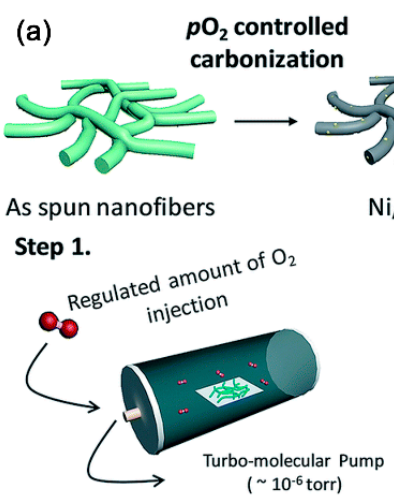

(f)

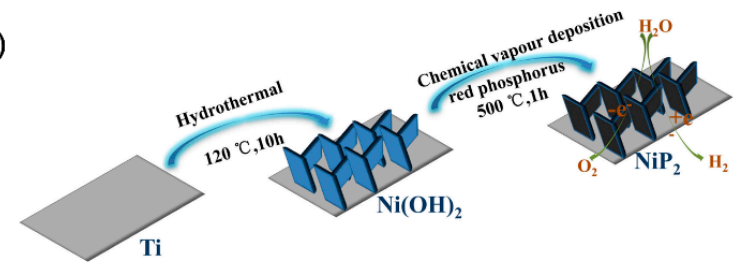

(b)

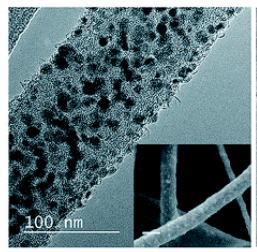

(c)

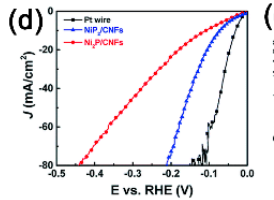

(g)

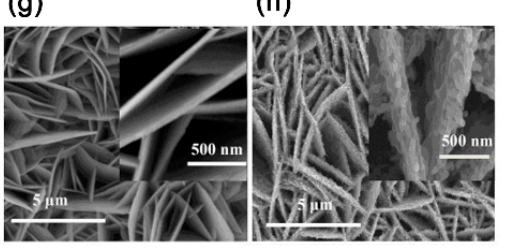

Figure 11. Schematic illustration for the overall synthesis of the Ni phosphide/CNFs (a). TEM (b) and SEM (insets) images of the Ni/CNFs-O $\mathrm{O}_{2} 1.0$ Torr, TEM image of the Ni phosphide/CNFs- $\mathrm{O}_{2} 1.0$ Torr (c), Polarization curves (d), and Tafel plots (e) of the $\mathrm{Ni}_{2} \mathrm{P} / \mathrm{CNFs}, \mathrm{NiP}_{2} / \mathrm{CNF}$, and Pt wire. Reproduced with permission from Reference [51], Copyright the Royal Society of Chemistry, 2019. Schematic illustration of the experimental procedure used for $\mathrm{NiP}_{2}$ synthesis (f), $\mathrm{SEM}$ images of $\mathrm{Ni}(\mathrm{OH})_{2}(\mathbf{g})$, and $\mathrm{NiP}_{2}(\mathbf{h})$ nanosheets on Ti foil. Reproduced with permission from Reference [49] Copyright Elsevier B.V., 2019.

Table 5. Summary of the nickel phosphide electrocatalysts prepared through thermal phosphidation with red phosphorus for HER in an acidic electrolyte.

\begin{tabular}{|c|c|c|c|c|c|c|c|}
\hline Material and Morphology & Precursors ${ }^{1}$ & Supports $^{2}$ & $\begin{array}{l}\text { Loading } \\
\mathrm{mg} / \mathrm{cm}^{2}\end{array}$ & $\begin{array}{c}\text { Tafel Slope } \\
\text { mV/dec }\end{array}$ & $\underset{\mathrm{mA} / \mathrm{cm}^{2}}{\mathrm{~J}}$ & $\eta \mathbf{m V}$ & Reference \\
\hline $\mathrm{Ni}_{3} \mathrm{P}$ microparticles & Ni powder & Ti plate & - & $41 \pm 2$ & 10 & 66 & [48] \\
\hline $\mathrm{Ni}_{2} \mathrm{P}$ nanosheet & $\mathrm{NiSO}_{4}$ & Ni foam & 2 & 57 & 10 & 67 & [122] \\
\hline $\mathrm{Ni}_{5} \mathrm{P}_{4} / \mathrm{Ni}_{2} \mathrm{P} / \mathrm{NiP}_{2}$ Nano-catalysts & $\mathrm{NiSO}_{4}$ and $\mathrm{NiCl}_{2}$ & carbon fiber & 25.8 & 58.8 & 10 & 98 & [119] \\
\hline $\mathrm{Ni}_{5} \mathrm{P}_{4}$ films & $\mathrm{Ni}$ foil & Ni foil & 3.475 & 40 & 10 & 140 & [113] \\
\hline $\mathrm{Ni}_{5} \mathrm{P}_{4} / \mathrm{Ni}_{2} \mathrm{P}$ nanosheet & Ni foam & Ni foam & 68.2 & 79.1 & 10 & 120 & [114] \\
\hline $\mathrm{Ni}_{5} \mathrm{P}_{4} / \mathrm{NiP}_{2}$ nanoparticles & $\begin{array}{l}\mathrm{Ni} \text { foam and } \\
\mathrm{Ni}\left(\mathrm{NO}_{3}\right)_{2}\end{array}$ & Ni foam & - & 44 & 10 & 35 & [118] \\
\hline $\mathrm{NiP}_{2}$ nanosheets & $\mathrm{Ni}\left(\mathrm{NO}_{3}\right)_{2}$ & Ti foil & - & 49.5 & 10 & 140 & [49] \\
\hline $\mathrm{Ni}_{5} \mathrm{P}_{4} / \mathrm{NiP}_{2}$ nanosheets & Ni foam & Ni foam & 39.3 & 52.8 & 10 & 92 & [117] \\
\hline $\mathrm{Ni}_{2} \mathrm{P}$ nanoparticle & $\mathrm{NiSO}_{4}$ & Ti foils & - & 84 & 100 & 163 & [96] \\
\hline $\mathrm{Ni}_{2} \mathrm{P}$ nanoflakes & Ni foam & Ni foam & - & 30 & 10 & 55 & [123] \\
\hline
\end{tabular}

${ }^{1} \mathrm{Ni}(\mathrm{ac})_{2}$ : nickel acetate. ${ }^{2} \mathrm{GC}$ : glassy carbon. 
Table 6. Summary of the nickel phosphide electrocatalysts prepared through thermal phosphidation with red phosphorus for HER in an alkaline electrolyte.

\begin{tabular}{|c|c|c|c|c|c|c|c|}
\hline Material and Morphology & Precursors & Supports & $\begin{array}{l}\text { Loading } \\
\mathrm{mg} / \mathrm{cm}^{2}\end{array}$ & $\begin{array}{c}\text { Tafel Slope } \\
\text { mV/dec }\end{array}$ & $\underset{\mathrm{mA} / \mathrm{cm}^{2}}{\mathrm{~J}}$ & $\eta \mathrm{mV}$ & Reference \\
\hline $\mathrm{Ni}_{3} \mathrm{P}$ nanosheet & Ni powder & Ti plate & - & $119 \pm 2$ & 10 & 291 & [48] \\
\hline $\mathrm{Ni}_{2} \mathrm{P}$ nanosheet & $\mathrm{NiSO}_{4}$ & Ni foam & 2 & 82 & 10 & 89 & [122] \\
\hline $\mathrm{Ni}_{5} \mathrm{P}_{4}$ films & Ni foil & Ni foil & 3.475 & 53 & 10 & 150 & [113] \\
\hline $\mathrm{Ni}_{2} \mathrm{P}$ nanowires & $\mathrm{Ni}$ foam & $\mathrm{Ni}$ foam & - & - & 100 & 224 & {$[124]$} \\
\hline $\mathrm{NiP}_{2}$ nanosheets & $\mathrm{Ni}\left(\mathrm{NO}_{3}\right)_{2}$ & Ti foil & - & 60.5 & 10 & 134 & [49] \\
\hline
\end{tabular}

\subsection{Hydrogen Reduction of Phosphates}

Although highly crystallized nickel phosphide electrocatalysts with high HER performance can be prepared by thermal phosphidation with hypophosphite or red phosphorus, the $\mathrm{PH}_{3}$ gas and $\mathrm{P}$ vapor generated during the process are relatively dangerous. Therefore, a safer and facile protocol that can produce highly crystallized nickel phosphide structures with high HER activity is still required. It is well known that hydrogen shows high reducibility under certain conditions. Thus, some researchers have employed hydrogen to reduce phosphates at a higher temperature to produce nickel phosphide structures. For example, Bai et al. demonstrated the preparation of novel peapod-like $\mathrm{Ni}_{2} \mathrm{P} / \mathrm{C}$ nanocomposites via a two-step process, which is schematically shown in Figure 12a [125]. They first prepared $\mathrm{NiNH}_{4} \mathrm{PO}_{4} \cdot \mathrm{H}_{2} \mathrm{O}$ nanorods via a facile hydrothermal method at $170{ }^{\circ} \mathrm{C}$ for $24 \mathrm{~h}$. The morphology and crystal phase of the $\mathrm{NiNH}_{4} \mathrm{PO}_{4} \cdot \mathrm{H}_{2} \mathrm{O}$ nanorods can be clearly known through a SEM image (Figure 12b), XRD pattern (Figure 12c), and TEM image (Figure 12d,e). Subsequently, the crystalline $\mathrm{NiNH}_{4} \mathrm{PO}_{4} \cdot \mathrm{H}_{2} \mathrm{O}$ nanorods were converted to peapod-like $\mathrm{Ni}_{2} \mathrm{P} / \mathrm{C}$ nanocomposites by calcination under hydrogen at $70{ }^{\circ} \mathrm{C}$ for $200 \mathrm{~min}$. Through the SEM image (Figure 12f), the XRD pattern (Figure 12g), and TEM image (Figure 12h,i), it can be clearly seen that the $\mathrm{NiNH}_{4} \mathrm{PO}_{4} \cdot \mathrm{H}_{2} \mathrm{O}$ nanorods have been successfully transformed into peapod-like $\mathrm{Ni}_{2} \mathrm{P} / \mathrm{C}$ nanocomposites after calcination. The $\mathrm{Ni}_{2} \mathrm{P} / \mathrm{C}$ nanocomposites showed excellent electrocatalytic HER activities in $0.5 \mathrm{M} \mathrm{H}_{2} \mathrm{SO}_{4}$ with a small overpotential of $87 \mathrm{mV}$ to attain the current density of $10 \mathrm{~mA} / \mathrm{cm}^{2}$ and a notably low Tafel slope of $54 \mathrm{mV} / \mathrm{dec}$ (Figure 12j,k). The peapod-like $\mathrm{Ni}_{2} \mathrm{P} / \mathrm{C}$ nanocomposites can be used not only as an electrocatalytic hydrogen evolution reaction material, but also as an anode material for lithium-ion batteries. Then, by utilizing the similar approach, they successfully fabricated a novel 1-D peapod array of $\mathrm{Ni}_{2} \mathrm{P} @$ graphitized carbon fiber composites on Ti foil substrate by hydrothermal growth and polymerization, which is followed by annealing in an $\mathrm{H}_{2}$ atmosphere [126]. Miao et al. synthesized a core/shell structured chainmail catalyst of ultrathin P-doped carbon shell-encapsulated nickel phosphides on graphene through a facile solvothermal method following by an annealing treatment in hydrogen atmosphere, which exhibits remarkable electrocatalytic HER activities [127]. 

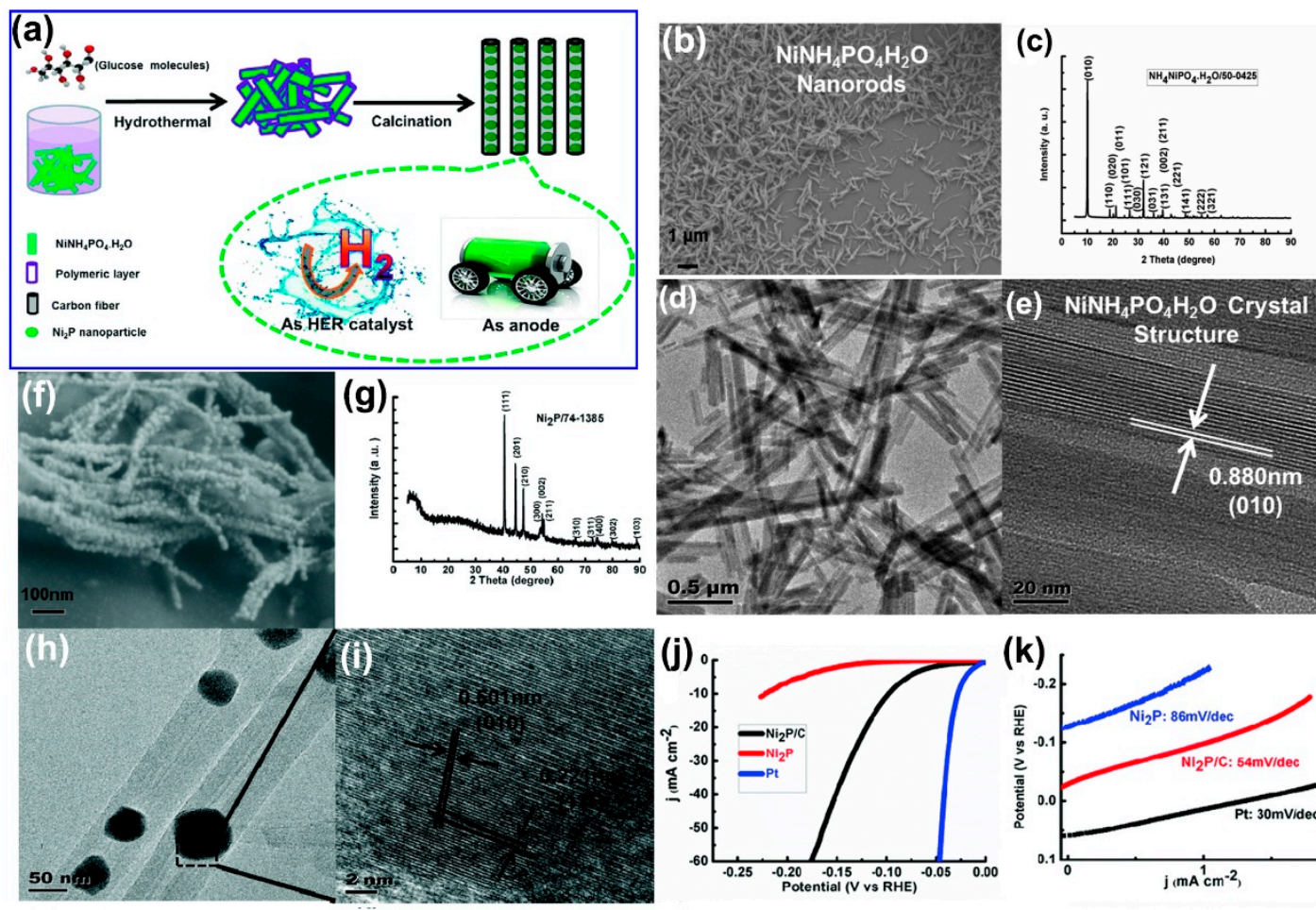

(e) $\mathrm{NiNH}_{4} \mathrm{PO}_{4} \mathrm{H}_{2} \mathrm{O}$ Crystal

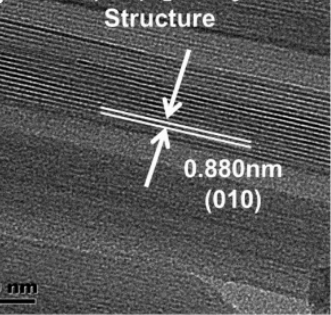

Figure 12. Schematic illustration of the synthetic procedure for the peapod-like $\mathrm{Ni}_{2} \mathrm{P} / \mathrm{C}$ nanocomposites (a), SEM image (b), XRD pattern (c), TEM (d), and HRTEM (e) images of $\mathrm{NiNH}_{4} \mathrm{PO}_{4} \cdot \mathrm{H}_{2} \mathrm{O}$ nanorods. SEM image (f), XRD pattern (g), TEM (h), and HRTEM (i) images of $\mathrm{Ni}_{2} \mathrm{P} / \mathrm{C}$ composites. Polarization curves $(\mathbf{j})$ and corresponding Tafel plots $(\mathbf{k})$ for $\mathrm{Ni}_{2} \mathrm{P}$ and $\mathrm{Ni}_{2} \mathrm{P} / \mathrm{C}$ electrodes in $0.5 \mathrm{M} \mathrm{H}_{2} \mathrm{SO}_{4}$. Reproduced with permission from Reference [127], Copyright The Royal Society of Chemistry, 2015.

The tunable compositions and hetero atom-enriched characteristics of inorganic-organic metal phosphonate hybrids make them promising templates and precursors to create high-performance nanomaterials as electrocatalysts for HER by high-temperature reduction. Lv et al. demonstrated the preparation of nitrogen-doped carbon-coated nickel phosphide nanoparticles on Ni foam by hydrogen reduction of the precursors of nickel phosphonates loaded on Ni foam [128]. Wang et al. reported the in-situ preparation of embedded ultrafine nickel phosphides in $\mathrm{N}$-doped porous carbon nanofibers $\left(\mathrm{Ni}_{2} \mathrm{P} @ \mathrm{NPCNFs}\right)$ by electrospinning the precursors, which is followed by a controllable pyrolyzed reduction in an $\mathrm{H}_{2}$ atmosphere. The $\mathrm{Ni}_{2} \mathrm{P} @ \mathrm{NPCNF}$ show excellent catalytic performance as an HER catalyst in acidic media, and good durability in neutral and basic media. This method was also demonstrated to prepare $\mathrm{Fe}_{2} \mathrm{P} @ \mathrm{NPCNF}, \mathrm{Co}_{2} \mathrm{P} @ \mathrm{NPCNF}$, and $\mathrm{Cu}_{3} \mathrm{P} @ \mathrm{NPCNF}$ with the same nanostructure as $\mathrm{Ni}_{2} \mathrm{P} @ \mathrm{NPCNF}$. This work provides a general approach for fabrication of transition metal phosphide structures with enhanced conductivity and catalytic activity. Table 7 summarizes the morphologies, mass loadings, and corresponding electrocatalytic HER performance in an acidic electrolyte of nickel phosphide electrocatalysts prepared through hydrogen reduction of phosphate precursors. As stated above, this hydrogen reduction of the phosphates method does not produce toxic or dangerous $\mathrm{PH}_{3}$ gas or $\mathrm{P}$ vapor during the phosphidation process, and is very suitable for preparation of nickel phosphide electrocatalysts together with conductive supports (e.g., carbon). This is beneficial for the dispersion of the catalysts for high HER activities. However, it should also be noted that it is rather difficult to design or control the morphologies of the final nickel phosphides, and the process requires a relatively high temperature and involves explosive hydrogen gas. 
Table 7. Summary of the nickel phosphide electrocatalysts prepared through hydrogen reduction of phosphates for HER in acidic electrolyte.

\begin{tabular}{ccccccccc}
\hline $\begin{array}{c}\text { Material and } \\
\text { Morphology }\end{array}$ & Precursors ${ }^{1}$ & Middle Product & Supports ${ }^{2}$ & $\begin{array}{c}\text { Loading } \\
\mathbf{m g} / \mathbf{c m}^{2}\end{array}$ & $\begin{array}{c}\text { Tafel Slope } \\
\mathbf{m V} / \mathbf{d e c}\end{array}$ & $\begin{array}{c}\mathbf{J} \\
\mathbf{m A} / \mathbf{c m}^{2}\end{array}$ & $\eta \mathbf{m V}$ & Reference \\
\hline $\mathrm{Ni}_{2} \mathrm{P}$ nanoparticles & $\mathrm{Ni}\left(\mathrm{NO}_{3}\right)_{2}$ & $\mathrm{NiNH}_{4} \mathrm{PO}_{4}$ & $\mathrm{GC}$ & 0.36 & 54 & 10 & 87 & {$[125]$} \\
$\mathrm{Ni}_{2} \mathrm{P}$ nanoparticles & $\mathrm{Ni}\left(\mathrm{NO}_{3}\right)_{2}$ & - & $\mathrm{GC}$ & 0.51 & 58.6 & 10 & 110 & {$[127]$} \\
$\mathrm{Ni}_{2} \mathrm{P}$ peapods & $\mathrm{Ni}\left(\mathrm{NO}_{3}\right)_{2}$ & $\mathrm{NH}_{4} \mathrm{NiPO}_{4}$ & $\mathrm{Ti}$ foil & 0.38 & 46 & 10 & 45 & {$[126]$} \\
$\mathrm{Ni}_{2} \mathrm{P}$ Nanoparticles & $\mathrm{Ni}(\mathrm{ac})_{2}$ & $\begin{array}{c}\text { Nickel phosphonate } \\
\text { powder }\end{array}$ & $\mathrm{Ni}$ foam & - & 64 & 10 & 68 & {$[128]$} \\
$\mathrm{Ni}_{2} \mathrm{P}$ nanoparticles & $\mathrm{NiSO}_{4}$ & - & $\begin{array}{c}\text { carbon } \\
\text { cloth }\end{array}$ & 0.337 & 56.7 & 10 & 63.2 & {$[129]$} \\
$\mathrm{Ni}_{-} \mathrm{Ni}_{3} \mathrm{P}$ nanoparticles & $\mathrm{Ni}(\mathrm{ac})_{2}$ & - & $\mathrm{NPC} / \mathrm{rGO}$ & - & 57.93 & 10 & 73 & {$[130]$} \\
\hline 1
\end{tabular}

${ }^{1} \mathrm{Ni}(\mathrm{ac})_{2}$ : nickel acetate. ${ }^{2} \mathrm{GC}$ : glassy carbon. NPC/rGO: N, P-doped carbon on 3D graphene frameworks.

\subsection{Electrochemical Deposition}

Electrochemical deposition, which involves the migration of the anions and cations in the electrolyte solution under an external electric field and the redox reactions on the electrode surfaces to deposit production layers, is recognized as a facile and mild preparation method due to the conditions generally at room temperature. Generally, it is difficult to obtain highly crystallized products and to control the morphologies through electrochemical deposition. For preparation of nickel phosphides, nickel and phosphorus alloys are generally produced by electrochemical deposition. In the preparation process, nickel-containing salts and phosphorus-containing salts are usually employed as precursors, and a conductive substrate is necessary to act as the electrode to support the depositions. So far, some interesting nickel phosphide structures have been successfully prepared by electrochemical deposition. Cao et al. demonstrated the preparation of hierarchical radial amorphous nickel phosphide $\left(\mathrm{Ni}_{x} \mathrm{P}\right)$ nanospheres on $\mathrm{Ni}$ foam $\left(\mathrm{Ni}_{\mathrm{x}} \mathrm{P} / \mathrm{NF}\right)$ at a constant potential of $-0.8 \mathrm{~V}$ (vs. $\mathrm{Ag} / \mathrm{AgCl}$ ) under a nitrogen atmosphere by using a nickel chloride and sodium hypophosphite electrolyte [131]. Figure 13a shows a schematic image of the electrodeposition preparation of the hierarchical radial $\mathrm{Ni}_{\mathrm{x}} \mathrm{P}$ nanospheres on $\mathrm{Ni}$ foam at different times. The SEM images in Figure 13b, d together with the TEM images in Figure 13e,f,g clearly show the radial microstructure and morphology of the as-prepared $\mathrm{Ni}_{\mathrm{x}} \mathrm{P}$ nanospheres. The $\mathrm{Ni}_{x} \mathrm{P}$ nanosphere has an amorphous phase and is composed of ultrathin nanosheets with a thickness of $8 \mathrm{~nm}$ near to the surface. The elemental mapping images in Figure $13 \mathrm{~h}$ further verify the homogeneous distribution of $\mathrm{Ni}$ and $\mathrm{P}$ elements in $\mathrm{Ni}_{\mathrm{x}} \mathrm{P}$ nanospheres. The polarization curves in Figure $13 \mathrm{i}$ and Tafel plots in Figure 13j exhibit the electrocatalytic HER performance of the NixP nanospheres. Among them, the $\mathrm{Ni}_{\mathrm{x}} \mathrm{P} / \mathrm{NF}-20$ electrode exhibits the best HER performance in $1 \mathrm{M} \mathrm{KOH}$ solution with very low overpotential of $63 \mathrm{mV}$ to achieve a current density of $10 \mathrm{~mA} / \mathrm{cm}^{2}$, and a Tafel slope as low as $55 \mathrm{mV} / \mathrm{dec}$, which can be attributed to the 3D open-pore Ni foam structures with a high specific surface area and the high conductivity contributed by the in-situ deposition of highly ordered $\mathrm{Ni}_{\mathrm{x}} \mathrm{P}$ nanospheres on conductive $\mathrm{Ni}$ foam. Figure $13 \mathrm{k}$ illustrates the advantages of $\mathrm{Ni}_{x} \mathrm{P} / \mathrm{NF}-20$ electrode during hydrogen evolution process in $1 \mathrm{M} \mathrm{KOH}$, which follows the equation: $4 \mathrm{e}^{-}+4 \mathrm{H}_{2} \mathrm{O} \rightarrow 4 \mathrm{OH}^{-}+2 \mathrm{H}_{2}$ [132]. Chen et al. reported the preparation of $\mathrm{NiP}_{\mathrm{x}}$ nanospheres on carbon cloth by cyclic voltammetry $(\mathrm{CV})$ scanning between $0.2 \mathrm{~V}$ and $-0.7 \mathrm{~V}$ (vs. NHE) at a scan rate of $50 \mathrm{mV} / \mathrm{s}$ by using nickel acetate $\left(\mathrm{Ni}(\mathrm{ac})_{2}\right)$ and sodium hypophosphite as precursors in acetate buffer solution $(\mathrm{pH}=7)$ [133]. The $\mathrm{NiP}_{\mathrm{x}}$-coated carbon cloth electrode exhibits good HER performance in phosphate buffer saline (PBS) $(\mathrm{pH}=7)$ solution. Similarly, Liu et al. deposited nickel-phosphorus nanoparticle films on $\mathrm{Cu}$ foam (Ni-P/CF) by CV scanning for 15 cycles between -1.0 and $-0.3 \mathrm{~V}$ at a scan rate of $10 \mathrm{mV} / \mathrm{s}$ in electrolyte containing $\mathrm{NiSO}_{4}$, $\mathrm{KOH}$, and NaOAc [134]. The Ni-P/CF can deliver a current density of $10 \mathrm{~mA} / \mathrm{cm}^{2}$ at an overpotential of $98 \mathrm{mV}$ for hydrogen production and $325 \mathrm{mV}$ for oxygen generating in $1 \mathrm{M} \mathrm{KOH}$ solution. A two-electrode water electrolyzer using Ni-P/CF as cathode and anode produces $10 \mathrm{~mA} / \mathrm{cm}^{2}$ at a cell voltage of $1.68 \mathrm{~V}$ with high stability. Sun et al. prepared P-doped nickel $\left(\mathrm{NiP}_{\mathrm{x}}\right)$ superstructure films on $\mathrm{Cu}$ foil by potentio-static deposition (PSD) and potentio-dynamic (PDD) approach, respectively [135]. By comparing the two deposition methods, it is found that the latter model with a potentio-dynamic 
control is a valid electrochemical protocol to create crack-free $\mathrm{NiP}_{\mathrm{x}}$ films. The PDD-NiP film shows a high HER activity under alkaline conditions. The PDD-Ni-10P achieved a low overpotential of 105 $\mathrm{mV}$ to deliver a current density of $10 \mathrm{~mA} / \mathrm{cm}^{2}$ with a small Tafel slope of $44.7 \mathrm{mV} / \mathrm{dec}$ and excellent catalytic stability for at least $60 \mathrm{~h}$. Tang et al. reported the preparation of Ni-P alloy nanoparticle films on $\mathrm{Ni}$ foam by a linear voltammetry scan in the range of 1.2 to $0.2 \mathrm{~V}$ (vs. SCE) in the electrolyte solution of nickel sulfate, sodium hypophosphite, and sodium acetate [136]. The as-prepared Ni-P alloy nanoparticle film electrode can act as an efficient bifunctional water-splitting catalyst in strongly alkaline media, which drives $10 \mathrm{~mA} / \mathrm{cm}^{2}$ at overpotentials of 80 and $309 \mathrm{mV}$ for HER and OER, respectively, and its two-electrode water electrolyzer needs a cell voltage of $1.67 \mathrm{~V}$ to achieve 10 $\mathrm{mA} / \mathrm{cm}^{2}$. Cheng et al. fabricated an Ni-P alloy on the plate via pulsed electrodeposition, and the $\mathrm{Ni}-\mathrm{P}$ alloy with high capacitance performs the best HER catalytic activity [137]. In addition, Wu et al. fabricated self-supported Ni-P cathode by linear voltammetry scan from -0.3 to $-0.9 \mathrm{~V}$ (vs $\mathrm{Ag} / \mathrm{AgCl})$ at a scan rate of $10 \mathrm{mV} \mathrm{s}^{-1}$ [138]. The Ni-P cathode performed a low onset over-potential, good catalytic activity, and long-term stability under neutral and alkaline conditions. The structural information, mass loading, and electrochemical HER performance in the alkaline electrolyte are summarized in Table 8 for comparison.
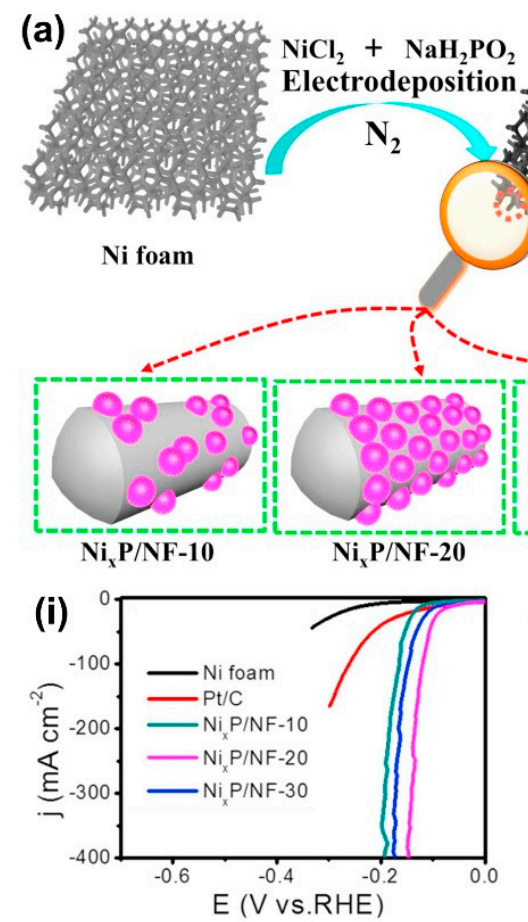

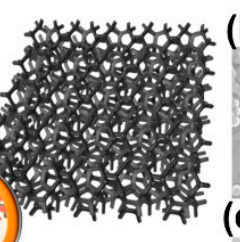

$\mathrm{Ni}_{\mathbf{x}} \mathrm{P}$ grown on Ni foam
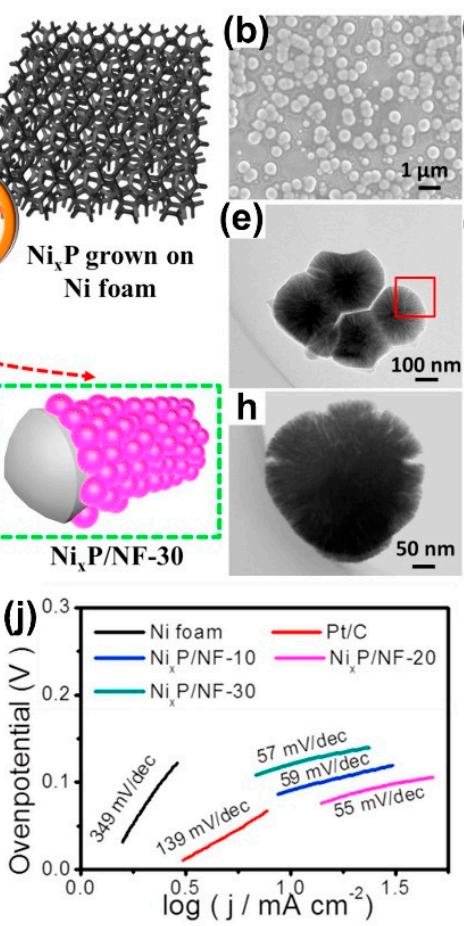

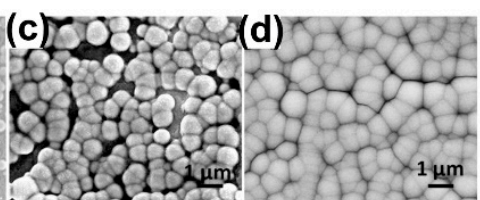

(f)

(g)

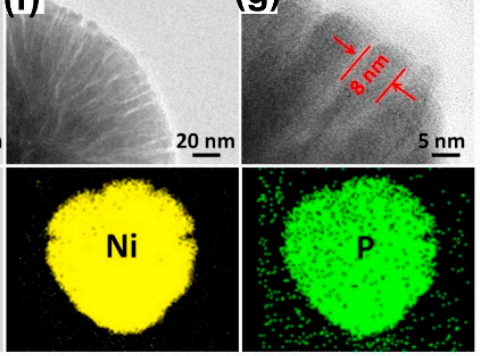

(k)

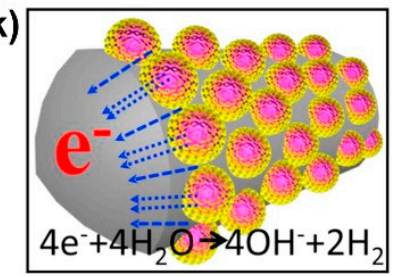

Figure 13. Schematic illustration for the electrochemical deposition of hierarchical radial $\mathrm{Ni}_{\mathrm{x}} \mathrm{P}$ nanospheres on $\mathrm{Ni}$ foam (a), SEM images of $\mathrm{Ni}_{\mathrm{x}} \mathrm{P} / \mathrm{NF}-10(\mathbf{b}), \mathrm{Ni} \mathrm{i}_{\mathrm{x}} \mathrm{P} / \mathrm{NF}-20$ (c), and $\mathrm{Ni}_{\mathrm{x}} \mathrm{P} / \mathrm{NF}-30$ (d), TEM image of radial $\mathrm{Ni}_{\mathrm{x}} \mathrm{P}-10$ nanospheres $(\mathbf{e})$, the magnified TEM image of a red squared indicated area $(\mathbf{f})$, $\operatorname{HRTEM}(\mathbf{g})$, and elemental mapping images of the radial Ni $\mathrm{i}_{\mathrm{x}} \mathrm{P}-10$ nanospheres $(\mathbf{h})$. iR-corrected LSV curves for $\mathrm{Ni}_{\mathrm{x}} \mathrm{P} / \mathrm{Ni}$ foam, pristine $\mathrm{Ni}$ foam, and $\mathrm{Pt} / \mathrm{C}$ electrodes for HER (i) and corresponding Tafel plots $(\mathbf{j})$, and schematic illustration of the advantages of the brushy surface of $\mathrm{Ni}_{\times} \mathrm{P} / \mathrm{NF}-20$ for HER $(\mathbf{k})$. Reproduced with permission from Reference [131], Copyright Elsevier B.V., 2018. 
Table 8. Summary of the nickel phosphide electrocatalysts prepared through electrochemical deposition for HER.

\begin{tabular}{|c|c|c|c|c|c|c|c|c|}
\hline $\begin{array}{l}\text { Material and } \\
\text { Morphology }\end{array}$ & Precursors $^{1}$ & Supports ${ }^{2}$ & Electrolytes ${ }^{3}$ & $\begin{array}{l}\text { Loading } \\
\mathrm{mg} / \mathrm{cm}^{2}\end{array}$ & $\begin{array}{l}\text { Tafel Slope } \\
\text { mV/dec }\end{array}$ & $\underset{\mathrm{mA} / \mathrm{cm}^{2}}{\mathrm{~J}}$ & $\eta \mathrm{mV}$ & Reference \\
\hline $\mathrm{NiP}_{x}$ films & $\mathrm{NiCl}_{2}$ & $\mathrm{Cu}$ foil & $1 \mathrm{M} \mathrm{KOH}$ & 0.55 & 47.7 & 10 & 105 & [135] \\
\hline $\mathrm{Ni}_{\mathrm{x}} \mathrm{P}$ nanospheres & $\mathrm{NiCl}_{2}$ & $\mathrm{Ni}$ foam & $1 \mathrm{M} \mathrm{KOH}$ & 4.4 & 55 & 10 & 63 & [131] \\
\hline Ni-P nanoparticles film & $\mathrm{NiSO}_{4}$ & $\mathrm{Cu}$ foam & $1 \mathrm{M} \mathrm{KOH}$ & $\sim 5$ & 55 & 10 & 98 & [134] \\
\hline $\mathrm{Ni}-\mathrm{P}$ alloy & $\mathrm{NiSO}_{4}$ & Ni plate & $1 \mathrm{M} \mathrm{NaOH}$ & 3.85 & 59.7 & 10 & 134 & [137] \\
\hline $\mathrm{Ni}-\mathrm{Ni}_{\mathrm{X}} \mathrm{P}$ nanospheres & $\mathrm{NiSO}_{4}$ & carbon cloth & $0.5 \mathrm{M} \mathrm{H}_{2} \mathrm{SO}_{4}$ & - & 76 & 10 & 164 & [139] \\
\hline Single-phase $\mathrm{Ni}_{5} \mathrm{P}_{4}$ & $\mathrm{NiCl}_{2}$ & $\mathrm{Cu}$ foam & $0.5 \mathrm{M} \mathrm{H}_{2} \mathrm{SO}_{4}$ & - & 49 & 10 & 90 & [142] \\
\hline $\mathrm{Ni}_{x} \mathrm{P} / \mathrm{CNT}$ hybrid & $\mathrm{NiSO}_{4}$ & $\mathrm{CNT}$ & $0.5 \mathrm{M} \mathrm{H}_{2} \mathrm{SO}_{4}$ & - & 61.8 & 10 & 150 & [143] \\
\hline $\mathrm{NiP}_{\mathrm{x}}$ nanospheres & $\mathrm{Ni}(\mathrm{ac})_{2}$ & carbon cloth & $\begin{array}{c}0.1 \mathrm{M} \text { PBS } \\
(\mathrm{pH}=7)\end{array}$ & 0.235 & 101 & 10 & 230 & [133] \\
\hline
\end{tabular}

Nickel phosphides prepared by the electrochemical deposition method also show remarkable HER activities in acidic solution. For instance, Ren et al. prepared nickel/nickel phosphide nanospheres electrode via in-situ reduction of $\mathrm{NiSO}_{4}$ and $\mathrm{NaH}_{2} \mathrm{PO}_{2}$ on carbon cloth substrates using square-wave and CV methods, respectively [139]. It is found that nickel/nickel phosphide nanospheres prepared with the pulse deposition procedure exhibits higher HER performance than those prepared through the $\mathrm{CV}$ approach. As-prepared nickel/nickel phosphide/carbon cloth electrodes exhibit a cathodic current of $10 \mathrm{~mA} / \mathrm{cm}^{2}$ at the overpotential of $164 \mathrm{mV}$ in a $0.5 \mathrm{M} \mathrm{H}_{2} \mathrm{SO}_{4}$ solution and a Tafel slope of $76 \mathrm{mV} / \mathrm{dec}$. Wasalathanthri et al. prepared amorphous nickel phosphide thin films on $\mathrm{Cu}$ foil by electrodeposition at a constant current density of $10 \mathrm{~mA} / \mathrm{cm}^{2}$ for $10 \mathrm{~min}$, which exhibits a good activity and long-term stability in acidic medium, with a potential of $-222 \mathrm{mV}$ to achieve $10 \mathrm{~mA} / \mathrm{cm}^{2}$ [140]. Wang et al. reported the preparation of amorphous sponge-like nickel phosphide-carbon nanotube $\left(\mathrm{Ni}_{x} \mathrm{P} / \mathrm{CNT}\right)$ hybrid electrodes through $\mathrm{CV}$ deposition [143]. These $\mathrm{Ni}_{\mathrm{x}} \mathrm{P} / \mathrm{CNTs}$ exhibit superior catalytic activity for sustained hydrogen evolution in acidic, neutral, and basic media, which is attributed to the 3D porous nanoarchitecture consisting of a highly conductive 3D porous CNT backbone and a well-deposited $\mathrm{Ni}_{x} \mathrm{P}$ nanoparticle catalyst. Apart from this, Kim et al. reported that pulse electrodeposition can be used to prepare an amorphous Ni-P catalyst with a high portion of $\mathrm{P}$, which confers acid-resistant properties to the catalyst [141]. Most of the nickel phosphide catalysts prepared by electrodeposition are amorphous, but Das et al. fabricated copper foam @ single-phase $\mathrm{Ni}_{5} \mathrm{P}_{4}$ superhydrophilic and aerophobic core-shell nanostructures through a two-step process [142]. They first prepared a copper foam electrode by implementing a constant current density of $1 \mathrm{~A} / \mathrm{cm}^{2}$. Then, electrodeposition of $\mathrm{Ni}_{5} \mathrm{P}_{4}$ on copper foam was conducted by implementing a constant potential of $-0.8 \mathrm{~V}$. Figure 14a clearly shows the schematic image of the electrochemical synthesis of the copper foam @ $\mathrm{Ni}_{5} \mathrm{P}_{4}$ structures. The SEM images in Figure 14b,c indicate the microstructures and morphologies of the as-prepared $\mathrm{Cu} @ \mathrm{Ni}_{5} \mathrm{P}_{4}$. As shown in Figure $14 \mathrm{~d}, \mathrm{e}, \mathrm{f}, \mathrm{g}$, the density functional theory (DFT) model, $\mathrm{Ni}_{5} \mathrm{P}_{4}(0001)$ and $\mathrm{Ni}_{5} \mathrm{P}_{4}(0001) / \mathrm{Cu}(111)$ surface with $\mathrm{H}^{*}$ adsorbed over the three-fold Ni site (site I) exhibited a negative value of $\mathrm{DGH}^{*}$, which favors HER activity. DFT calculations elucidated the origin of a very high negative $\mathrm{DGH}^{*}$ in $\mathrm{Ni}_{5} \mathrm{P}_{4}(0001) / \mathrm{Cu}(111)$ upon hydrogen adsorption. This arises due to a localized charge density distribution around the three-fold Ni site of the adsorbate, which is favorable for the HER activity of the catalyst. The super-hydrophilic and aero-phobic nanostructured surface also contributes to the HER performance by reducing the contact resistance and the fast release of air bubbles during the catalysis process. In order to evaluate the HER performance of the materials prepared by electrochemical deposition in an acidic solution, the structural information, mass loading, and electrochemical HER performance in an acidic electrolyte are also summarized in Table 8. It can be easily found that the electrochemical deposition method for preparation of nickel phosphides shows some apparent advantages such as mild preparation with no need of high temperature, low cost, and high safety with no toxic chemicals. However, there are still some weakness of this method. For 
instance, it is difficult to control the morphologies and the products are generally amorphous, which may limit the intrinsic activities. Therefore, efforts are still required to address the above issues to obtain stable and highly crystallized nickel phosphide electrocatalysts with high HER activities.
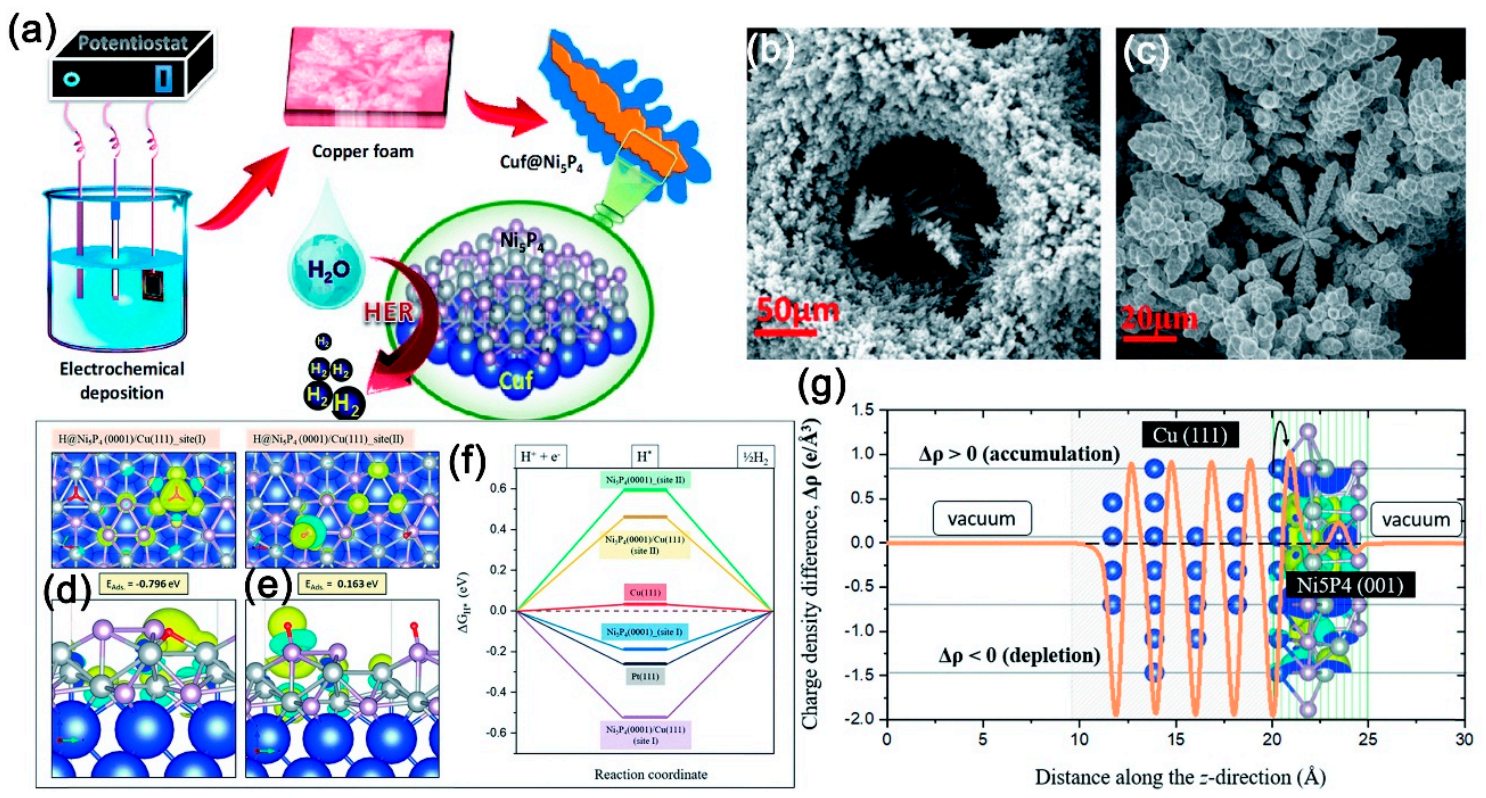

Figure 14. Schematic illustration of the electrochemical synthesis of nickel phosphides on $\mathrm{Cu}$ foam (a), SEM images of the $\mathrm{Ni}_{5} \mathrm{P}_{4}$ on $\mathrm{Cu}$ foam $(\mathbf{b}, \mathbf{c})$, top and side view of $\mathrm{H}^{*}$ adsorption over the three-fold $\mathrm{Ni}$ site of the $\mathrm{Ni}_{5} \mathrm{P}_{4}(0001) / \mathrm{Cu}(111)$ (site I) (d), and $\mathrm{H}^{*}$ over the on-top P site of the $\mathrm{Ni}_{5} \mathrm{P}_{4}(0001) / \mathrm{Cu}$ (111) surface (site II) (e). The differential ground state charge density distribution around the adsorbate $\left(\mathrm{H}^{*}\right)$ is at an iso-level of $0.59 \times 10^{-2} \mathrm{e}^{-3}$. The $\Delta \mathrm{G}_{\mathrm{H}^{*}}$ of the reaction intermediate $\left(\mathrm{H}^{*}\right)$ on different metal-catalyst surfaces (f) and charge density difference and charge transfer at the interface between $\mathrm{Cu}$ (111) and $\mathrm{Ni}_{5} \mathrm{P}_{4}$ (001) surface (g). Reproduced with permission from Reference [142], Copyright The Royal Society of Chemistry, 2019.

\section{Conclusions and Perspectives}

In this review, we have comprehensively summarized the progresses of nickel phosphide electrocatalysts for a hydrogen evolution reaction based on the preparation approaches. There are five main protocols, i.e., solution-phase synthesis, thermal phosphidation with hypophosphite, thermal phosphidation with red phosphorus, hydrogen reduction of phosphates, and electrochemical deposition method, to fabricate nickel phosphide structures in which the advantages and weakness are discussed in the article and also summarized in Table 9. The morphologies and HER performances of nickel phosphide electrocatalysts prepared by each approach are discussed and compared in detail, which suggest that the nickel phosphide structures prepared through thermal phosphidation with hypophosphite or red phosphorus exhibit higher HER activities. The thermal phosphidation methods show versatility on the control of the structures and morphologies. Notably, the solution-phase approach is suitable for preparation of nickel phosphide catalysts ink, which is compatible with printing technologies to produce membrane electrodes, even though this method has a relatively high cost. 
Table 9. Comparison of the preparation methods of nickel phosphide electrocatalysts for HER.

\begin{tabular}{|c|c|c|}
\hline Methods & Advantages & Disadvantages \\
\hline Solution-phase method & $\begin{array}{l}\text { Easy to fabricate nickel phosphide } \\
\text { nanoparticles with small size and high } \\
\text { surface area, compatible with the printing } \\
\text { technologies for membrane electrodes }\end{array}$ & $\begin{array}{l}\text { High cost and toxicity of the organic } \\
\text { phosphine, relatively complicated post } \\
\text { process after the reaction, difficult to control } \\
\text { structures and morphologies of } \\
\text { the products }\end{array}$ \\
\hline $\begin{array}{l}\text { Thermal phosphidation } \\
\text { with hypophosphite }\end{array}$ & $\begin{array}{l}\text { Easy to control the morphologies by } \\
\text { controlling the morphologies of } \\
\text { pre-prepared Ni precursors, easy fabrication } \\
\text { on conductive supports as electrodes }\end{array}$ & $\begin{array}{l}\text { Toxic } \mathrm{PH}_{3} \text { generated in the } \\
\text { phosphidation process }\end{array}$ \\
\hline $\begin{array}{l}\text { Thermal phosphidation } \\
\text { with red phosphorus }\end{array}$ & $\begin{array}{l}\text { Relatively high safety, easy to control the } \\
\text { morphologies by controlling the } \\
\text { pre-prepared Ni precursors, easy fabrication } \\
\text { on conductive supports as electrodes }\end{array}$ & $\begin{array}{l}\text { Precursors mainly based on metallic } \\
\text { nickel materials }\end{array}$ \\
\hline $\begin{array}{l}\text { Hydrogen reduction } \\
\text { of phosphates }\end{array}$ & $\begin{array}{c}\text { Relatively high safety, easy preparation of } \\
\text { nickel phosphides, relatively low cost, } \\
\text { relatively large scale }\end{array}$ & $\begin{array}{l}\text { Difficult to control the structures and } \\
\text { morphologies of the final nickel phosphides }\end{array}$ \\
\hline $\begin{array}{l}\text { Electrochemical } \\
\text { deposition }\end{array}$ & Mild preparation, low cost, high safety & $\begin{array}{l}\text { Generally amorphous phase, mainly } \\
\text { forming Ni-P alloy, particularly difficult to } \\
\text { control the structures and morphologies of } \\
\text { the nickel phosphides, relatively inferior } \\
\text { HER activities, preparation only on } \\
\text { conductive electrodes }\end{array}$ \\
\hline
\end{tabular}

The HER activities, high conductivity, and high physicochemical stability endow nickel phosphides with outstanding HER performances, especially in an acidic electrolyte, which have gone beyond the state-of-the-art transition metal sulfide catalysts. However, challenges still exist for next-generation HER electrocatalysts based on nickel phosphides. First, it is urgently necessary to deeply understand the active sites of nickel phosphide or other transition metal phosphide electrocatalysts toward the HER reaction, especially the catalytic process (i.e., hydrogen adsorption, diffusion, and combination) on the surfaces. The influence of the nickel phosphide crystal phase on HER activity is still not fully understood, even though some studies have involved such issues. Further studies are required to elucidate the relationship between the HER activity and a specific facet of nickel phosphides, as well as the relationship between HER activity and the stoichiometry of Ni and P. Second, to date, the intrinsic electrocatalytic HER activity of nickel phosphides is still too low for practical applications. Some studies reported high-performance HER electrocatalysts based on nickel phosphide structures, but the mass loading is too high, which remarkably reduces the competitiveness with noble Pt-based catalysts in practical use. Fortunately, researchers have recognized that heteroatomic doping or defect engineering, which allow structural modulation at the lattice level is effective to improve the intrinsic electrocatalytic HER activity of nickel phosphides through the synergistic effect. Third, the exposure of sufficient active sites is required to improve the comprehensive HER performance, which is critical for practical applications. Generally, the construction of hierarchical or porous structures with a high surface area and optimized pore size distribution is carried out to maximize the effective active surface area to participate in the electrocatalytic reactions. However, current results still hardly satisfy the demand due to the loss of activities at most of the exposure sites, even though some beautiful hierarchical or porous structures with high electrochemical surface areas have been developed. Therefore, principle studies focusing on the dependence of HER activities on the crystal phase, crystal facet, compositions, doping, and defects by combining experiments and theoretical simulation, which elucidate the origins of the high activity and the possible synergistic effects, may provide a fundamental instruction for rational design and construction of next generation electrocatalysts based on nickel phosphides for hydrogen production. 
Author Contributions: Conceptualization, J.C. Resources, C.H., C.L., and S.L. Writing-original draft preparation, C.H., C.L., S.L., and J.C. Writing-review and editing, J.C., Y.S., J.S., Z.Z., and A.W. Visualization, C.H., C.L., S.L., and J.C. Project administration, Y.S., J.S., and Z.Z. Funding acquisition, J.C. and A.W. All authors have read and agreed to the published version of the manuscript.

Funding: The National Natural Science Foundation of China (No. 21603201), Institute of Materials, China Academy of Engineering Physics (item No. TP02201303), and JSPS KAKENHI Grant Number JP15H04132 and JSPS KAKENHI Grant Number JP19H05356 funded this work.

Conflicts of Interest: The authors declare no conflict of interest.

\section{References}

1. Turner, J.A. Sustainable Hydrogen Production. Science 2004, 305, 972. [CrossRef] [PubMed]

2. Caban-Acevedo, M.; Stone, M.L.; Schmidt, J.R.; Thomas, J.G.; Ding, Q.; Chang, H.-C.; Tsai, M.-L.; He, J.-H.; Jin, S. Efficient hydrogen evolution catalysis using ternary pyrite-type cobalt phosphosulphide. Nat. Mater. 2015, 14, 1245-1251. [CrossRef] [PubMed]

3. Le Goff, A.; Artero, V.; Jousselme, B.; Tran, P.D.; Guillet, N.; Métayé, R.; Fihri, A.; Palacin, S.; Fontecave, M. From Hydrogenases to Noble Metal-Free Catalytic Nanomaterials for $\mathrm{H}_{2}$ Production and Uptake. Science 2009, 326, 1384. [CrossRef] [PubMed]

4. Luo, J.; Im, J.-H.; Mayer, M.T.; Schreier, M.; Nazeeruddin, M.K.; Park, N.-G.; Tilley, S.D.; Fan, H.J.; Grätzel, M. Water photolysis at $12.3 \%$ efficiency via perovskite photovoltaics and Earth-abundant catalysts. Science 2014, 345, 1593. [CrossRef]

5. Hellstern, T.R.; Benck, J.D.; Kibsgaard, J.; Hahn, C.; Jaramillo, T.F. Engineering Cobalt Phosphide (CoP) Thin Film Catalysts for Enhanced Hydrogen Evolution Activity on Silicon Photocathodes. Adv. Energy Mater. 2016, 6, 1501758. [CrossRef]

6. Anantharaj, S.; Ede, S.R.; Sakthikumar, K.; Karthick, K.; Mishra, S.; Kundu, S. Recent Trends and Perspectives in Electrochemical Water Splitting with an Emphasis on Sulfide, Selenide, and Phosphide Catalysts of Fe, Co, and Ni: A Review. ACS Catal. 2016, 6, 8069-8097. [CrossRef]

7. Li, A.; Sun, Y.; Yao, T.; Han, H. Earth-Abundant Transition-Metal-Based Electrocatalysts for Water Electrolysis to Produce Renewable Hydrogen. Chem.-Eur. J. 2018, 24, 18334-18355. [CrossRef]

8. McKone, J.R.; Marinescu, S.C.; Brunschwig, B.S.; Winkler, J.R.; Gray, H.B. Earth-abundant hydrogen evolution electrocatalysts. Chem. Sci. 2014, 5, 865-878. [CrossRef]

9. Ledendecker, M.; Schlott, H.; Antonietti, M.; Meyer, B.; Shalom, M. Experimental and Theoretical Assessment of Ni-Based Binary Compounds for the Hydrogen Evolution Reaction. Adv. Energy Mater. 2016, 7, 1601735. [CrossRef]

10. Vij, V.; Sultan, S.; Harzandi, A.M.; Meena, A.; Tiwari, J.N.; Lee, W.-G.; Yoon, T.; Kim, K.S. Nickel-Based Electrocatalysts for Energy-Related Applications: Oxygen Reduction, Oxygen Evolution, and Hydrogen Evolution Reactions. ACS Catal. 2017, 7, 7196-7225. [CrossRef]

11. Abbas, M.A.; Bang, J.H. Rising Again: Opportunities and Challenges for Platinum-Free Electrocatalysts. Chem. Mater. 2015, 27, 7218-7235. [CrossRef]

12. Chen, Z.; Shan, A.; Cui, Y.; Wang, R.; Chen, C. Catalysis of hydrogen evolution reaction by $\mathrm{Ni}_{12} \mathrm{P}_{5}$ single crystalline nanoplates and spherical nanoparticles. CrystEngComm 2019, 21, 228-235. [CrossRef]

13. Gong, M.; Dai, H. A mini review of NiFe-based materials as highly active oxygen evolution reaction electrocatalysts. Nano Res. 2015, 8, 23-39. [CrossRef]

14. Han, L.; Dong, S.; Wang, E. Transition-Metal (Co, Ni, and Fe)-Based Electrocatalysts for the Water Oxidation Reaction. Adv. Mater. 2016, 28, 9266-9291. [CrossRef]

15. Kim, J.S.; Kim, B.; Kim, H.; Kang, K. Recent Progress on Multimetal Oxide Catalysts for the Oxygen Evolution Reaction. Adv. Energy Mater. 2018, 8, 1702774. [CrossRef]

16. Li, D.; Shi, J.; Li, C. Transition-Metal-Based Electrocatalysts as Cocatalysts for Photoelectrochemical Water Splitting: A Mini Review. Small 2018, 14, 1704179. [CrossRef]

17. Owens-Baird, B.; Kolen'ko, Y.V.; Kovnir, K. Structure-Activity Relationships for Pt-Free Metal Phosphide Hydrogen Evolution Electrocatalysts. Chem.-Eur. J. 2018, 24, 7298-7311. [CrossRef]

18. Pei, Y.; Cheng, Y.; Chen, J.; Smith, W.; Dong, P.; Ajayan, P.M.; Ye, M.; Shen, J. Recent developments of transition metal phosphides as catalysts in the energy conversion field. J. Mater. Chem. A 2018, 6, 23220-23243. [CrossRef] 
19. Tareen, A.K.; Priyanga, G.S.; Khan, K.; Pervaiz, E.; Thomas, T.; Yang, M. Nickel-Based Transition Metal Nitride Electrocatalysts for the Oxygen Evolution Reaction. ChemSusChem 2019, 12, 3941-3954. [CrossRef]

20. Liu, X.; Chi, J.; Dong, B.; Sun, Y. Recent Progress in Decoupled $\mathrm{H}_{2}$ and $\mathrm{O}_{2}$ Production from Electrolytic Water Splitting. ChemElectroChem 2019, 6, 2157-2166. [CrossRef]

21. Xiao, P.; Chen, W.; Wang, X. A Review of Phosphide-Based Materials for Electrocatalytic Hydrogen Evolution. Adv. Energy Mater. 2015, 5, 1500985. [CrossRef]

22. Roger, I.; Symes, M.D. First row transition metal catalysts for solar-driven water oxidation produced by electrodeposition. J. Mater. Chem. A 2016, 4, 6724-6741. [CrossRef]

23. McCrory, C.C.L.; Jung, S.; Ferrer, I.M.; Chatman, S.M.; Peters, J.C.; Jaramillo, T.F. Benchmarking Hydrogen Evolving Reaction and Oxygen Evolving Reaction Electrocatalysts for Solar Water Splitting Devices. J. Am. Chem. Soc. 2015, 137, 4347-4357. [CrossRef]

24. McCrory, C.C.L.; Jung, S.; Peters, J.C.; Jaramillo, T.F. Benchmarking Heterogeneous Electrocatalysts for the Oxygen Evolution Reaction. J. Am. Chem. Soc. 2013, 135, 16977-16987. [CrossRef]

25. Manzanares Palenzuela, C.L.; Luxa, J.; Sofer, Z.; Pumera, M. MoSe 2 Dispersed in Stabilizing Surfactant Media: Effect of the Surfactant Type and Concentration on Electron Transfer and Catalytic Properties. ACS Appl. Mater. Interfaces 2018, 10, 17820-17826. [CrossRef]

26. Burke, M.S.; Zou, S.; Enman, L.J.; Kellon, J.E.; Gabor, C.A.; Pledger, E.; Boettcher, S.W. Revised Oxygen Evolution Reaction Activity Trends for First-Row Transition-Metal (Oxy)hydroxides in Alkaline Media. J. Phys. Chem. Lett. 2015, 6, 3737-3742. [CrossRef]

27. Browne, M.P.; Sofer, Z.; Pumera, M. Layered and two dimensional metal oxides for electrochemical energy conversion. Energy Environ. Sci. 2019, 12, 41-58. [CrossRef]

28. Lyons, M.E.G.; Doyle, R.L.; Fernandez, D.; Godwin, I.J.; Browne, M.P.; Rovetta, A. The mechanism and kinetics of electrochemical water oxidation at oxidized metal and metal oxide electrodes. Part 1. General considerations: A mini review. Electrochem. Commun. 2014, 45, 60-62. [CrossRef]

29. Walter, M.G.; Warren, E.L.; McKone, J.R.; Boettcher, S.W.; Mi, Q.; Santori, E.A.; Lewis, N.S. Solar Water Splitting Cells. Chem. Rev. 2010, 110, 6446-6473. [CrossRef]

30. Conway, B.E.; Tilak, B.V. Interfacial processes involving electrocatalytic evolution and oxidation of $\mathrm{H}_{2}$, and the role of chemisorbed H. Electrochim. Acta 2002, 47, 3571-3594. [CrossRef]

31. Li, Y.; Wang, H.; Xie, L.; Liang, Y.; Hong, G.; Dai, H. MoS2 Nanoparticles Grown on Graphene: An Advanced Catalyst for the Hydrogen Evolution Reaction. J. Am. Chem. Soc. 2011, 133, 7296-7299. [CrossRef] [PubMed]

32. Sultan, S.; Tiwari, J.N.; Singh, A.N.; Zhumagali, S.; Ha, M.; Myung, C.W.; Thangavel, P.; Kim, K.S. Single Atoms and Clusters Based Nanomaterials for Hydrogen Evolution, Oxygen Evolution Reactions, and Full Water Splitting. Adv. Energy Mater. 2019, 9, 1900624. [CrossRef]

33. Wang, J.; Xu, F.; Jin, H.; Chen, Y.; Wang, Y. Non-Noble Metal-based Carbon Composites in Hydrogen Evolution Reaction: Fundamentals to Applications. Adv. Mater. 2017, 29, 1605838. [CrossRef] [PubMed]

34. Fang, M.; Dong, G.; Wei, R.; Ho, J.C. Hierarchical Nanostructures: Design for Sustainable Water Splitting. Adv. Energy Mater. 2017, 7, 1700559. [CrossRef]

35. Yu, X.; Zhao, J.; Zheng, L.-R.; Tong, Y.; Zhang, M.; Xu, G.; Li, C.; Ma, J.; Shi, G. Hydrogen Evolution Reaction in Alkaline Media: Alpha- or Beta-Nickel Hydroxide on the Surface of Platinum? ACS Energy Lett. 2018, 3, 237-244. [CrossRef]

36. Prins, R.; De Beer, V.H.J.; Somorjai, G.A. Structure and Function of the Catalyst and the Promoter in Co-Mo Hydrodesulfurization Catalysts. Catal. Rev. 1989, 31, 1-41. [CrossRef]

37. Merki, D.; Hu, X. Recent developments of molybdenum and tungsten sulfides as hydrogen evolution catalysts. Energy Environ. Sci. 2011, 4, 3878-3888. [CrossRef]

38. Liu, P.; Rodriguez, J.A.; Asakura, T.; Gomes, J.; Nakamura, K. Desulfurization Reactions on $\mathrm{Ni}_{2} \mathrm{P}(001)$ and $\alpha$-Mo2C(001) Surfaces: Complex Role of P and C Sites. J. Phys. Chem. B 2005, 109, 4575-4583. [CrossRef]

39. Liu, P.; Rodriguez, J.A. Catalysts for hydrogen evolution from the NiFe hydrogenase to the $\mathrm{Ni}_{2} \mathrm{P}(001)$ surface: The importance of ensemble effect. J. Am. Chem. Soc. 2005, 127, 14871-14878. [CrossRef]

40. Rundqvist, S.; Yhland, M.; Dahlbom, R.; Sjövall, J.; Theander, O.; Flood, H. X-Ray Investigations of $\mathrm{Mn}_{3} \mathrm{P}$, $\mathrm{Mn}_{2} \mathrm{P}$, and $\mathrm{Ni}_{2}$ P. Acta Chem. Scand. 1962, 16, 992-998. [CrossRef]

41. Prins, R.; Bussell, M.E. Metal Phosphides: Preparation, Characterization and Catalytic Reactivity. Catal. Lett. 2012, 142, 1413-1436. [CrossRef] 
42. Oyama, S.T. Novel catalysts for advanced hydroprocessing: Transition metal phosphides. J. Catal. 2003, 216, 343-352. [CrossRef]

43. Sawhill, S.J.; Phillips, D.C.; Bussell, M.E. Thiophene hydrodesulfurization over supported nickel phosphide catalysts. J. Catal. 2003, 215, 208-219. [CrossRef]

44. Layman, K.A.; Bussell, M.E. Infrared Spectroscopic Investigation of Thiophene Adsorption on Silica-Supported Nickel Phosphide Catalysts. J. Phys. Chem. B 2004, 108, 15791-15802.

45. Popczun, E.J.; McKone, J.R.; Read, C.G.; Biacchi, A.J.; Wiltrout, A.M.; Lewis, N.S.; Schaak, R.E. Nanostructured Nickel Phosphide as an Electrocatalyst for the Hydrogen Evolution Reaction. J. Am. Chem. Soc. 2013, 135, 9267-9270.

46. Lai, C.; Liu, X.; Deng, Y.; Yang, H.; Jiang, H.; Xiao, Z.; Liang, T. Rice-shape nanocrystalline $\mathrm{Ni}_{5} \mathrm{P}_{4}$ : A promising bifunctional electrocatalyst for hydrogen evolution reaction and oxygen evolution reaction. Inorg. Chem. Commun. 2018, 97, 98-102. [CrossRef]

47. Wang, C.; Ding, T.; Sun, Y.; Zhou, X.; Liu, Y.; Yang, Q. $\mathrm{Ni}_{12} \mathrm{P}_{5}$ nanoparticles decorated on carbon nanotubes with enhanced electrocatalytic and lithium storage properties. Nanoscale 2015, 7, 19241-19249. [CrossRef]

48. Laursen, A.B.; Wexler, R.B.; Whitaker, M.J.; Izett, E.J.; Calvinho, K.U.D.; Hwang, S.; Rucker, R.; Wang, H.; Ji, J.; Garfunkel, E.; et al. Climbing the Volcano of Electrocatalytic Activity while Avoiding Catalyst Corrosion: $\mathrm{Ni}_{3} \mathrm{P}$, a Hydrogen Evolution Electrocatalyst Stable in Both Acid and Alkali. ACS Catal. 2018, 8, 4408-4419. [CrossRef]

49. Cao, Q.; Wang, C.; Chen, S.; Xu, X.; Liu, F.; Geng, X.; Wang, J. Vertically aligned $\mathrm{NiP}_{2}$ nanosheets with interlaced mesh network for highly efficient water splitting under alkaline and acid solutions. Int. J. Hydrog. Energ. 2019, 44, 6535-6543. [CrossRef]

50. Pan, Y.; Liu, Y.; Zhao, J.; Yang, K.; Liang, J.; Liu, D.; Hu, W.; Liu, D.; Liu, Y.; Liu, C. Monodispersed nickel phosphide nanocrystals with different phases: Synthesis, characterization and electrocatalytic properties for hydrogen evolution. J. Mater. Chem. A 2015, 3, 1656-1665. [CrossRef]

51. Kim, J.-Y.; Park, H.; Joo, W.; Nam, D.-H.; Lee, S.; Kim, H.G.; Ahn, I.-K.; Kang, H.-Y.; Lee, G.-B.; Jung, I.-h.; et al. Predictive fabrication of $\mathrm{Ni}$ phosphide embedded in carbon nanofibers as active and stable electrocatalysts. J. Mater. Chem. A 2019, 7, 7451-7458.

52. Moon, J.-S.; Jang, J.-H.; Kim, E.-G.; Chung, Y.-H.; Yoo, S.J.; Lee, Y.-K. The nature of active sites of $\mathrm{Ni}_{2} \mathrm{P}$ electrocatalyst for hydrogen evolution reaction. J. Catal. 2015, 326, 92-99. [CrossRef]

53. Li, Y.; Cai, P.; Ci, S.; Wen, Z. Strongly Coupled 3D Nanohybrids with $\mathrm{Ni}_{2} \mathrm{P} /$ Carbon Nanosheets as pH-Universal Hydrogen Evolution Reaction Electrocatalysts. ChemElectroChem 2017, 4, 340-344.

54. Li, H.; Wang, W.; Gong, Z.; Yu, Y.; Piao, 1.; Chen, H.; Xia, J. Shape-controlled synthesis of nickel phosphide nanocrystals and their application as hydrogen evolution reaction catalyst. J. Phys. Chem. Solids 2015, 80, 22-25. [CrossRef]

55. Pan, Y.; Lin, Y.; Liu, Y.; Liu, C. Size-dependent magnetic and electrocatalytic properties of nickel phosphide nanoparticles. Appl. Surf. Sci. 2016, 366, 439-447. [CrossRef]

56. Zhang, C.; Xin, B.; Xi, Z.; Zhang, B.; Li, Z.; Zhang, H.; Li, Z.; Hao, J. Phosphonium-Based Ionic Liquid: A New Phosphorus Source toward Microwave-Driven Synthesis of Nickel Phosphide for Efficient Hydrogen Evolution Reaction. ACS Sustain. Chem. Eng. 2018, 6, 1468-1477. [CrossRef]

57. Wang, X.; Kolen'ko, Y.V.; Liu, L. Direct solvothermal phosphorization of nickel foam to fabricate integrated $\mathrm{Ni}_{2}$ P-nanorods/Ni electrodes for efficient electrocatalytic hydrogen evolution. Chem. Commun. 2015, 51, 6738-6741. [CrossRef]

58. Yu, J.; Li, Q.; Chen, N.; Xu, C.-Y.; Zhen, L.; Wu, J.; Dravid, V.P. Carbon-Coated Nickel Phosphide Nanosheets as Efficient Dual-Electrocatalyst for Overall Water Splitting. ACS Appl. Mater. Interfaces 2016, 8, 27850-27858. [CrossRef]

59. Shi, Y.; Xu, Y.; Zhuo, S.; Zhang, J.; Zhang, B. Ni 2 P Nanosheets/Ni Foam Composite Electrode for Long-Lived and pH-Tolerable Electrochemical Hydrogen Generation. ACS Appl. Mater. Interfaces 2015, 7, 2376-2384.

60. Roberts, E.J.; Read, C.G.; Lewis, N.S.; Brutchey, R.L. Phase Directing Ability of an Ionic Liquid Solvent for the Synthesis of HER-Active $\mathrm{Ni}_{2} \mathrm{P}$ Nanocrystals. ACS Appl. Energy Mater. 2018, 1, 1823-1827.

61. Huang, Z.; Chen, Z.; Chen, Z.; Lv, C.; Meng, H.; Zhang, C. $\mathrm{Ni}_{12} \mathrm{P}_{5}$ Nanoparticles as an Efficient Catalyst for Hydrogen Generation via Electrolysis and Photoelectrolysis. ACS Nano 2014, 8, 8121-8129. [CrossRef] 
62. Lin, Y.; Zhang, J.; Pan, Y.; Liu, Y. Nickel phosphide nanoparticles decorated nitrogen and phosphorus co-doped porous carbon as efficient hybrid catalyst for hydrogen evolution. Appl. Surf. Sci. 2017, 422, 828-837. [CrossRef]

63. Li, H.; Lu, S.; Sun, J.; Pei, J.; Liu, D.; Xue, Y.; Mao, J.; Zhu, W.; Zhuang, Z. Phase-Controlled Synthesis of Nickel Phosphide Nanocrystals and Their Electrocatalytic Performance for the Hydrogen Evolution Reaction. Chem.-Eur. J. 2018, 24, 11748-11754. [CrossRef]

64. Seo, B.; Baek, D.S.; Sa, Y.J.; Joo, S.H. Shape effects of nickel phosphide nanocrystals on hydrogen evolution reaction. CrystEngComm 2016, 18, 6083-6089. [CrossRef]

65. Laursen, A.B.; Patraju, K.R.; Whitaker, M.J.; Retuerto, M.; Sarkar, T.; Yao, N.; Ramanujachary, K.V.; Greenblatt, M.; Dismukes, G.C. Nanocrystalline $\mathrm{Ni}_{5} \mathrm{P}_{4}$ : A hydrogen evolution electrocatalyst of exceptional efficiency in both alkaline and acidic media. Energy Environ. Sci. 2015, 8, 1027-1034. [CrossRef]

66. Lin, Y.; Pan, Y.; Zhang, J. In-situ grown of $\mathrm{Ni}_{2} \mathrm{P}$ nanoparticles on $2 \mathrm{D}$ black phosphorus as a novel hybrid catalyst for hydrogen evolution. Int. J. Hydrog. Energ. 2017, 42, 7951-7956. [CrossRef]

67. Chang, J.; Li, S.; Li, G.; Ge, J.; Liu, C.; Xing, W. Monocrystalline $\mathrm{Ni}_{12} \mathrm{P}_{5}$ hollow spheres with ultrahigh specific surface areas as advanced electrocatalysts for the hydrogen evolution reaction. J. Mater. Chem. A 2016, 4, 9755-9759. [CrossRef]

68. Jin, L.; Xia, H.; Huang, Z.; Lv, C.; Wang, J.; Humphrey, M.G.; Zhang, C. Phase separation synthesis of trinickel monophosphide porous hollow nanospheres for efficient hydrogen evolution. J. Mater. Chem. A 2016, 4, 10925-10932. [CrossRef]

69. Pan, Y.; Liu, Y.; Liu, C. Nanostructured nickel phosphide supported on carbon nanospheres: Synthesis and application as an efficient electrocatalyst for hydrogen evolution. J. Power Sources 2015, 285, 169-177. [CrossRef]

70. Pan, Y.; Yang, N.; Chen, Y.; Lin, Y.; Li, Y.; Liu, Y.; Liu, C. Nickel phosphide nanoparticles-nitrogen-doped graphene hybrid as an efficient catalyst for enhanced hydrogen evolution activity. J. Power Sources 2015, 297, 45-52. [CrossRef]

71. Chung, Y.-H.; Gupta, K.; Jang, J.-H.; Park, H.S.; Jang, I.; Jang, J.H.; Lee, Y.-K.; Lee, S.-C.; Yoo, S.J. Rationalization of electrocatalysis of nickel phosphide nanowires for efficient hydrogen production. Nano Energy 2016, 26, 496-503. [CrossRef]

72. Hansen, M.H.; Stern, L.-A.; Feng, L.; Rossmeisl, J.; Hu, X. Widely available active sites on $\mathrm{Ni}_{2} \mathrm{P}$ for electrochemical hydrogen evolution - insights from first principles calculations. Phys. Chem. Chem. Phys. 2015, 17, 10823-10829. [CrossRef]

73. Surendran, S.; Shanmugapriya, S.; Shanmugam, S.; Vasylechko, L.; Kalai Selvan, R. Interweaved Nickel Phosphide Sponge as an Electrode for Flexible Supercapattery and Water Splitting Applications. ACS Appl. Energy Mater. 2018, 1, 78-92. [CrossRef]

74. Menezes, P.W.; Indra, A.; Das, C.; Walter, C.; Göbel, C.; Gutkin, V.; Schmeißer, D.; Driess, M. Uncovering the Nature of Active Species of Nickel Phosphide Catalysts in High-Performance Electrochemical Overall Water Splitting. ACS Catal. 2017, 7, 103-109. [CrossRef]

75. Sun, H.; Xu, X.; Yan, Z.; Chen, X.; Cheng, F.; Weiss, P.S.; Chen, J. Porous Multishelled $\mathrm{Ni}_{2} \mathrm{P}$ Hollow Microspheres as an Active Electrocatalyst for Hydrogen and Oxygen Evolution. Chem. Mater. 2017, 29, 8539-8547. [CrossRef]

76. Jiang, P.; Liu, Q.; Sun, $\mathrm{X} . \mathrm{NiP}_{2}$ nanosheet arrays supported on carbon cloth: An efficient 3D hydrogen evolution cathode in both acidic and alkaline solutions. Nanoscale 2014, 6, 13440-13445. [CrossRef]

77. Zheng, H.; Huang, X.; Wu, Z.; Gao, H.; Dong, W.; Wang, G. Controlled Synthesis of 3D Flower-like Ni2P Composed of Mesoporous Nanoplates for Overall Water Splitting. Chem.-Asian J. 2017, 12, 2956-2961. [CrossRef]

78. Wang, H.; Xie, Y.; Cao, H.; Li, Y.; Li, L.; Xu, Z.; Wang, X.; Xiong, N.; Pan, K. Flower-Like Nickel Phosphide Microballs Assembled by Nanoplates with Exposed High-Energy (001) Facets: Efficient Electrocatalyst for the Hydrogen Evolution Reaction. Chemsuschem 2017, 10, 4899-4908. [CrossRef]

79. Li, J.; Li, J.; Zhou, X.; Xia, Z.; Gao, W.; Ma, Y.; Qu, Y. Highly Efficient and Robust Nickel Phosphides as Bifunctional Electrocatalysts for Overall Water-Splitting. ACS Appl. Mater. Interfaces 2016, 8, 10826-10834. [CrossRef]

80. Wang, X.-D.; Cao, Y.; Teng, Y.; Chen, H.-Y.; Xu, Y.-F.; Kuang, D.-B. Large-Area Synthesis of a Ni ${ }_{2}$ P Honeycomb Electrode for Highly Efficient Water Splitting. ACS Appl. Mater. Interfaces 2017, 9, 32812-32819. [CrossRef] 
81. Yan, L.; Dai, P.; Wang, Y.; Gu, X.; Li, L.; Cao, L.; Zhao, X. In Situ Synthesis Strategy for Hierarchically Porous $\mathrm{Ni}_{2}$ P Polyhedrons from MOFs Templates with Enhanced Electrochemical Properties for Hydrogen Evolution. ACS Appl. Mater. Interfaces 2017, 9, 11642-11650. [CrossRef]

82. He, S.; He, S.; Gao, F.; Bo, X.; Wang, Q.; Chen, X.; Duan, J.; Zhao, C. Ni 2 P@carbon core-shell nanorod array derived from ZIF-67-Ni: Effect of phosphorization temperature on morphology, structure and hydrogen evolution reaction performance. Appl. Surf. Sci. 2018, 457, 933-941. [CrossRef]

83. Cai, Z.-X.; Song, X.-H.; Wang, Y.-R.; Chen, X. Electrodeposition-Assisted Synthesis of Ni 2 P Nanosheets on 3D Graphene/Ni Foam Electrode and Its Performance for Electrocatalytic Hydrogen Production. ChemElectroChem 2015, 2, 1665-1671. [CrossRef]

84. Dou, X.; Liu, W.; Liu, Q.; Niu, Z. Nickel Phosphide Nanorod Arrays Vertically Grown on Ni Foam as High-Efficiency Electrocatalyst for the Hydrogen Evolution Reaction. Chin. J. Chem. 2017, 35, 405-409. [CrossRef]

85. Jung, C.S.; Park, K.; Lee, Y.; Kwak, I.H.; Kwon, I.S.; Kim, J.; Seo, J.; Ahn, J.-P.; Park, J. Nickel phosphide polymorphs with an active (001) surface as excellent catalysts for water splitting. Crystengcomm 2019, 21, 1143-1149. [CrossRef]

86. Zhou, R.; Zhang, J.; Chen, Z.; Han, X.; Zhong, C.; Hu, W.; Deng, Y. Phase and composition controllable synthesis of nickel phosphide-based nanoparticles via a low-temperature process for efficient electrocatalytic hydrogen evolution. Electrochim. Acta 2017, 258, 866-875. [CrossRef]

87. Xiao, J.; Lv, Q.; Zhang, Y.; Zhang, Z.; Wang, S. One-step synthesis of nickel phosphide nanowire array supported on nickel foam with enhanced electrocatalytic water splitting performance. RSC Adv. 2016, 6, 107859-107864. [CrossRef]

88. Tian, T.; Ai, L.; Jiang, J. Metal-organic framework-derived nickel phosphides as efficient electrocatalysts toward sustainable hydrogen generation from water splitting. RSC Adv. 2015, 5, 10290-10295. [CrossRef]

89. Feng, L.; Vrubel, H.; Bensimon, M.; Hu, X. Easily-prepared dinickel phosphide $\left(\mathrm{Ni}_{2} \mathrm{P}\right)$ nanoparticles as an efficient and robust electrocatalyst for hydrogen evolution. Phys. Chem. Chem. Phys. 2014, 16, 5917-5921. [CrossRef]

90. Pu, Z.; Liu, Q.; Tang, C.; Asiri, A.M.; Sun, X. Ni ${ }_{2}$ P nanoparticle films supported on a Ti plate as an efficient hydrogen evolution cathode. Nanoscale 2014, 6, 11031-11034. [CrossRef]

91. He, S.; He, S.; Bo, X.; Wang, Q.; Zhan, F.; Wang, Q.; Zhao, C. Porous $\mathrm{Ni}_{2} \mathrm{P} / \mathrm{C}$ microrods derived from microwave-prepared MOF-74-Ni and its electrocatalysis for hydrogen evolution reaction. Mater. Lett. 2018, 231, 94-97. [CrossRef]

92. Jeoung, S.; Seo, B.; Hwang, J.M.; Joo, S.H.; Moon, H.R. Direct conversion of coordination compounds into $\mathrm{Ni2P}$ nanoparticles entrapped in 3D mesoporous graphene for an efficient hydrogen evolution reaction. Mater. Chem. Front. 2017, 1, 973-978. [CrossRef]

93. Veeramani, V.; Matsagar, B.M.; Yamauchi, Y.; Badjah, A.Y.; Naushad, M.; Habila, M.; Wabaidur, S.; Alothman, Z.A.; Wang, Z.-L.; Wu, K.C.W. Metal organic framework derived nickel phosphide/graphitic carbon hybrid for electrochemical hydrogen generation reaction. J. Taiwan Inst. Chem. Eng. 2019, 96, 634-638. [CrossRef]

94. Liu, B.; Wu, C.; Chen, G.; Chen, W.; Peng, L.; Yao, Y.; Wei, Z.; Zhu, H.; Han, T.; Tang, D.; et al. All-in-one surface engineering strategy on nickel phosphide arrays towards a robust electrocatalyst for hydrogen evolution reaction. J. Power Sources 2019, 429, 46-54. [CrossRef]

95. Wan, L.; Zhang, J.; Chen, Y.; Zhong, C.; Hu, W.; Deng, Y. Varied hydrogen evolution reaction properties of nickel phosphide nanoparticles with different compositions in acidic and alkaline conditions. J. Mater. Sci. 2017, 52, 804-814. [CrossRef]

96. Zhou, Z.; Wei, L.; Wang, Y.; Karahan, H.E.; Chen, Z.; Lei, Y.; Chen, X.; Zhai, S.; Liao, X.; Chen, Y. Hydrogen evolution reaction activity of nickel phosphide is highly sensitive to electrolyte pH. J. Mater. Chem. A 2017, 5, 20390-20397. [CrossRef]

97. Ding, Y.; Miao, B.-Q.; Jiang, Y.-C.; Yao, H.-C.; Li, X.-F.; Chen, Y. Polyethylenimine-modified nickel phosphide nanosheets: Interfacial protons boost the hydrogen evolution reaction. J. Mater. Chem. A 2019, 7, 13770-13776. [CrossRef]

98. Jin, Y.; Zhao, C.; Wang, L.; Jiang, Q.; Ji, C.; He, X. Preparation of mesoporous $\mathrm{Ni}_{2} \mathrm{P}$ nanobelts with high performance for electrocatalytic hydrogen evolution and supercapacitor. Int. J. Hydrog. Energ. 2018, 43, 3697-3704. [CrossRef] 


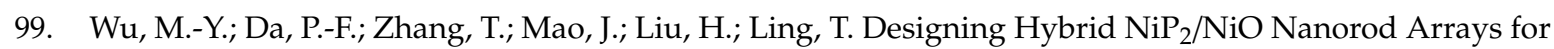
Efficient Alkaline Hydrogen Evolution. ACS Appl. Mater. Interfaces 2018, 10, 17896-17902. [CrossRef]

100. You, B.; Jiang, N.; Sheng, M.; Bhushan, M.W.; Sun, Y. Hierarchically Porous Urchin-Like $\mathrm{Ni}_{2}$ P Superstructures Supported on Nickel Foam as Efficient Bifunctional Electrocatalysts for Overall Water Splitting. ACS Catal. 2016, 6, 714-721. [CrossRef]

101. Zhang, T.; Yang, K.; Wang, C.; Li, S.; Zhang, Q.; Chang, X.; Li, J.; Li, S.; Jia, S.; Wang, J.; et al. Nanometric $\mathrm{Ni}_{5} \mathrm{P}_{4}$ Clusters Nested on $\mathrm{NiCo}_{2} \mathrm{O}_{4}$ for Efficient Hydrogen Production via Alkaline Water Electrolysis. Adv. Energy Mater. 2018, 8, 1801690. [CrossRef]

102. Liu, T.; Li, A.; Wang, C.; Zhou, W.; Liu, S.; Guo, L. Interfacial Electron Transfer of $\mathrm{Ni}_{2} \mathrm{P}_{-\mathrm{NiP}} \mathrm{N}_{2}$ Polymorphs Inducing Enhanced Electrochemical Properties. Adv. Mater. 2018, 30, 1803590. [CrossRef] [PubMed]

103. Sun, Y.; Zhang, T.; Li, X.; Bai, Y.; Lyu, X.; Liu, G.; Cai, W.; Li, Y. Bifunctional Hybrid Ni/Ni 2 P Nanoparticles Encapsulated by Graphitic Carbon Supported with N, S Modified 3D Carbon Framework for Highly Efficient Overall Water Splitting. Adv. Mater. Interfaces 2018, 5, 1800473. [CrossRef]

104. Dinh, K.N.; Sun, X.; Dai, Z.; Zheng, Y.; Zheng, P.; Yang, J.; Xu, J.; Wang, Z.; Yan, Q. O2 plasma and cation tuned nickel phosphide nanosheets for highly efficient overall water splitting. Nano Energy 2018, 54, 82-90. [CrossRef]

105. Yu, X.; Yu, Z.-Y.; Zhang, X.-L.; Zheng, Y.-R.; Duan, Y.; Gao, Q.; Wu, R.; Sun, B.; Gao, M.-R.; Wang, G.; et al. "Superaerophobic" Nickel Phosphide Nanoarray Catalyst for Efficient Hydrogen Evolution at Ultrahigh Current Densities. J. Am. Chem. Soc. 2019, 141, 7537-7543. [CrossRef] [PubMed]

106. Yan, L.; Jiang, H.; Xing, Y.; Wang, Y.; Liu, D.; Gu, X.; Dai, P.; Li, L.; Zhao, X. Nickel metal-organic framework implanted on graphene and incubated to be ultrasmall nickel phosphide nanocrystals acts as a highly efficient water splitting electrocatalyst. J. Mater. Chem. A 2018, 6, 1682-1691. [CrossRef]

107. Ren, J.; Hu, Z.; Chen, C.; Liu, Y.; Yuan, Z. Integrated $\mathrm{Ni}_{2} \mathrm{P}$ nanosheet arrays on three-dimensional Ni foam for highly efficient water reduction and oxidation. J. Energy Chem. 2017, 26, 1196-1202. [CrossRef]

108. Yan, Y.; Lin, J.; Bao, K.; Xu, T.; Qi, J.; Cao, J.; Zhong, Z.; Fei, W.; Feng, J. Free-standing porous $\mathrm{Ni}_{2} \mathrm{P}-\mathrm{Ni}_{5} \mathrm{P}_{4}$ heterostructured arrays for efficient electrocatalytic water splitting. J. Colloid Interface Sci. 2019, 552, 332-336. [CrossRef]

109. Jin, X.; Li, J.; Cui, Y.; Liu, X.; Wang, K.; Zhou, Y.; Yang, W.; Zhang, X.; Zhang, C.; Jiang, X.; et al. In-situ synthesis of porous $\mathrm{Ni}_{2} \mathrm{P}$ nanosheets for efficient and stable hydrogen evolution reaction. Int. J. Hydrog. Energ. 2019, 44, 5739-5747. [CrossRef]

110. Lin, Y.; He, L.; Chen, T.; Zhou, D.; Wu, L.; Hou, X.; Zheng, C. Cost-effective and environmentally friendly synthesis of $3 \mathrm{D} \mathrm{Ni}_{2} \mathrm{P}$ from scrap nickel for highly efficient hydrogen evolution in both acidic and alkaline media. J. Mater. Chem. A 2018, 6, 4088-4094. [CrossRef]

111. Li, J.; Wei, G.; Zhu, Y.; Xi, Y.; Pan, X.; Ji, Y.; Zatovsky, I.V.; Han, W. Hierarchical NiCoP nanocone arrays supported on $\mathrm{Ni}$ foam as an efficient and stable bifunctional electrocatalyst for overall water splitting. J. Mater. Chem. A 2017, 5, 14828-14837. [CrossRef]

112. Li, J.; Yan, M.; Zhou, X.; Huang, Z.-Q.; Xia, Z.; Chang, C.-R.; Ma, Y.; Qu, Y. Mechanistic Insights on Ternary $\mathrm{Ni}_{2-x} \mathrm{Co}_{x} \mathrm{P}$ for Hydrogen Evolution and Their Hybrids with Graphene as Highly Efficient and Robust Catalysts for Overall Water Splitting. Adv. Funct. Mater. 2016, 26, 6785-6796. [CrossRef]

113. Ledendecker, M.; Calderon, S.K.; Papp, C.; Steinrueck, H.-P.; Antonietti, M.; Shalom, M. The Synthesis of Nanostructured $\mathrm{Ni}_{5} \mathrm{P}_{4}$ Films and their Use as a Non-Noble Bifunctional Electrocatalyst for Full Water Splitting. Angew. Chem. Int. Ed. 2015, 54, 12361-12365. [CrossRef] [PubMed]

114. Wang, X.; Kolen'ko, Y.V.; Bao, X.-Q.; Kovnir, K.; Liu, L. One-Step Synthesis of Self-Supported Nickel Phosphide Nanosheet Array Cathodes for Efficient Electrocatalytic Hydrogen Generation. Angew. Chem. Int. Ed. 2015, 54, 8188-8192. [CrossRef]

115. Mishra, I.K.; Zhou, H.; Sun, J.; Dahal, K.; Ren, Z.; He, R.; Chen, S.; Ren, Z. Highly efficient hydrogen evolution by self-standing nickel phosphide-based hybrid nanosheet arrays electrocatalyst. Mater. Today Phys. 2018, 4, 1-6. [CrossRef]

116. Cai, W.; Liu, W.; Sun, H.; Li, J.; Yang, L.; Liu, M.; Zhao, S.; Wang, A. Ni $\mathrm{P}_{4}-\mathrm{NiP}_{2}$ nanosheet matrix enhances electron-transfer kinetics for hydrogen recovery in microbial electrolysis cells. Appl. Energ. 2018, 209, 56-64. [CrossRef] 
117. Liu, S.; Hu, C.; Lv, C.; Cai, J.; Duan, M.; Luo, J.; Song, J.; Shi, Y.; Chen, C.; Luo, D.; et al. Facile preparation of large-area self-supported porous nickel phosphide nanosheets for efficient electrocatalytic hydrogen evolution. Int. J. Hydrog. Energ. 2019, 44, 17974-17984. [CrossRef]

118. Chen, W.; Mishra, I.K.; Qin, Z.; Yu, L.; Zhou, H.; Sun, J.; Zhang, F.; Chen, S.; Wenya, G.E.; Yu, Y.; et al. Nickel phosphide based hydrogen producing catalyst with low overpotential and stability at high current density. Electrochim. Acta 2019, 299, 756-761. [CrossRef]

119. Wang, X.; Li, W.; Xiong, D.; Petrovykh, D.Y.; Liu, L. Bifunctional Nickel Phosphide Nanocatalysts Supported on Carbon Fiber Paper for Highly Efficient and Stable Overall Water Splitting. Adv. Funct. Mater. 2016, 26, 4067-4077. [CrossRef]

120. Hu, C.; Cai, J.; Liu, S.; Lv, C.; Luo, J.; Duan, M.; Chen, C.; Shi, Y.; Song, J.; Zhang, Z.; et al. General Strategy for Preparation of Porous Nickel Phosphide Nanosheets on Arbitrary Substrates toward Efficient Hydrogen Generation. ACS Appl. Energy Mater. 2019. [CrossRef]

121. Wu, X.; Guo, Y.; Wang, T.; Sun, B.; Liu, Z.; Wu, Y.; Zhang, S.; Zheng, J.; Li, X. Plasma enabled non-thermal phosphorization for nickel phosphide hydrogen evolution catalysts. Chem. Commun. 2019, 55, 4202-4205. [CrossRef]

122. Yan, Q.; Chen, X.; Wei, T.; Wang, G.; Zhu, M.; Zhuo, Y.; Cheng, K.; Ye, K.; Zhu, K.; Yan, J.; et al. Hierarchical Edge-Rich Nickel Phosphide Nanosheet Arrays as Efficient Electrocatalysts toward Hydrogen Evolution in Both Alkaline and Acidic Conditions. ACS Sustain. Chem. Eng. 2019, 7, 7804-7811. [CrossRef]

123. Han, A.; Jin, S.; Chen, H.; Ji, H.; Sun, Z.; Du, P. A robust hydrogen evolution catalyst based on crystalline nickel phosphide nanoflakes on three-dimensional graphene/nickel foam: High performance for electrocatalytic hydrogen production from $\mathrm{pH}$ 0-14. J. Mater. Chem. A 2015, 3, 1941-1946. [CrossRef]

124. Qu, G.; Zhao, Y.; Zhao, G.; Zhou, Y.; Cai, S.; Kang, Y.; Xu, C. Ultrahigh length-to-diameter ratio nickel phosphide nanowires as $\mathrm{pH}$-wide electrocatalyst for efficient hydrogen evolution. Electrochim. Acta 2019, 298, 943-949. [CrossRef]

125. Bai, Y.; Zhang, H.; Li, X.; Liu, L.; Xu, H.; Qiu, H.; Wang, Y. Novel peapod-like $\mathrm{Ni}_{2} \mathrm{P}$ nanoparticles with improved electrochemical properties for hydrogen evolution and lithium storage. Nanoscale 2015, 7, 1446-1453. [CrossRef]

126. Bai, Y.; Zhang, H.; Fang, L.; Liu, L.; Qiu, H.; Wang, Y. Novel peapod array of $\mathrm{Ni}_{2} \mathrm{P} @$ graphitized carbon fiber composites growing on Ti substrate: A superior material for Li-ion batteries and the hydrogen evolution reaction. J. Mater. Chem. A 2015, 3, 5434-5441. [CrossRef]

127. Miao, M.; Hou, R.; Liang, Z.; Qi, R.; He, T.; Yan, Y.; Qi, K.; Liu, H.; Feng, G.; Xia, B.Y. Chainmail catalyst of ultrathin P-doped carbon shell-encapsulated nickel phosphides on graphene towards robust and efficient hydrogen generation. J. Mater. Chem. A 2018, 6, 24107-24113. [CrossRef]

128. Lv, X.-W.; Hu, Z.-P.; Chen, L.; Ren, J.-T.; Liu, Y.-P.; Yuan, Z.-Y. Organic-Inorganic Metal Phosphonate-Derived Nitrogen-Doped Core-Shell $\mathrm{Ni}_{2} \mathrm{P}$ Nanoparticles Supported on Ni Foam for Efficient Hydrogen Evolution Reaction at All pH Values. ACS Sustain. Chem. Eng. 2019, 7, 12770-12778. [CrossRef]

129. Wang, M.-Q.; Ye, C.; Liu, H.; Xu, M.; Bao, S.-J. Nanosized Metal Phosphides Embedded in Nitrogen-Doped Porous Carbon Nanofibers for Enhanced Hydrogen Evolution at All pH Values. Angew. Chem. Int. Ed. 2018, 57, 1963-1967. [CrossRef]

130. Li, G.; Wang, J.; Yu, J.; Liu, H.; Cao, Q.; Du, J.; Zhao, L.; Jia, J.; Liu, H.; Zhou, W. Ni-Nis P nanoparticles embedded into N, P-doped carbon on 3D graphene frameworks via in situ phosphatization of saccharomycetes with multifunctional electrodes for electrocatalytic hydrogen production and anodic degradation. Appl. Catal. B: Environ. 2020, 261, 118147. [CrossRef]

131. Cao, X.; Jia, D.; Li, D.; Cui, L.; Liu, J. One-step co-electrodeposition of hierarchical radial $\mathrm{Ni}_{\mathrm{x}} \mathrm{P}$ nanospheres on $\mathrm{Ni}$ foam as highly active flexible electrodes for hydrogen evolution reaction and supercapacitor. Chem. Eng. J. 2018, 348, 310-318. [CrossRef]

132. Chaudhari, N.K.; Jin, H.; Kim, B.; Lee, K. Nanostructured materials on 3D nickel foam as electrocatalysts for water splitting. Nanoscale 2017, 9, 12231-12247. [CrossRef]

133. Chen, M.; Qi, J.; Zhang, W.; Cao, R. Electrosynthesis of $\mathrm{NiP}_{\mathrm{x}}$ nanospheres for electrocatalytic hydrogen evolution from a neutral aqueous solution. Chem. Commun. 2017, 53, 5507-5510. [CrossRef]

134. Liu, Q.; Gu, S.; Li, C.M. Electrodeposition of nickel-phosphorus nanoparticles film as a Janus electrocatalyst for electro-splitting of water. J. Power Sources 2015, 299, 342-346. [CrossRef] 
135. Sun, C.; Zeng, J.; Lei, H.; Yang, W.; Zhang, Q. Direct Electrodeposition of Phosphorus-Doped Nickel Superstructures from Choline Chloride-Ethylene Glycol Deep Eutectic Solvent for Enhanced Hydrogen Evolution Catalysis. ACS Sustain. Chem. Eng. 2019, 7, 1529-1537. [CrossRef]

136. Tang, C.; Asiri, A.M.; Luo, Y.; Sun, X. Electrodeposited Ni-P Alloy Nanoparticle Films for Efficiently Catalyzing Hydrogen- and Oxygen-Evolution Reactions. ChemNanoMat 2015, 1, 558-561. [CrossRef]

137. Cheng, C.; Shah, S.S.A.; Najam, T.; Zhang, L.; Qi, X.; Wei, Z. Highly active electrocatalysis of hydrogen evolution reaction in alkaline medium by Ni-P alloy: A capacitance-activity relationship. J. Energy Chem. 2017, 26, 1245-1251. [CrossRef]

138. Wu, R.; Dong, Y.; Jiang, P.; Wang, G.; Chen, Y.; Wu, X. Electrodeposited synthesis of self-supported Ni-P cathode for efficient electrocatalytic hydrogen generation. Prog. Nat. Sci. Mater. Int. 2016, 26, 303-307. [CrossRef]

139. Ren, Q.; Jin, H.; Xu, X.; Liu, A.; Li, J.; Wang, J.; Wang, S. Hydrogen evolution reaction catalyzed by nickel/nickel phosphide nanospheres synthesized through electrochemical methods. Electrochim. Acta 2019, 298, $229-236$. [CrossRef]

140. Wasalathanthri, R.N.; Jeffrey, S.; Su, N.; Sun, K.; Giolando, D.M. Stoichiometric Control of Electrocatalytic Amorphous Nickel Phosphide to Increase Hydrogen Evolution Reaction Activity and Stability in Acidic Medium. ChemistrySelect 2017, 2, 8020-8027. [CrossRef]

141. Kim, H.; Park, H.; Kim, D.-K.; Choi, I.; Kim, S.-K. Pulse-electrodeposited nickel phosphide for high-performance proton exchange membrane water electrolysis. J. Alloy. Compd. 2019, 785, 296-304. [CrossRef]

142. Das, M.; Jena, N.; Purkait, T.; Kamboj, N.; De Sarkar, A.; Dey, R.S. Single-phase $\mathrm{Ni}_{5} \mathrm{P}_{4}$-copper foam superhydrophilic and aerophobic core-shell nanostructures for efficient hydrogen evolution reaction. $J$. Mater. Chem. A 2019. [CrossRef]

143. Wang, S.; Zhang, L.; Li, X.; Li, C.; Zhang, R.; Zhang, Y.; Zhu, H. Sponge-like nickel phosphide-carbon nanotube hybrid electrodes for efficient hydrogen evolution over a wide pH range. Nano Res. 2017, 10, 415-425. [CrossRef] 